NASA CONTRACTOR REPORT
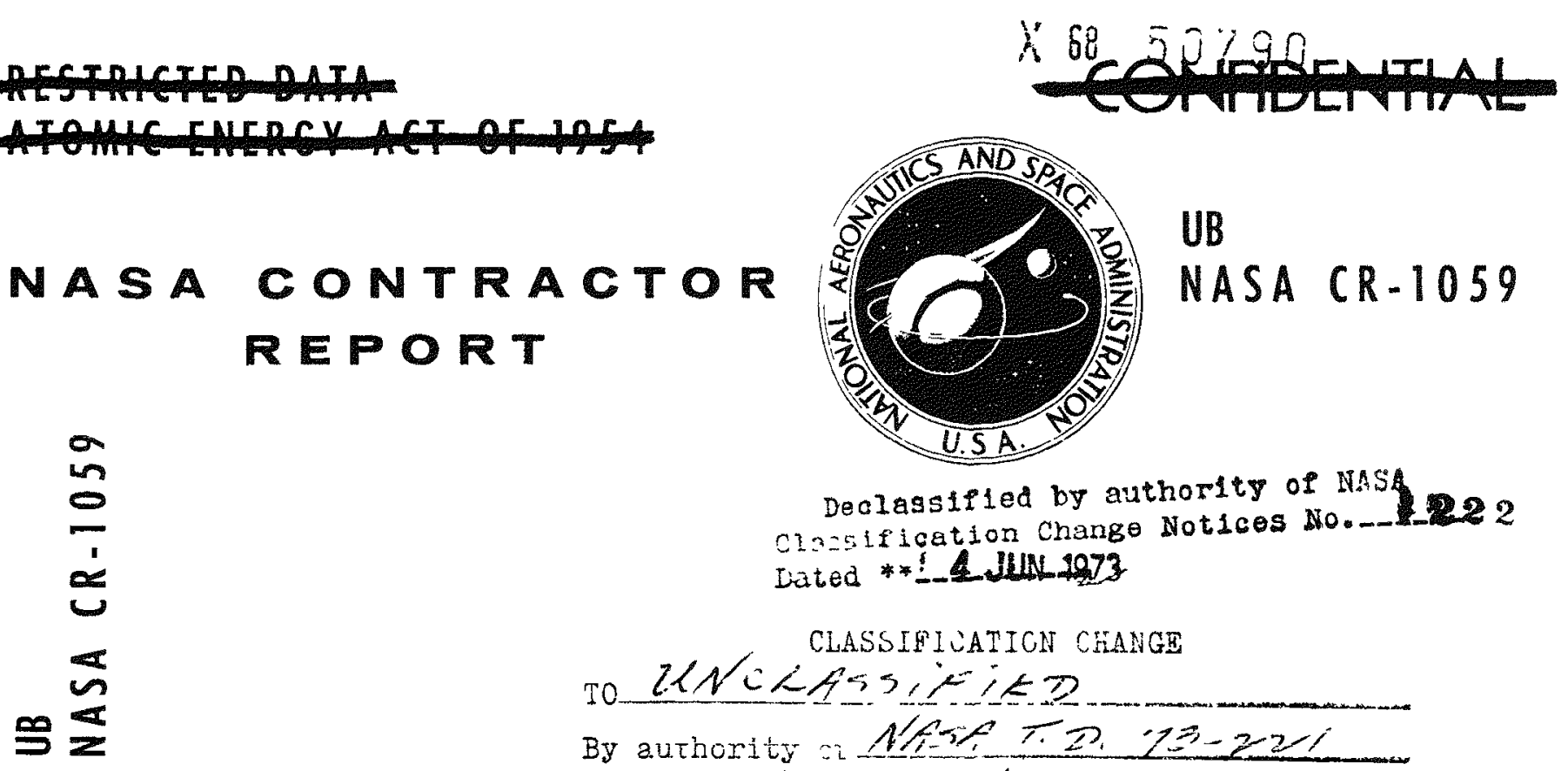

Declassified by authority of NASA Cin-sification Change Notices No..- 222 iated **-4. IUL 1073 TO ZLNCLGSS, CLE;ED

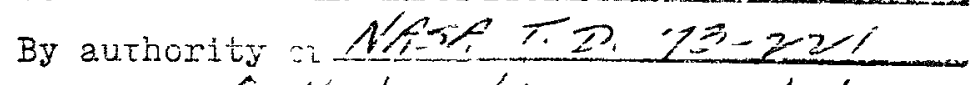
changed by

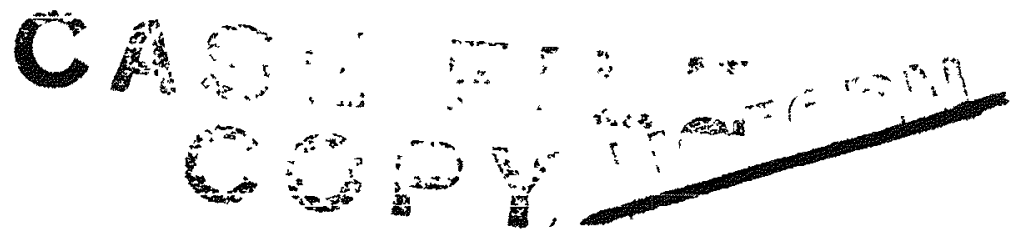

\title{
DEVELOPMENT OF URANIUM DIOXIDE - TUNGSTEN CERMET FUEL SPECIMENS FOR THERMIONIC APPLICATIONS
}

by P.J. Gripshover and J. H. Peterson

Prepared by

BATTELLE MEMORIAL INSTITUTE

Columbus, Ohio

for Leu'is Research Center
Declassifled by authority of NASA

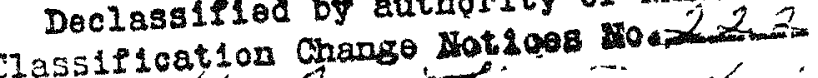

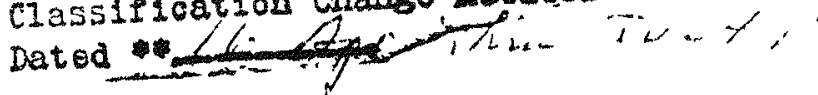

NATIONAL AERONAUTICS AND SPACE ADMINISTRATION • WASHINGTON, D.C. • JULY 1968 


\section{DISCLAIMER}

This report was prepared as an account of work sponsored by an agency of the United States Government. Neither the United States Government nor any agency Thereof, nor any of their employees, makes any warranty, express or implied, or assumes any legal liability or responsibility for the accuracy, completeness, or usefulness of any information, apparatus, product, or process disclosed, or represents that its use would not infringe privately owned rights. Reference herein to any specific commercial product, process, or service by trade name, trademark, manufacturer, or otherwise does not necessarily constitute or imply its endorsement, recommendation, or favoring by the United States Government or any agency thereof. The views and opinions of authors expressed herein do not necessarily state or reflect those of the United States Government or any agency thereof. 


\section{DISCLAIMER}

Portions of this document may be illegible in electronic image products. Images are produced from the best available original document. 


\section{DEVELOPMENT OF URANIUM DIOXIDE - TUNGSTEN CERMET FUEL SPECIMENS FOR THERMTONIC APPLICATIONS}

By P. J. Gripshover and J. H. Peterson

Distribution of this report is provided in the interest of information exchange. Responsibility for the contents resides in the author or organization that prepared it.
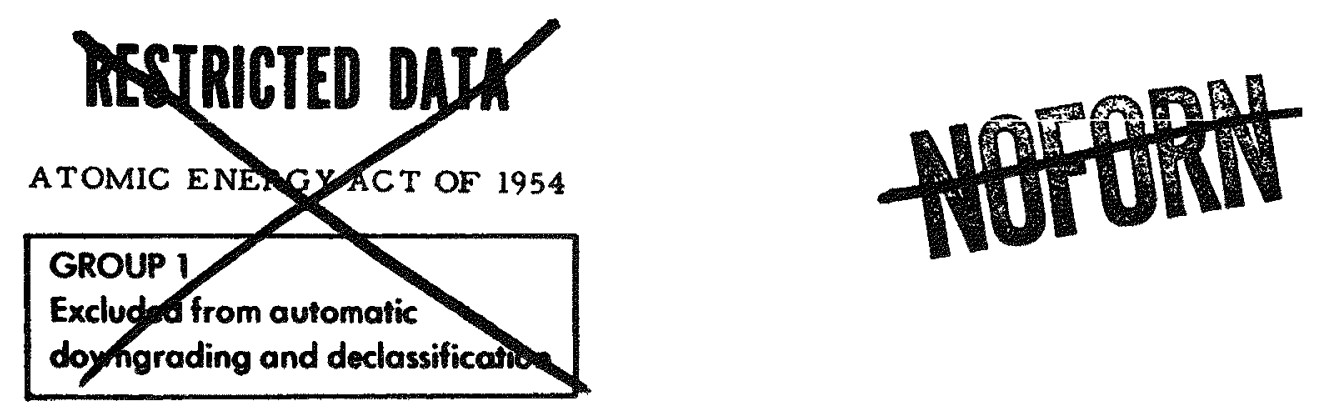

CLASIFIED DOCUMENT-TITLE UNCLASSIEIPS This moninl contains information getering the national defensu- the Unitad protes within the meaning of the espions rows, Tisle 18, U.S.C., Sacs. 793 and 290, the transmrswaner revelation of which any monner to on unauthortzeragen is nuibited by law.

\section{NOTICE}

This document should not be roturned after it has sotisfied your requirements. It may be disposed of in aceordance with your local security regula. tions or the appropriate provisions of the Industrial Security Manual for Safe-Guarding Clossified Information.

Prepared under Contract No. NAS $3-4255$ by

BATTELLE MEMORIAL INSTITUTE

Columbus, Ohio

for Lewis Research Center

NATIONAL AERONAUTICS AND SPACE ADMINISTRATION

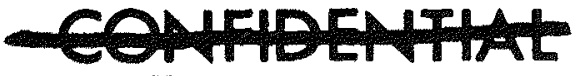




\section{FOREWORD}

The research described herein was conducted at the Battelle Memorial Institute Columbus Iaboratories under NASA Contract NAS3-4255. Mr. R. L. Brown, Nuclear Systems Division, Lewis Research Center, was the Technical Manager. 


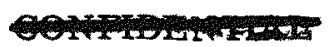

coneronum 
TABLE OF CONIENTS

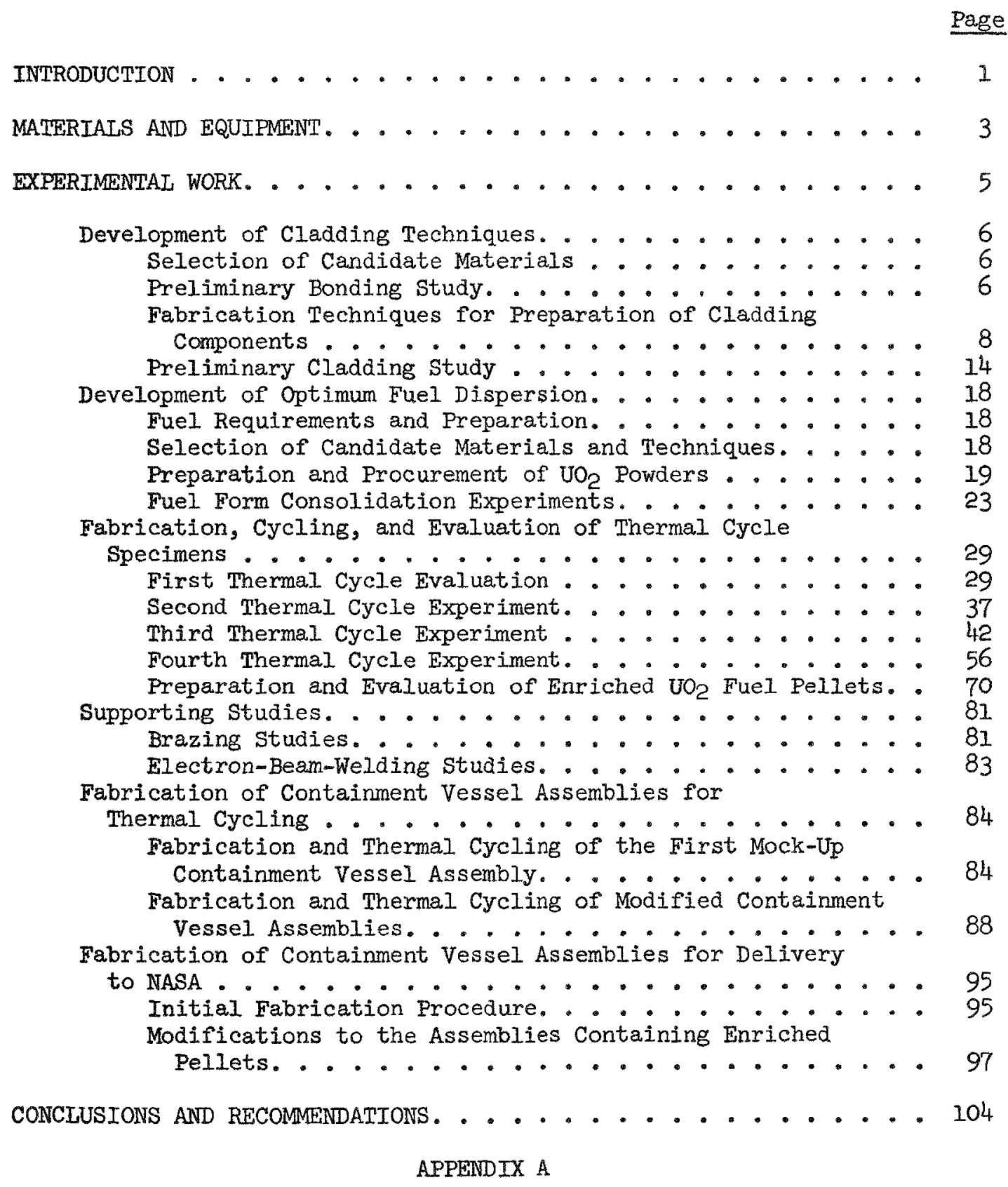

CLAD FUEL-PELIET CONTAINMENT VESSEL FABRICATION - PROCEDURE

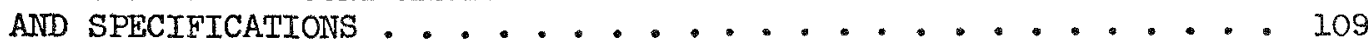

APPENDIX B

THERMAI HISTORY OF ENRICHED PELLETS. . . . . . . . . . . . . 115 
Page

FIGURE 1. DRAWING OF CONTAINMENT VESSEL ASSEMBLY ........ 4 FIGURE 2. TUNGGSTEN JOINED BY GAS-PRESSURE BONDING ........ 9

FTGURE 3. CLAD FUEL PELLET ........................ 10

FIGURE 4. CRACKS IN TUNGSIEN CLAD RESUITING FROM ELECTRICAL

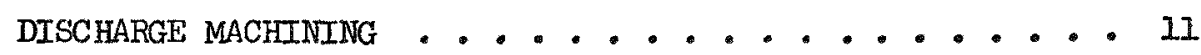

FIGURE 5. IMPROVED CLAD FUEL PEILET FABRICATION TECHNIQUE . . . 13

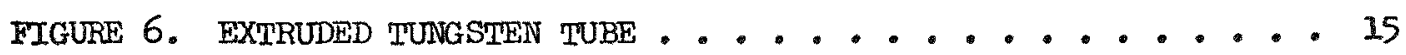

FTGURE 7. CLAD FUEL PELLET . . .................... 16

FIGURE 8. PHOTOMICROGRAPH SHOWING BONDING OF TUNGSTEN CLAD TO FUEL FORM ..................... 17

FICURE 9. VAPOR COATED UO 2 BEFORE AND AFTER HOT ISOSTATIC PRESSING - 24 FIGURE 10. FUEL FORM PRODUCED BY BLENDING COATED PARTICLES AND

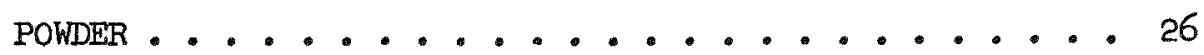
FTGURE 11. FUEL FORM FABRTCATED BY EXPLOSIVE COMPACTION . . . . . 28 FIGURE 12. SPECIMEN AFTTR FIVE THERMAL CYCLES . . . . . . 32 FTGURE 13. SPECIMEN CONTATNING DEFECT AREA AFTER FIVE THERMAL CYCLES. 33 FIGURE 14. CRACK IN FUEL FORM AS A RESUIT OF THERMAL CYCLING . . . 34 FIGURE 15. MICROCRACKS INITIATING AT THE INSIDE SURFACE OF THE

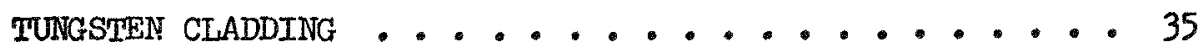

FIGURE 16. COMPARISON OF FUEL FORM MICROSTRUCTURE BEFORE AND AFTER

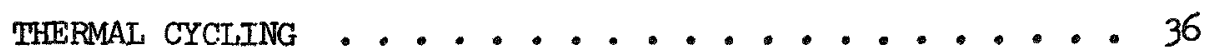
FIGURE 17. TRANSVERSE SECTION OF CLADDING FAILUURE . . . . . . 40 FIGURE 18. LONGITUDINAL SECTTON OF CLADDING FAILURE . . . . . . 40 
Page

FIGURE 19. LONGIRUDINAL SECTION OF BOND IN AS-BONDED PELIET . . • 41

FIGURE 20. IONGITUDINAL, SECTION OF THICK END PLUG BOND AFTER THERMAL CYCLING. ................... 41

FIGURE 21. PERCENT GROWTH AND WEIGHT LOSS CURVES FOR THERMAL

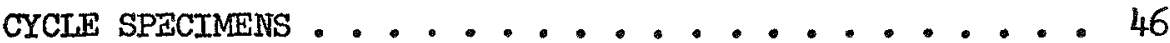
FIGURE 22. CLAD FUEL PELLETS AFTER 100 THERMAL CYCLES . . . . 48 FIGURE 23. TUNGSTTEN CLAD: TYPICAL CORE STRUCTURE ....... 49 FIGURE 24. TUNGSTEN CLAD: CORE-TO-CLAD BOND ......... 49 FIGURE 25. TUNGSTEN CLAD: BOND BETWEEN THIN-END PLUG AND CIAD TUBE. 50 FIGURE 26. TUUYGSTEN CLAD: BOND BETWEEN THICK-END PLUG AND CLAD

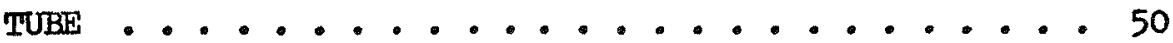

FIGURE 27. TUNGSTEN-RHENIUM CLAD: TYPICAL CORE STRUCTURE . . . . 52 FTGURE 28. TUNGSTEEN-RHENIUM CLAD; CORE-TO-CLAD BOND . . . . . . 52 FIGURE 29. TUNGSTEN-RHENIUM CLAD: BOND BETWEEN THIN-END PLUG AND

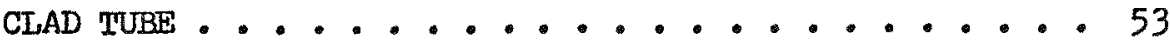

FIGURE 30. TUNGSTEN-RHENIUM CLAD: BOND BEL'WEHIN THICK-EIND FLUT AHND

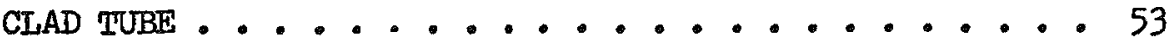

FIGURE 31. THORIA-TUNGSTEN CIAD; TYPICAL CORE STRUCTURE . . . . 54 FIGURE 32. THORIA-TUNGSTEN CLAD: CORE-TO-CLAD BOND . . . . . 54 FIGURE 33. THORIA-TUNGSTEN CLAD: BOND BETHEEN THIN-END PLUG AND

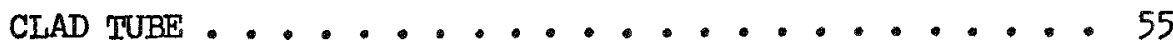

FIGURE 34. THORIA-TUNGSTEN CLAD: BOND BETWEEN THICK-END PLUG AND

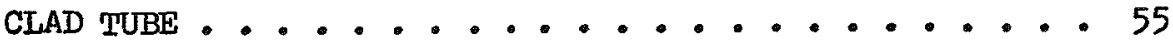

FIGURE 35. PERCENT GROWTH AND WEIGHT LOSS CURVES FOR THERMAL CYCLE

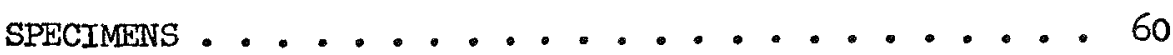

FIGURE 36. MICROSTRUCTURE OF EXPLOSIVELY COMPACTED PELIET AT VARIOUS STAGES OF FABRTCATION ........... 61 


\section{LIST OF FIGURES (Continued)}

Page

FIGURE 37. MICROSTRUCTURE OF HOT ISOSTATICALIY PRESSED PELUET

AT VARIOUS STAGES OF FABRICATION ......... 62

FIGURE 38. TYPICAL CORE AND CORE-TO-CLAD BOND STRUCTURES FOR

SPECIMEN $11 \ldots \ldots 64$

FIGURE 39. TYPICAL CORE AND CORE-TO-CLAD BOND STRUUCTURES FOR

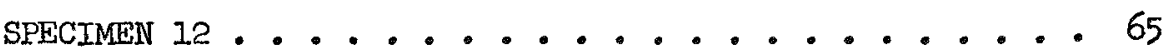

FIGURE 40. TYPICAL CORE AND CORE-TO-CLAD BOND STRUCTURES FOR

SPECIMEN $13 \ldots \ldots 66$

FIGURE 41. TYPICAL CORE AND CORE-TO-CLAD BOND STRUCTURES FOR

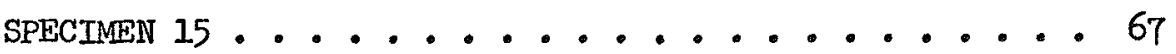

FIGURE 42. TYPICAL CORE AND CORE-TO-CLAD BOND STRUCTURES FOR

SPECIMEN $16 \ldots 68$

FIGURE 43. TYPICAL FAILURES OF THERMAL-CYCLED PELLETS . . . . . 6y

FIGURE 44. PERCENT GROWTH AND WEIGHP LOSS CURVES FOR ENRICHED THERMAI

CYCLE SPECIMENS .................. 75

FTGURE 45. PELLET E4 AFTER 200 THERMAL CYCLES . . . . . . 76

FIGURE 46. PELIET ES AFTER 100 THERMAL CYCLES . . . . . . . 77

FIGURE 47. PELTET ET AFTER 100 THERMAI CYCLES . . . . . . . 78

FIGURE 48. PELLET E8 AFTER 100 THERMAL CYCLES . . . . . . . 79

FIGURE 49. MICROSTRUCTURE OF PELLET EI . . . . . . . . . 80

FIGURE 50. MOCK-UP CONTAINMENT VESSEL ASSEMBLY AFTER 100 THERMAL

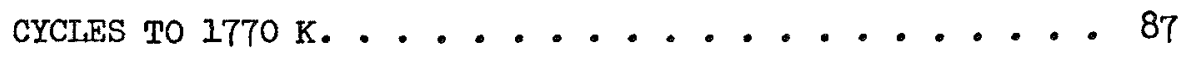

FIGURE 51. BRAZE OF THERMOCOUPLE WALI TO CLAD PELLET AFIER 100

THERMAL CYCLES ........................... 89

FIGURE 52. CLAD FUEL PELLET STRUCTURE AFTER THERMAL CYCLING . . . 90 


\section{IIST OF FIGURES (Continued)}

Page

FIGURE 53. STRUCTURE OF PEIIET EIO FOLIOWING 25 THERMAT CYCIES

IN A CONTAINMENT VESSEL ASSEMBLY . . . . . . . . . . 91

FIGURE 54. CONTAINMENT VESSEL ASSEMBLY CONTAINING ENRICHED FUEL

PELTET EIO AFTER 25 CYCLES TO $1770 \mathrm{~K}$. . . . . . 94

FIGURE 55. CONTAINMENT VESSEL MODIFICATION PRIOR TO WETDING . . . 98

FIGURE 56. CLAD FUEL PELLET INCORPORATING MODIFIED RECESSES FOR

THE THERMOCOUPLE WELLS . . . . . . . . . 100

FIGURE 57. CONTAINMENT VESSEL COMPONENTS PRIOR TO ASSEMRLY. . . . . 102

FIGURE 58. COMPLETED CONTAINMENT VESSEL ASSEMBLY. . . . . . . . 103

FIGURE 59. RADIOGRAPH OF CONTAIINENT VESSEIS 304-010 AND 304-011

AFTER WELDING, PRESSURE CHECKTNG, AND SEATING . . . . 105

\section{LIST OF TABLES}

TABIE 1. URANTUM DIOXTDE FUEL CHARACTERISTICS--INITIAL STUDTES. . . 20

TABLE 2. URANIUM DIOXIDE FUEL CHARACTERISTICS--THERMAL CYCLE STUDIES. . . . . . . . . . . . . . . . . . 21

TABIE 3. URANTUM DIOXIDE FUEL CHARACTERISTICS-ENRICHED PELIETS . - 22 TABLE 4. ANALYSIS OF ENRICHED UO 2 PARTICLES AFTER COATING WTTH

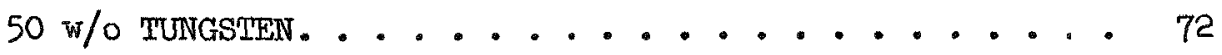


DEVEIOPMENT OF URANIUM DIOXTDE - TUNGSTEN CERMET FUEL

SPECIMENS FOR THERMIONIC APPLICATIONS

by P. J. Gripshover and J. H. Peterson

Battelle Memorial Institute

Columbus, Ohio

\section{INTRODUCTION}

The Iewis Research Center of the National Aeronautics and Space Administration initiated a project at Battelle Memorial Institute for the purpose of fabricating clad fuel pellet containment vessel assemblies. These assemblies house clad fuel pellets containing enriched fuel. Irradiation studies of these assemblies in the NASA PIum Brook Reactor will provide data required for the design of thermionic converter reactors being considered by NASA.

Three major objectives were defined at the initiation of this project at Battelle. These were (1) to provide containment vessel assemblies for irradiation studies, (2) to identify the best fuel dispersion/ cladding combination for the fueled pellets, and (3) to identify and optimize the most promising fabrication technique to the extent necessary to provide reproducible specimens. In addition to these major objectives, other goals were defined in relation to supporting studies required for the successful conclusion of this program. 
The approach for accomplishing these objectives involved the cooperation of various research and research support groups at Battelle. These groups contributed to the overall program by involvement in the following areas:

(1) Preparation or procurement of various types of $\mathrm{UO}_{2}$ fuel particles

(2) Application of tungsten coating to the fuel. particles

(3) Development of various powder-consolidation techniques for the fuel form including use of explosive methods and hot isostatic pressing

(4) Selection and evaluation of high-temperature claddings for the fuel form

(5) Development of techniques for cladding application to the fuel form

(6) Evaluation of candidate systems by thermal cycling

(7) Fabrication of irradiation containment vessels and the associated components

(8) Conduction of appropriate supporting studies associated with welding and brazing of the containment vessel components.

The objectives of this program were accomplished to the extent that two clad fuel pellet containment vessel assemblies were completed and forwarded to NASA for irradiation testing. In conjunction with this effort, a compatible fuel-cladding system was developed for the clad fuel pellet as well as a fabrication process. In addition to the accomplishment of these major goals, other valuble information relating to the fabrication and assembly of the containment vessel components was developed. 
This final report on NASA Contract No. NAS $3-4255$ covers all work performed from the initiation of the program on JuIy 1, 1963, to the conclusion on April 8, 1967.

\section{MATERIALS AND EQUIPMENT}

The materials used in the fabrication of the containment vessel assembly are indicated in Figure 1 . This figure shows the configuration and dimensions of the capsule as indicated on NASA Drawing No. CF351044. A detailed description of these materials is given below.

The following materials were used in the fabrication of the assembly.

(1) The tungsten cladding material is arc-cast tungsten. This material has a minimun purity of 99.97 percent.

(2) The materials used in the fabrication of the containment vessel, thermocouple wells, support spring, and fill tube are tantalum-10 $\% / 0$ tungoten. An execption to this specification is the thermocouple wells on Containment Vessel 304-011. The thermocouple wells on this vessel are unalloyed tantalum.

(3) The extension tubes brazed to the thermocouple wells are fabricated from Type 304-I stainless steel.

(4) The braze material used in the joining of the thermocouple wells to the containment vessel and to the clad fuel pellet is unalloyed columbium.

(5) The braze material used in the joining of the stainless steel extension tubes to the thermocouple wells is highpurity copper. 


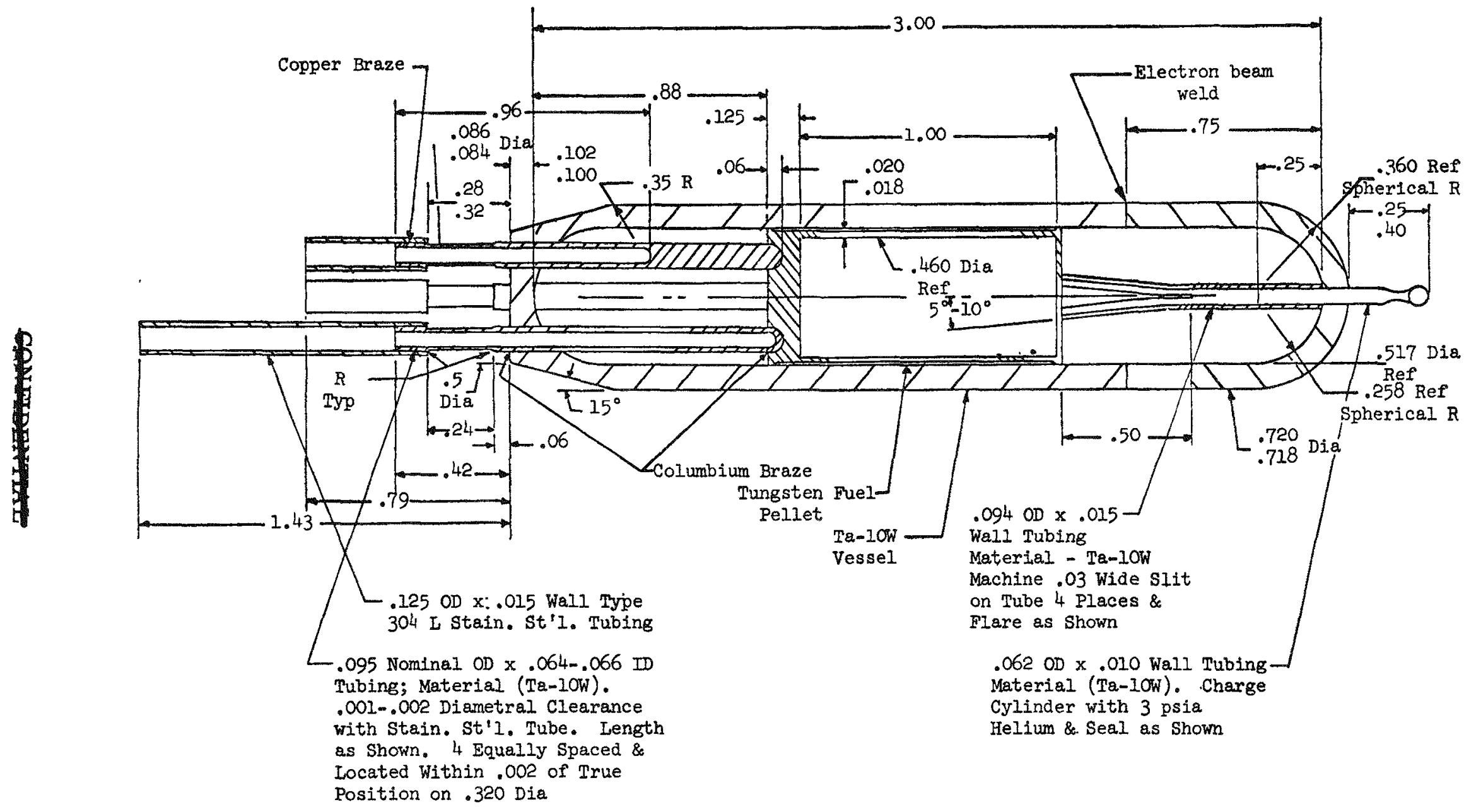

FIGURE 1. DRAWLIV OF CONTAINMENT VESSEL ASSEMBLY 
(6) The uranium dioxide particles and the tungsten material used in the fabrication of the fuel form are discussed in another section of this report.

In addition to the above materials, gas-pressure-bonding containers for the fuel pellet were also utilized. Arc-cast molybdenum was selected for the bonding container because of its weldability and ease of removal from the pellet by selective leaching in dilute nitric acid. Tantalum was used to double-can the bonding container (i.e., to encase the molybdenum container to provide increased reliability during bonding).

Equipment used during this program consisted of specialized gaspressure-bonding equipment capable of temperatures to $3200 \mathrm{~F}$ and pressure in excess of 30,000 psi. Also utilized were machine-shop facilities, hightemperature vacuum and hydrogen furnaces, helium leak detectors, the metallographic laboratory, and spectrographic and chemical analysis facilities. Radiographic and dye-penetrant test equipment were used for nondestructive testing.

\section{EXPERIMENTAL WORK}

In the initial stages of the program, work was directed toward development of preparation and bonding procedures for the cladding material and the development of an optimum fuel dispersion for the fuel form. After these procedures were developed, clad fuel pellets were prepared for thermal cycling and subsequent evaluation. Concurrent with the above work supporting studies on the welding, brazing, and fabrication of the containment vessel assemblies were being conducted. After a fabrication procedure for the complete assembly had been selected, three containment vessel assemblies were evaluated by thermal cycling prior to preparation of the final assemblies containing enriched $\mathrm{UO}_{2}$ for delivery to NASA. 
Development of Cladding Techniques

The purpose of the cladding material for the fuel pellet is three-

fold. First, it must provide containment for the fission products; second, the cladding material should provide strength to the structure so that growth during repeated cycling is minimized; and lastly, the cladding must function as an emmiter in the final application. In this study the primary goals were to develop claddings aimed at the first two requirements.

\section{Selection of Candidate Materials}

The primary material of interest for this application is tungsten. Tungsten cladding would have the required high-temperature properties, good strength and low-vapor pressure and would be compatible with the tungsten$\mathrm{UO}_{2}$ fuel system being considered for the fuel form. During the course of the study, other tungsten base materials were also considered. These were tungsten -25 percent rhenium and 1 percent thoriated tungsten. The tungstenrhenium alloy was selected to provide improved ductility in the cladding material and the thoriated tungsten was evaluated because of its higher elevated temperature strength.

These materials were evaluated primarily by thermal-cycle tests in the form of a clad fuel pellet. The final analysis indicated that the pure tungsten clad was equal to or better than either of the other candidate materials.

Preliminary Bonding Study

To evaluate the effect of surface preparation, a bonding study was conducted with 0.020 -in.-thick tungsten sheet. In this study, four different surface preparations were evaluated after three different chemical preparations. 
The four surface preparations evaluated were:

1. Rough grinding (60 $\mathrm{ms})$

2. Smooth grinding ( $5-10 \mathrm{rms})$

3. As-rolled

4. Metallographic polish.

Each of these preparations was then given the following chemical preparations:

1. Cleaning (MEK and absolute alcohol)

2. Pickling ( $\mathrm{HNO}_{3}-\mathrm{HF}$ ) followed by cleaning

3. Electropolishing.

Three specimens were then prepared. Each specimen contained all four surface preparations which had been given the same chemical preparation.

After gas-pressure bonding these components in molybdenum containers at 2850-2900 F and 10,000 psi for $3 \mathrm{hr}$, the various preparations were evaluated metallographically. The following general conclusions were drawn from this study:

I. I'he surfaces receiving the cieaning treatment consisting of washing in MEK and absolute alcohol are of equal quality to those pickled or electropolished.

2. Tungsten sheet which received no surface preparation exhibited fair to good bonds.

3. Grinding of the surface had a deleterious effect on bonding with bond quality decreasing as the surface roughness increased.

4. Metallographic polishing appears the most promising preparation approach. 
A photomicrograph of polished surfaces after bonding is shown in Figure 2. The bond line can be determined but only by a few scattered voids. Good grain growth across the interface is evident.

It would, therefore, be desirable to provide the bast possible surface finish on the mating surfaces to provide bonds of high quality between the cladding components and the cladding and the fuel forr.

\section{Fabrication Techniques for Preparation of Cladding Components}

The basic fabrication technique for the cladding components changed very little through the course of the program. However, numerous minor changes and additions were incorporated as the data obtained from gas-pressure bonding and thermal cycling experiments became avaijable. Basically, the approach included the preparation of tungsten tube from solid bar stock and the end plugs for the tube from either sheet or bar stock.

Initially, the cladding components were machined. to the dimensions show in Figure 3. This shows a clad fuel pellet prior to bonding. The desired pellet size after bonding is shown also in this figure and would be achieved by grinding the $O D$ and any excess from the ends of the tube. It was anticipated initially that no machining of the fuel form would be required. The hole thro ugh the center of the tube was accomplished by electrical dis. charge machining. The end plugs were ground to 0.465 diameter from 0.125 -in. and 0.020-in. tungsten sheet material. All tungsten was vacuum arc cast rather than powder metallurgy stock and met the 99.97 percent purity specifications.

As work progressed on the program and failure mechanisms for the cracking of the cladding material were investigated, it became apparent that the electrical discharged machined surface contained microcracks. This is shown in Figure 4. A.lthough these small cracks may heal during gas-pressure bonding, 


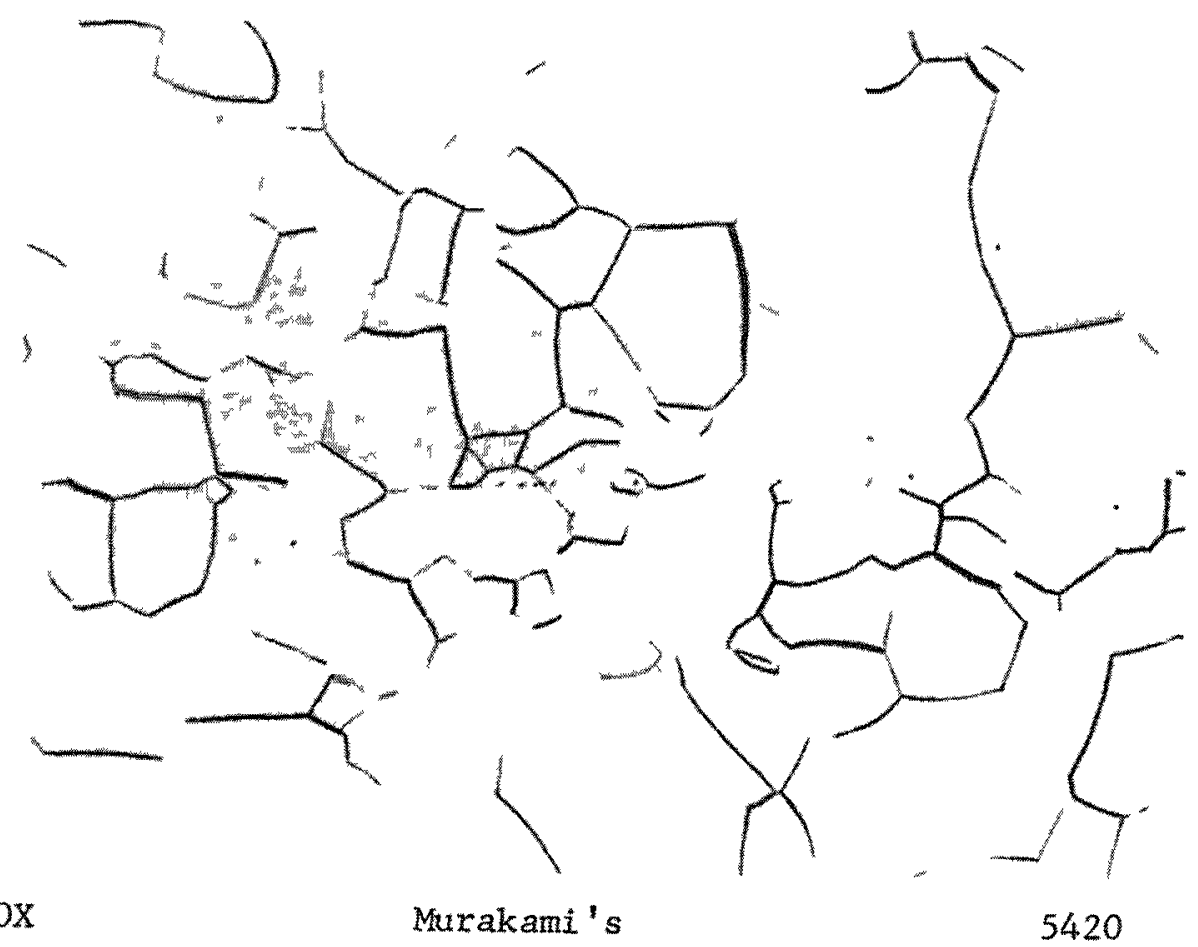

FIGURE 2. TUNGSTEN JOINED BY GAS-PRESSURE BONDING

These polished surfaces were bonded at $2900 \mathrm{~F}$ and 10,000 psi for three hours. 


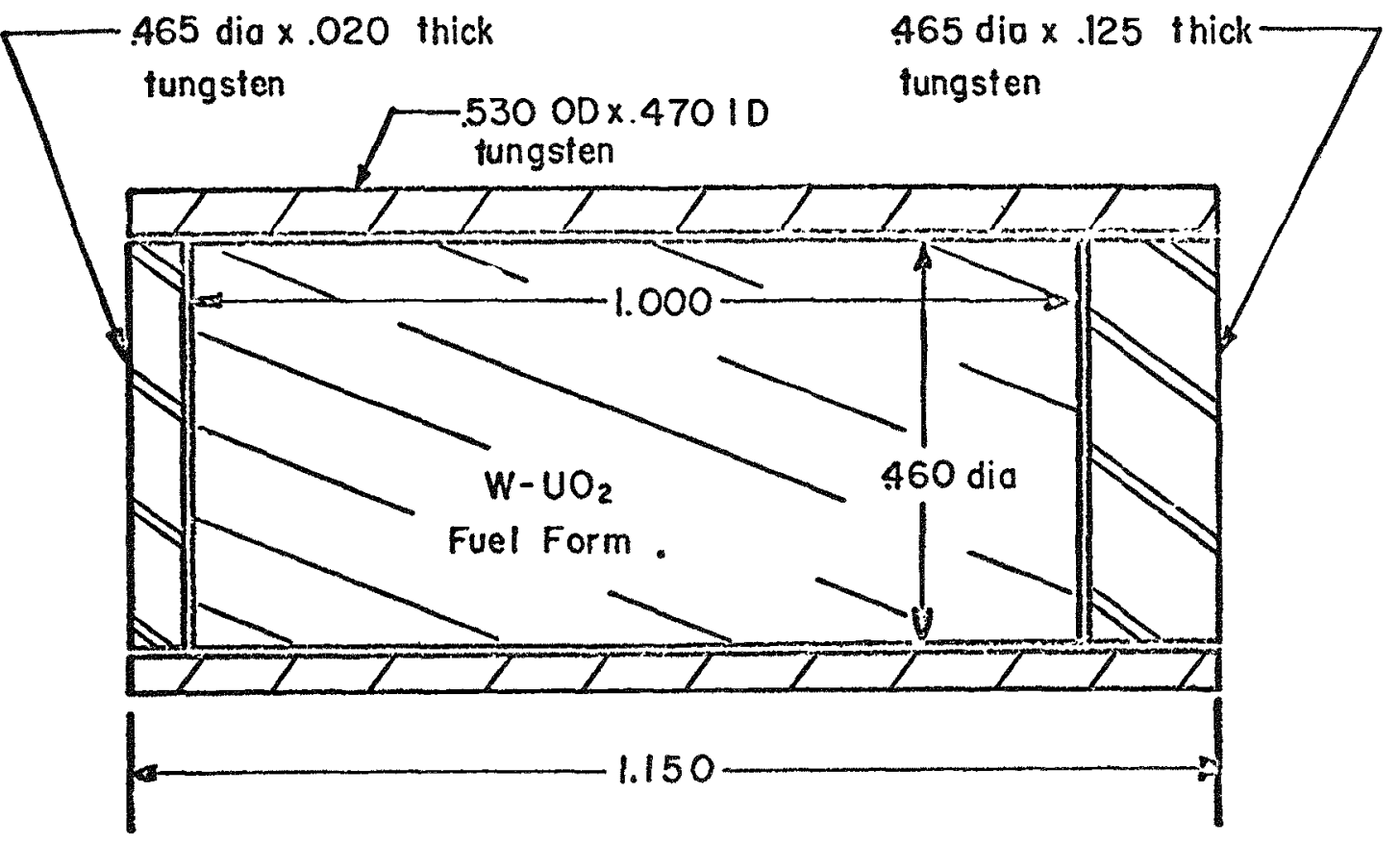

a. Before Bonding

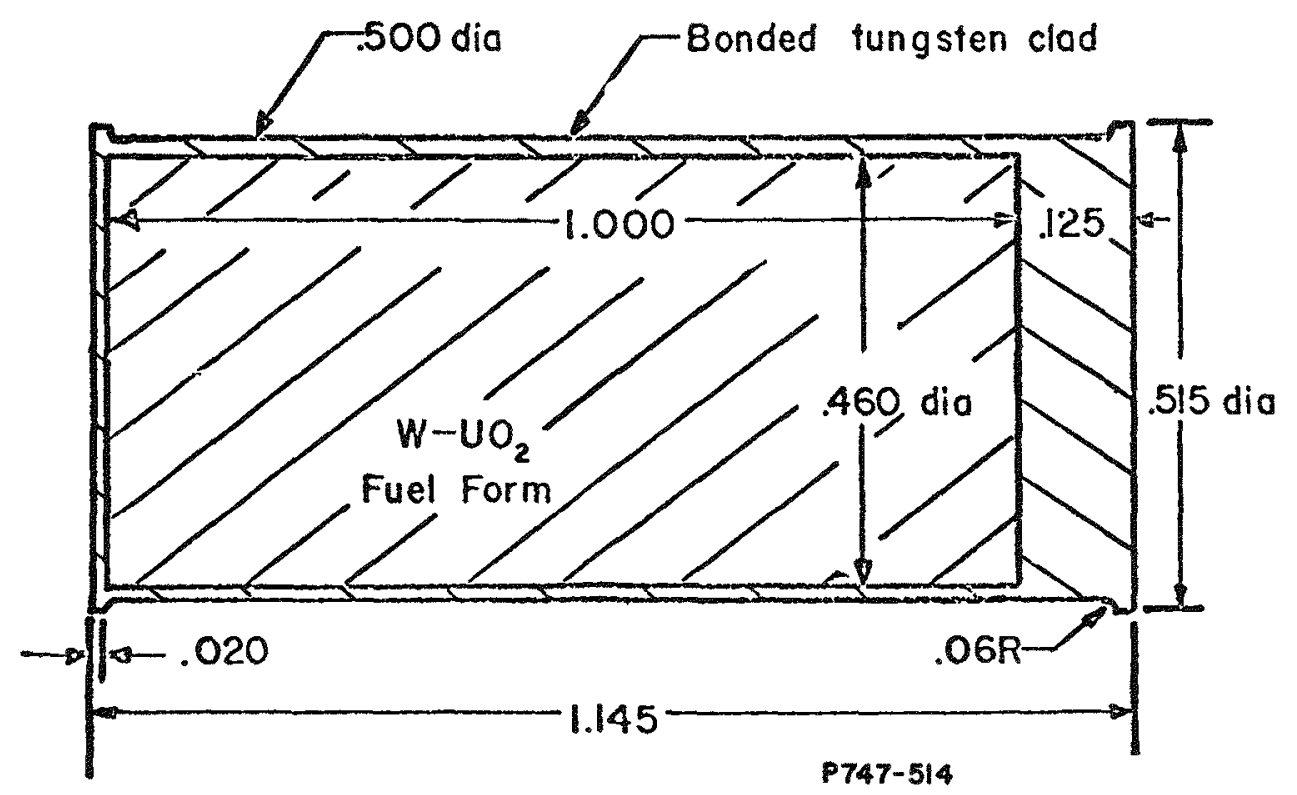

b. After Bonding and Grinding

FIGURE 3. CLAD FUEL PELLET 


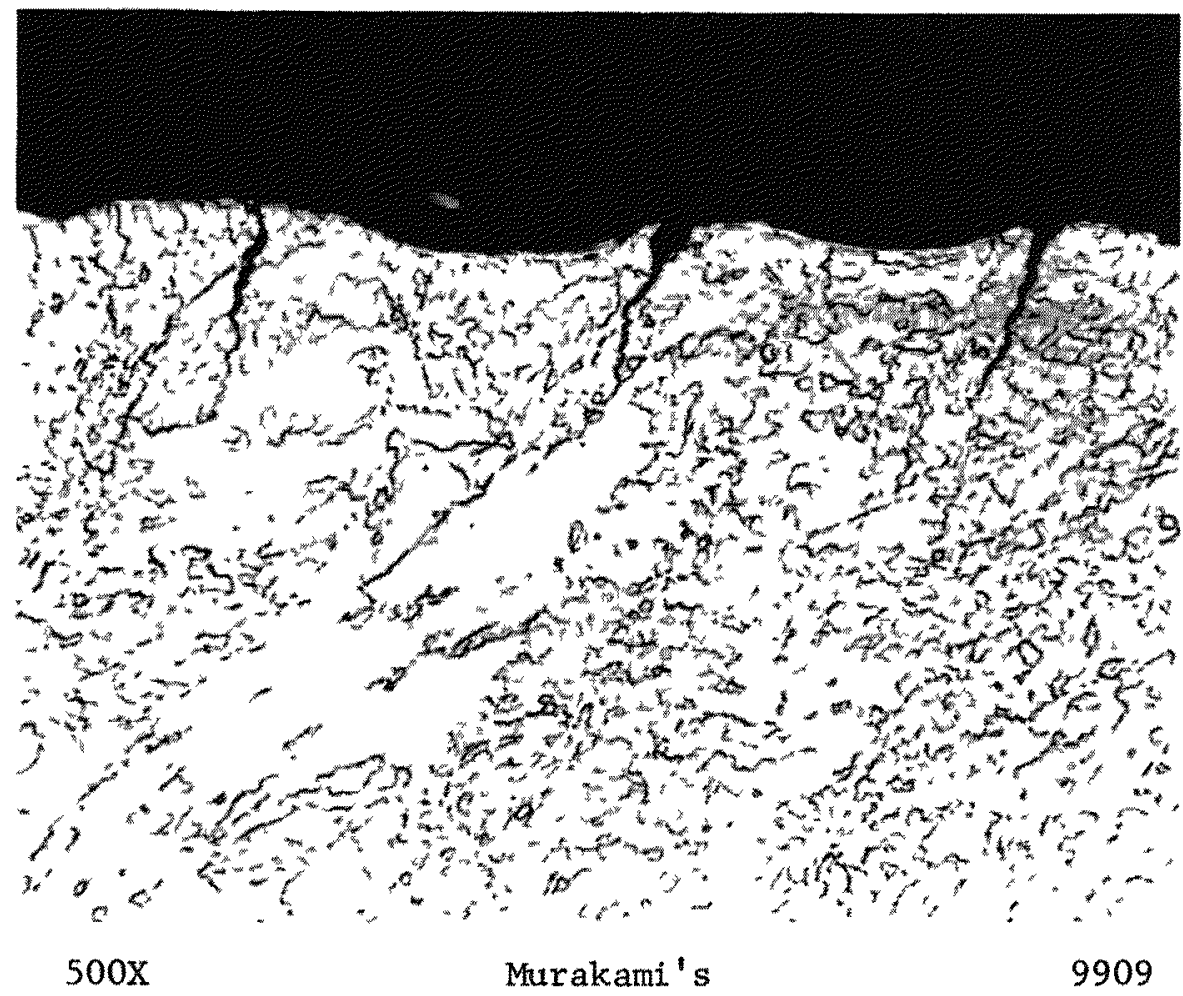

FIGURE 4. CRACKS IN TUNGSTEN CLAD RESULTING FROM ELECTRICAL DISCHARGE MACHINING 
these could well be sites where cracking during thermal cycling could initiate. To remove these cracks and also provide a smoother surface for bonding, the tubes were EDM'd undersize and then honed to final size. A minimum of 0.005 in. was removed from the surface to eliminate these cracks. A 2500 F stress relief was also found to be beneficial prior to honing to minimize the tendancy of crack propagation. It was also found desirable to reduce the clearance between the clad and the pellet to minimize the deformation required to achieve intimate contact between all components. Another improvement that evolved from this work was to make the end plugs thicker than required and the tube longer than required so that the ends of the pellet could be ground to remove any evidence of the bond interface. A drawing showing the cladding dimensions is shown in Figure 5. The final dimensions of the pellet are also shown.

other improvements incorporated during the program included an increase in the temperature and gas pressure during pressure bonding and hydrogen treating of the components prior to bonding. These hydrogen treatments are discussed in a later section of this report. Initial bonding of these components was conducted at 2850-2900 F and a gas pressure of 10,000 psi. These conditions were found to be marginal and were changed to 3100$3200 \mathrm{~F}$ and at least $15,000 \mathrm{psi}$ for a minimum of $1-1 / 2 \mathrm{hr}$. This resulted in reliable bonding of the clad components and of the clad to the fueled core. To allow full relaxation of the tungsten during the bonding cycle, the pressure in the autoclave is released while at the bonding temperature at the rate of $100 \mathrm{psi}$ per min until approximately $300 \mathrm{psi}$ is reached. Then, the autoclave furnace is turned off. A relaxation experiment with tungsten rod was used to determine that this rate of pressure release was not too rapid. A tungsten specimen was placed under 1000-psi tensile stress at a temperature of $2500 \mathrm{~F}$. Complete relaxation from thic stress required a maximum of $5 \mathrm{~min}$. 


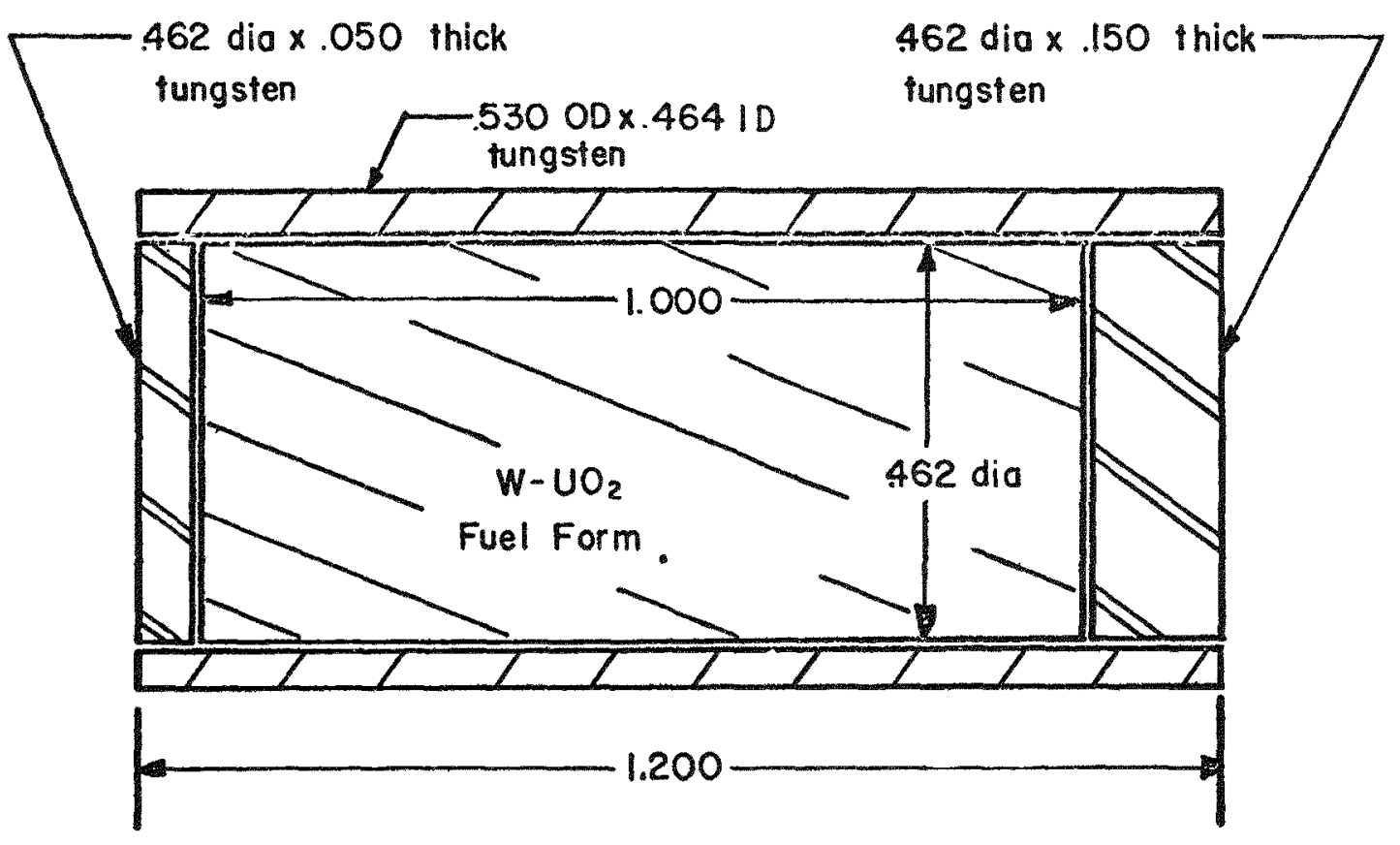

a. Before Bonding

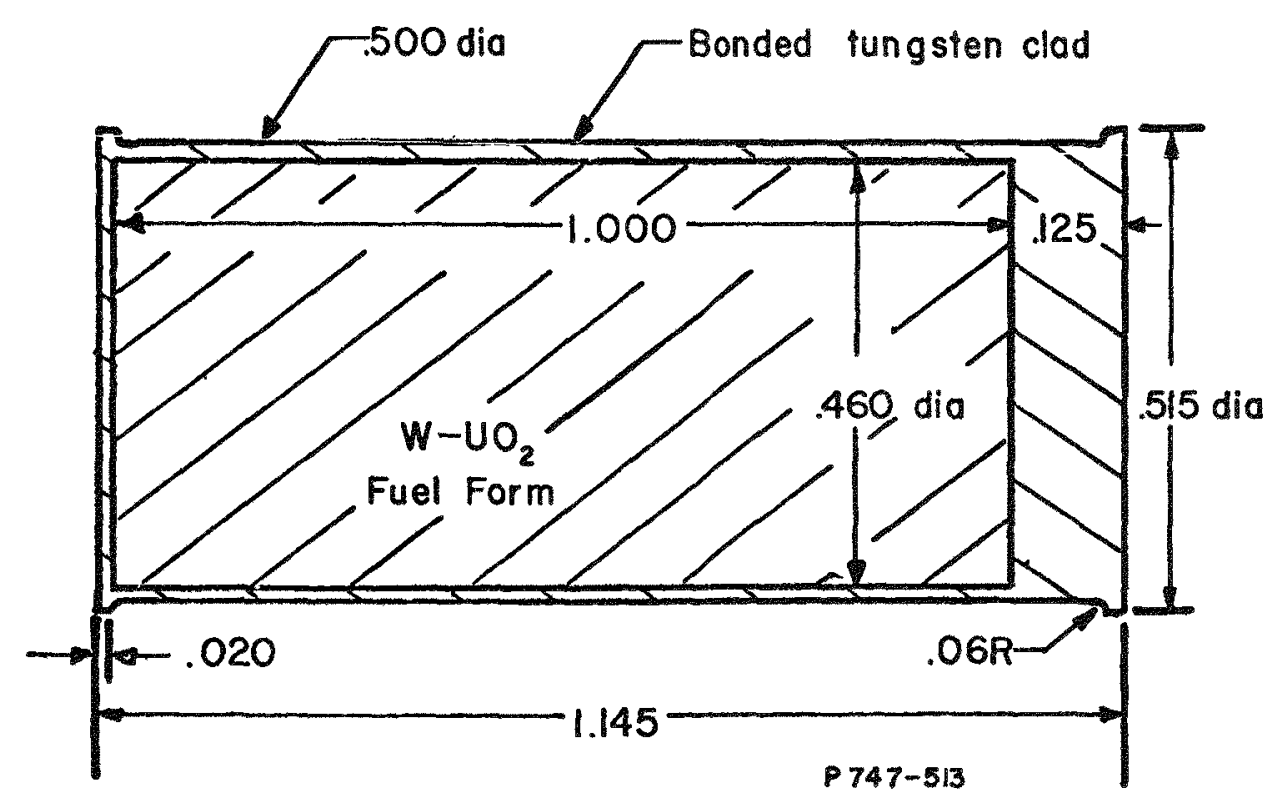

b. After Bonding and Grinding

FIGURE 5. IMPROVED CLAD FUEL PELLET FABRICATION TECHNIQUE 
Inspection of the tungsten tube during processing was accomplished primarily by dye penetrant inspection. The use of other techniques such as inspection through stereo binoculars at $30 \mathrm{X}$ magnification was also used.

The use of extruded tungsten tubing was evaluated early in this program but was not available in sufficient quantity to be considered attractive. Tubing of this type if it should become available at a reasonable cost should be considered. A photomicrograph of this tube after five thermal cycles to $1800 \mathrm{C}$ is shown in Figure 6. Note the fine grain size after thermal cycling.

Preliminary Cladding Study

Early in the program three fuel forms were clad with tungsten although the conditions were not optimum. The fuel forms were undersize, about 0.430-in. diameter rather than 0.460-in. diameter, and excessive clearances resulted between the fuel form and the clad which was $0.470-$ in. ID. The diameters of the end plugs matched the diameter of the fuel form. These pellets were bonded at 2850-2900 F and 10,000 psi for $3 \mathrm{hr}$. Molybdenum end plugs extruded into the gap formed between the undersize end plugs and the tungsten tube and caused some dumbelling of the specimen as shown in Figure 7. This extrusion of the molybdenum also prevented good bonding of the tube to the tungsten end plugs. A transverse section was taken through the center of the specimen to inspect the bonding of the tungsten clad to the fuel form. A photomicrograph of a tyrical area is shown in Figure 8. Good bonding of the tungsten clad to the fuel form can be noted. The only preparation to the components in this case was a hydrogen heat treatment at $1500 \mathrm{~F}$ prior to assembly. The tungsten tube was in the as-EDM'd condition. 


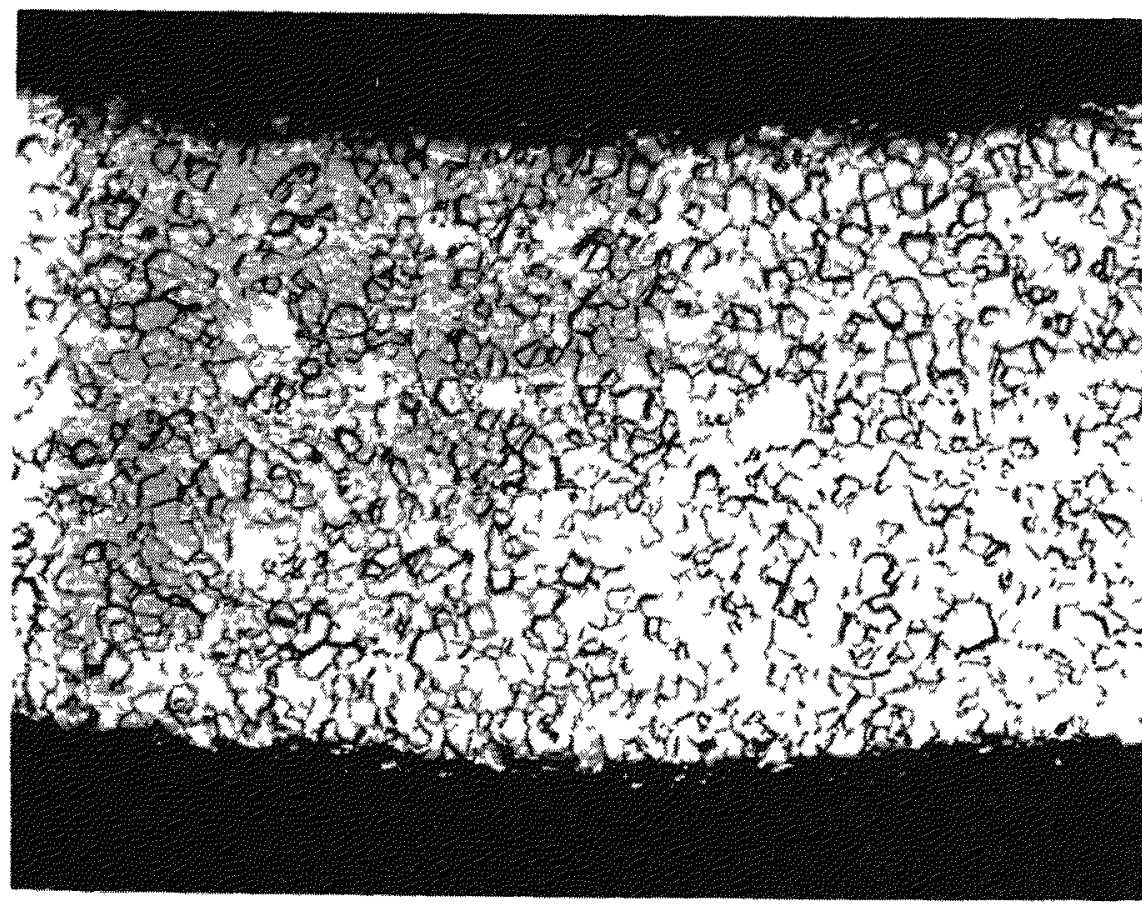

$150 \mathrm{x}$

Murakami's

10943

FIGURE 6. EXTRUDED TUNGSTEN TUBE

This tube has been subjected to

five thermal cycles to $1800 \mathrm{C}$. 


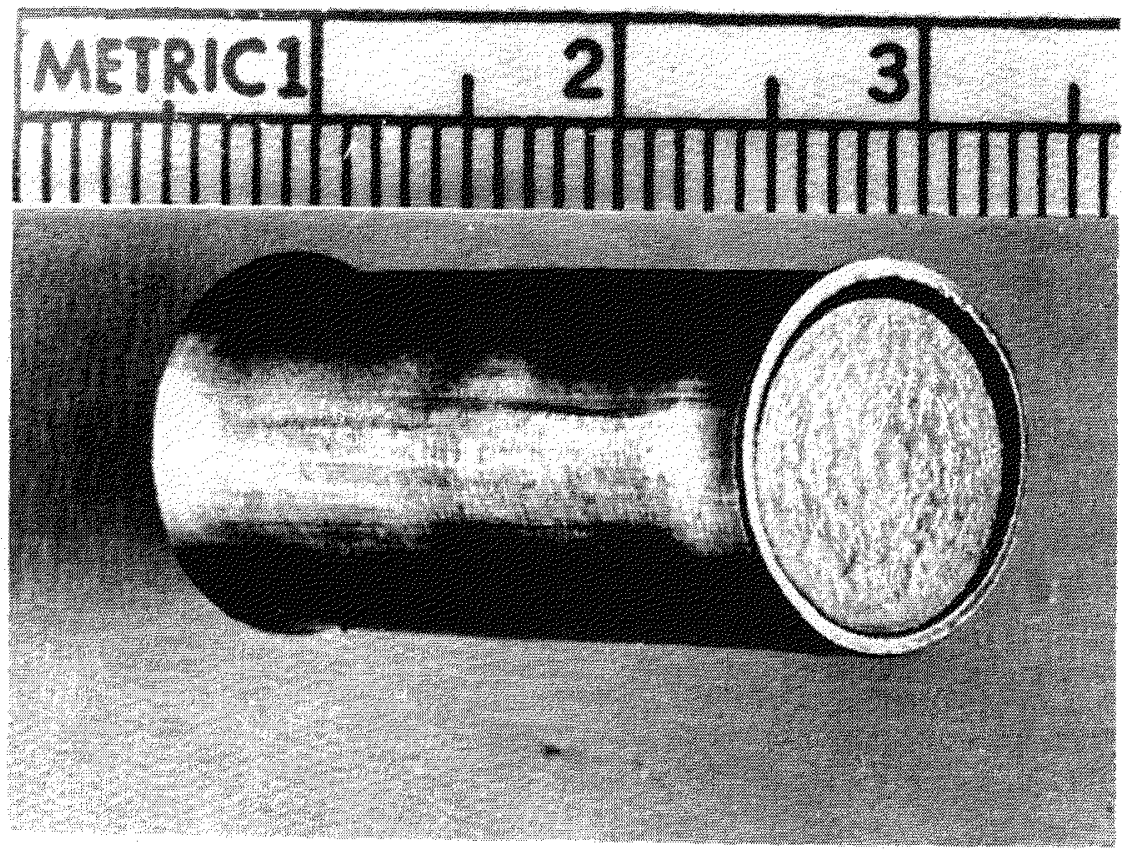

$3 \mathrm{x}$

4958

FIGURE 7. CLAD FUEL PELLET

The use of an undersize fuel form resulted in dumbelling of the specimen. 


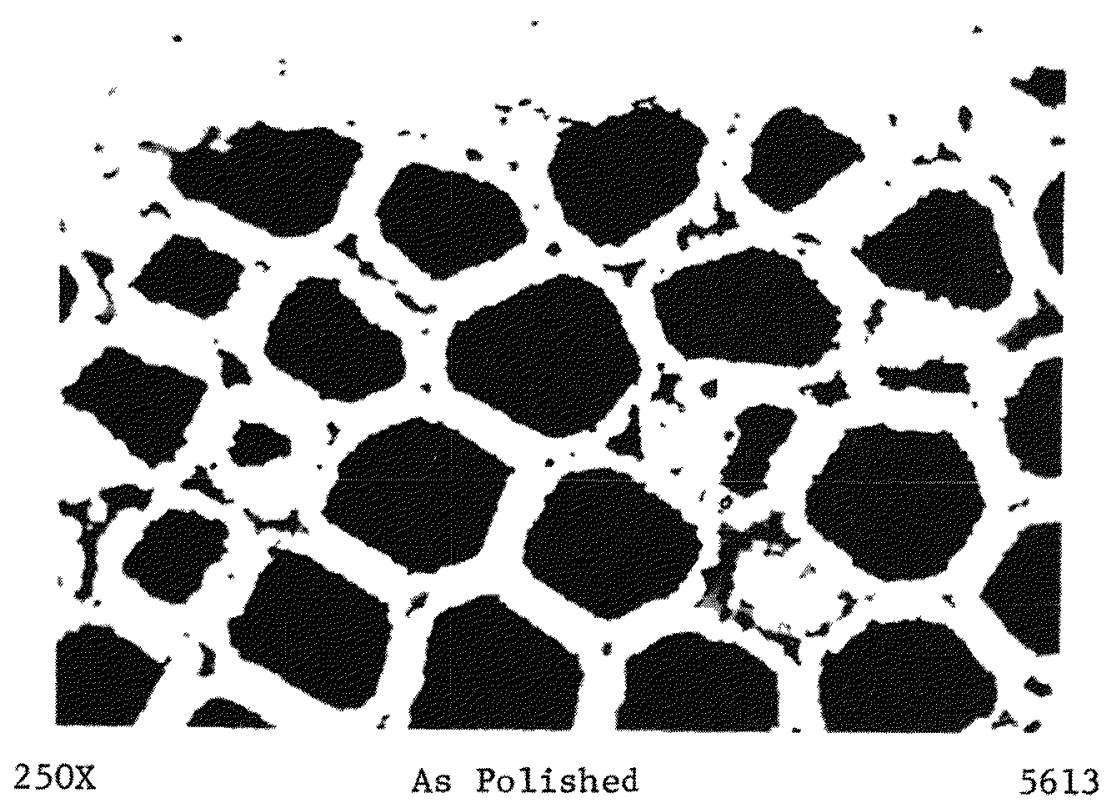

FIGURE 8. PHOTOMICROGRAPH SHOWING BONDING OF TUNGSTEN CLAD TO FUEL FORM 
The results of this indicated that bonding of the clad to the fuel form could be readily obtained. Another encouraging factor was even though the tungsten tube had undergone considerable deformation no cracking was detected by dye-penetrant inspection.

\section{Development of Optimum Fuel Dispersion}

One of the primary research areas on this program was the development of the tungsten-UO $\mathrm{UO}_{2}$ fuel form which was subsequently clad and contained within the vessel assembly. This fuel form was a dispersion of spherical $\mathrm{UO}_{2}$ within a tungsten matrix. The fuel loading was 50 volume percent. of primary interest in this area was the consolidation of the fuel form to obtain a high-density high-strength structure without causing excessive deformation of the spherical $\mathrm{UO}_{2}$ in the processing procedure.

Fuel Requirements and Preparation

The $\mathrm{UO}_{2}$ fuel for the pellets was to be spherical in shape and have a diameter of 60 to 100 microns. The stoichiometry of the $\mathrm{UO}_{2}$ could not vary more than 1 part per hundred of oxygen from true stoichiometry. The total impurity was not to exceed 2 parts per hundred and the halide content not to exceed $30 \mathrm{ppm}$. The density of the $\mathrm{UO}_{2}$ initially was to exceed 97 percent of theoretical. This was later lowered to fall within the range of $92-95$ percent.

\section{Selection of Candidate Materials and Techniques}

The material for the fabrication of the fuel form was $\mathrm{UO}_{2}$ vapor coated with tungsten to obtain a fuel loading of 50 volume percent. If the ratio of fuel to tungsten did not meet these specifications, fine tungsten powder would be added to achieve the desired loading. Consolidation of the fuel form was to be accomplished by hot isostatic pressing to a minimum 
19

density of 92 percent of theoretical. Initially, the fuel form was to be consolidated to final size (0.460-in. diameter by 1.00-in. Iong) but later in the program the fuel form was made oversize and machined to achieve the desired dimensions shown in Figure 5. In order to maintain sphericity of the $\mathrm{UO}_{2}$, processing of the fuel form was modified to include coating of tungsten powder onto a thin vapor-coated $\mathrm{UO}_{2}$ particle. This technique achieved the desired fuel loading and aided in maintaining the spherical shape of the $\mathrm{UO}_{2}$ particles.

Preparation and Procurement of $\mathrm{UO}_{2}$ Powders

Efforts were made at Battelle to produce high-density natural $\mathrm{UO}_{2}$ particles to meet the specifications of the initial contract because long lead times were required for commercial material. These brief attempts to produce those particles were unsuccessful. Particles meeting the density requirements were oversize, and a change in process parameters to produce particles of the desired size resulted in a marked decrease-in density. The program could not warrant additional effort in this area after the commercial material was received. The characteristics of the $\mathrm{UO}_{2}$ used in the initial experimental work is show in Table 1 . The $\mathrm{UO}_{2}$ used in subsequent experiments is characterized in Table 2. This latter $\mathrm{UO}_{2}$ was used for all work which involved thermal cycling of clad pellets. The enriched $\mathrm{UO}_{2}$ characteristics are outlined in Table 3. This enriched material was originally coated to obtain a $50 \mathrm{v} / 0$ loading. Subsequent research studies showed that it was advantageous to coat the fuel to obtain a $63.8 \mathrm{v} / 0(50 \mathrm{w} / 0)$ fuel loading and add tungsten as fines to achieve the required $50 \mathrm{v} / 0$ loading. This material was decoated and then coated again to the revised specification. 
TABIE 1. URANIUM DIOXIDE FUEI CHARACTERISTICS--INITIAL STUDIES

TYPE - Depleted

DENSITY - $10.6 \mathrm{~g} / \mathrm{cc}-96.6$ percent

PARITCLE SIZE - 53-74 microns diameter

O/U RATIO - 2.01

ANALYSIS

$\mathrm{CI}+\mathrm{F}-\quad<20 \mathrm{ppm}$

Sum of all other impurities $\quad-\quad<100 \mathrm{ppm}$

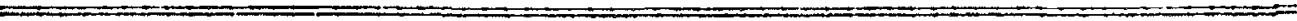


TABIE 2. URAIIUM DIOXIDE FUEL CHARACTERISTICS--THERMAI CYCLE STUDIES

TYPE - Depleted

DENSITY - $10.4 \mathrm{~g} / \mathrm{cc}-94.8$ percent

PARTICLE SIZE - 63-74 microns

O/U RATIO - 2.01

ANALYSIS - ppm

\begin{tabular}{lllc} 
Ag & $<0.01$ & $\mathrm{~F}$ & $<10$ \\
$\mathrm{AI}$ & 5 & $\mathrm{Fe}$ & 5 \\
$\mathrm{~B}$ & 0.5 & $\mathrm{Mg}$ & 4 \\
$\mathrm{Ca}$ & 8 & $\mathrm{Mn}$ & $<2$ \\
$\mathrm{Cd}$ & 0.3 & $\mathrm{Ni}$ & 1 \\
$\mathrm{Cl}$ & 8 & $\mathrm{~Pb}$ & $<1$ \\
$\mathrm{Cr}$ & 1 & $\mathrm{Si}$ & $<20$ \\
$\mathrm{Cu}$ & 3 & $\mathrm{Sn}$ & $<1$ \\
\hline
\end{tabular}




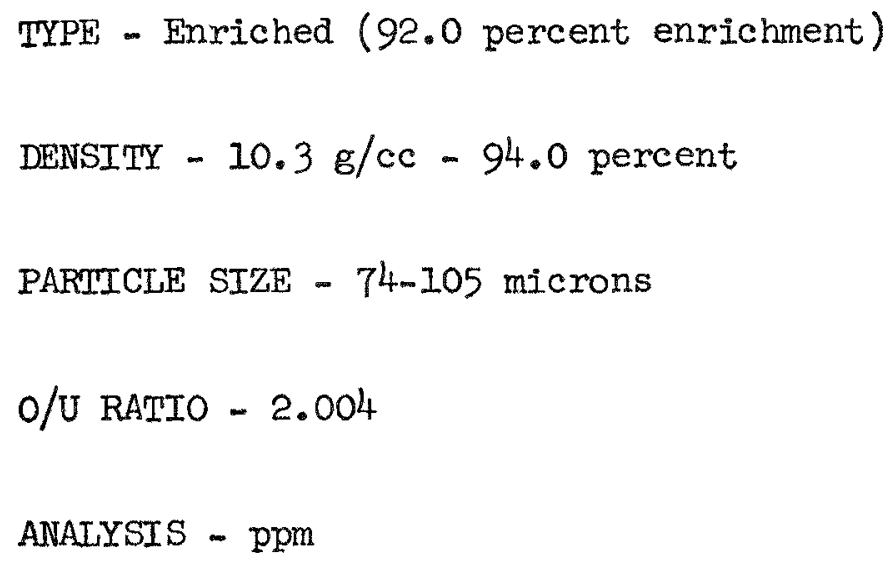

* The fluorine analysis was taken following the remcval of the initial coating. 
Fuel Form Consolidation Experiments

The initial objectives in the fabrication of the fuel form were to produce a right-cylindrical shape, $0.46 \mathrm{in}$. in diameter by $1.00 \mathrm{in}$. Iong, with a $50 \mathrm{v} / 0$ fuel loading. The $\mathrm{UO}_{2}$ spheres were vapor coated by the reduction of tungsten hexafluoride with hydrogen. It was desired to eliminate machining of the densified fuel form by consolidating to final size by the hot isostaticpressing process. A density in excess of 92 percent of theoretical was desired.

In the final experimental work in this area, eight specimens were prepared. The coated particles had a $47 \mathrm{v} / 0$ tungsten loading so fine tungsten powder was added to produce the desired loading of $50 \mathrm{v} / \mathrm{o}$ tungsten. This material was loaded into molybdenum containers of various designs to evaluate deformation characteristics. These specimens were consolidated at $2900 \mathrm{~F}$ and 10,000 psi gas pressure for $3 \mathrm{hr}$. Five of the specimens leaked. The remaining specimens were evaluated for dimensions prior to the preparation of four additional specimens. These four specimens were bonded from coated particles having the exact fuel loading so the addition of fines was not required. The three good specimens from the first hot isostatic-pressing run and the results of the second run indicated two problem areas. These were (I) nonuniformity of dimensions resulted in a fuel form which could not be used directly and (2) loss in sphericity of the $\mathrm{UO}_{2}$ during consolidation. The loss of sphericity of the $\mathrm{UO}_{2}$ is shown in Figure 9.

It was believed that the desired dimensions in the fuel form could be achieved; however, the change in shape of the $\mathrm{UO}_{2}$ during consolidation was unacceptable. The processing was modified to use of a thin tungsten coating (5-6 microns) on the $\mathrm{UO}_{2}$ and blending of tungsten fines to achieve the desired fuel loading. The fines would be displaced to void areas on pressing and raintain the desired $\mathrm{UO}_{2}$ shape. 


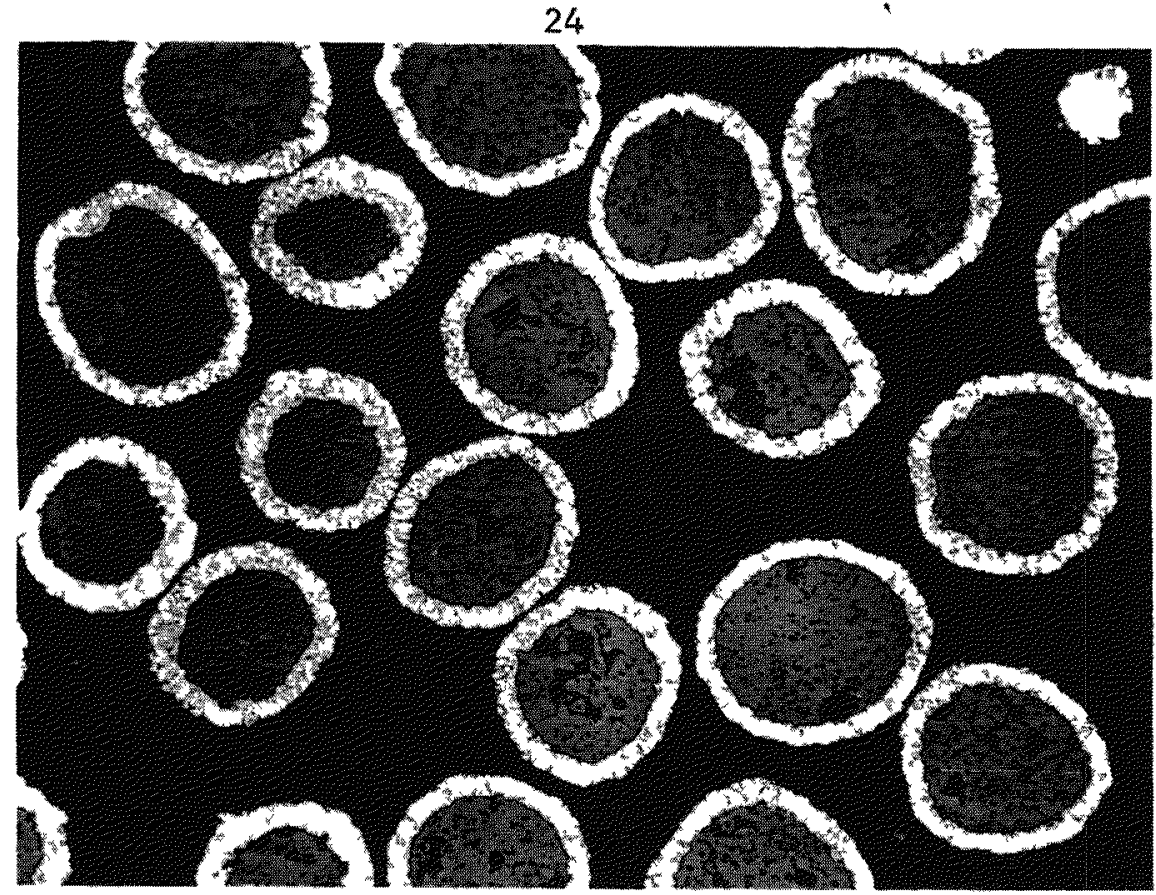

$250 \mathrm{x}$

Murakani"s

4376

a. $\mathrm{UO}_{2}$ after coating - $50 \mathrm{v} / 0$ tungsten.

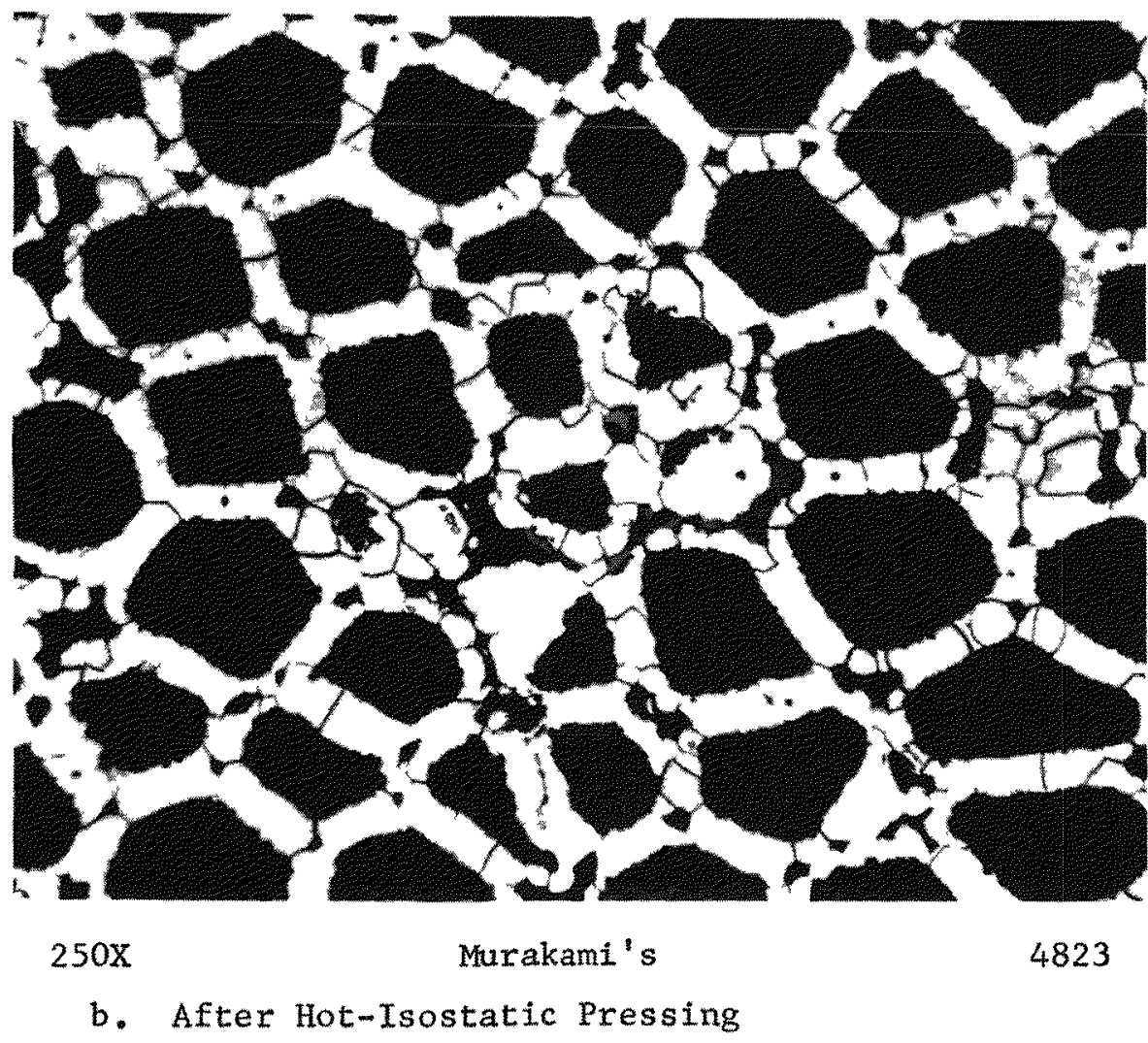

FIGURE 9. VAPOR COATED UO ${ }_{2}$ BEFORE AND AFTER HOT-ISOSTATIC PRESSING Note the loss in sphericity of the $\mathrm{UO}_{2}$ after consolidation. 
Several experiments were conducted to determine the optimum blending techniques. Parawax additions of $0.1-2.0$ percent were used to bind the fine tungsten powder to the coated particles. The particles were cold die pressed, heat treated at $2500 \mathrm{~F}$ to remove the Parawax binder, and gas-pressure bonded for evaluation. The bonding conditions were $2850 \mathrm{~F}$ and 10,000 psi for $3 \mathrm{hr}$. The Parawax addition of 0.2 percent appeared to be optimum for this application. This was sufficient binder to cause the tungsten fines to adhere to coated particles but did not cause break-up of the cold pressed shape during outgassing as did the 2.0 percent Parawax adition. A photomicrograph of the fuel forms fabricated by the optimum procedure are shown in Figure 10. It should be noted that the spherical nature of the $\mathrm{UO}_{2}$ is much improved over the earlier specimens that had the full amount of tungsten applied by vapor deposition.

Two problem areas were encountered in this fuel-form fabrication technique. These were the agglomerates of fine powder and the tendency for high carbon in the pellet. In both areas care in preparation of materfals and processing resulted in acceptable microstructures and carbon levels (<40 ppm). This process was not only used for the application of pure tungsten powder to the coated particles but also was used to blend $1 \mathrm{w} / \mathrm{o}$ thoriated tungsten powder with the coated particles.

Sintering at $3100 \mathrm{~F}$ and $4000 \mathrm{~F}$ for $3 \mathrm{hr}$ was also evaluated as a consolidation technique. No increase in density over the cold pressed density of 72 percent was noted at either sintering temperature. This approach was discontinued since the process involving a combination of powder blending and hot isostatic pressing produced satisfactory results. 


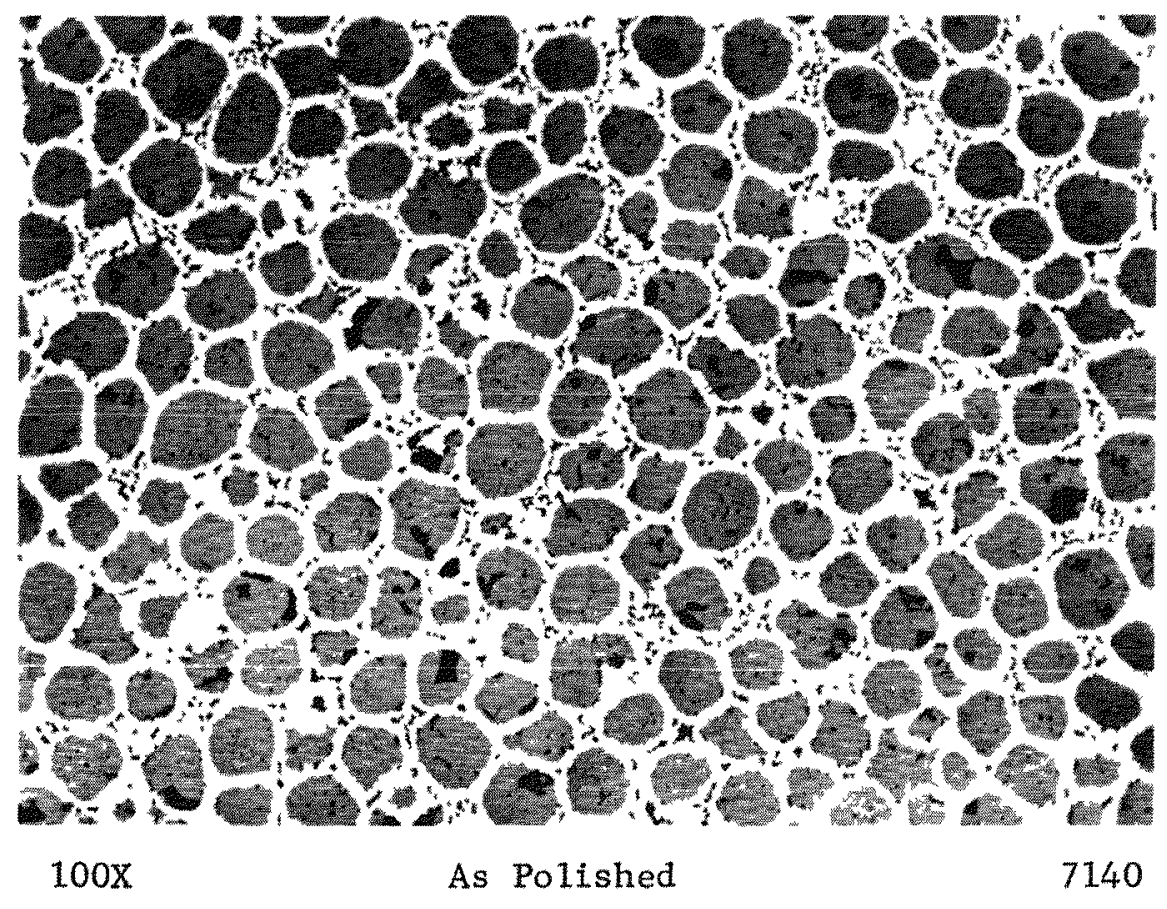

FIGURE 10. FUEL FORM PRODUCED BY BLENDING COATED PARTICLES AND POWDER 
Repeated attempts to hot isostatically press the fuel form to the exact final dimensions were not successful. The failure to obtain the desired configuration was not one single problem but a combination of variables which involved the cold-pressed density and the uniformity of density in the cold-pressed pellet, container design, and consistency in exact duplication of the hot isostatic pressing run. Because of this problem it was mutually agreed to fabricate the pellets slightly oversize and machine to the desired dimensions aftex consolidation. No further problems were encountered in the fabrication of the desired fuel forms using this approach.

In addition to the blending of tungsten coated particles with fines to produce the desired fuel loading, two other fabrication approaches were evaluated during the program. Both of these approaches involved the blending of $I \mathrm{w} / \mathrm{o}$ thoriated tungsten powder with uncoated $\mathrm{UO}_{2}$ spheres. In one instance the consolidation was achieved by explosive compaction while the other case used hot isostatic compaction as the consolidation process. The pellets were formed by die pressing a slurry consisting of the powder and the $\mathrm{UO}_{2}$ particles. The burnout material was removed by vacuum outgassing. The pellets scheduled for explosive compaction were loaded into steel containers and compacted to a density of about 95 percent. Because the pellets were machinable in this condition no further processing was done until the cladding step. Those pellets scheduled for hot isostatic pressing were loaded into molybdenum containers and consolidated at 2850-2900 F and 10,000 psi for a period of $3 \mathrm{hr}$. The structure of a typical pellet of this type is shown in Figure 11. The $\mathrm{UO}_{2}$ is not deformed but the uniformity of the dispersion of the $\mathrm{UO}_{2}$ in the matrix is not as satisfactory as that obtained when the coated particles are used. 


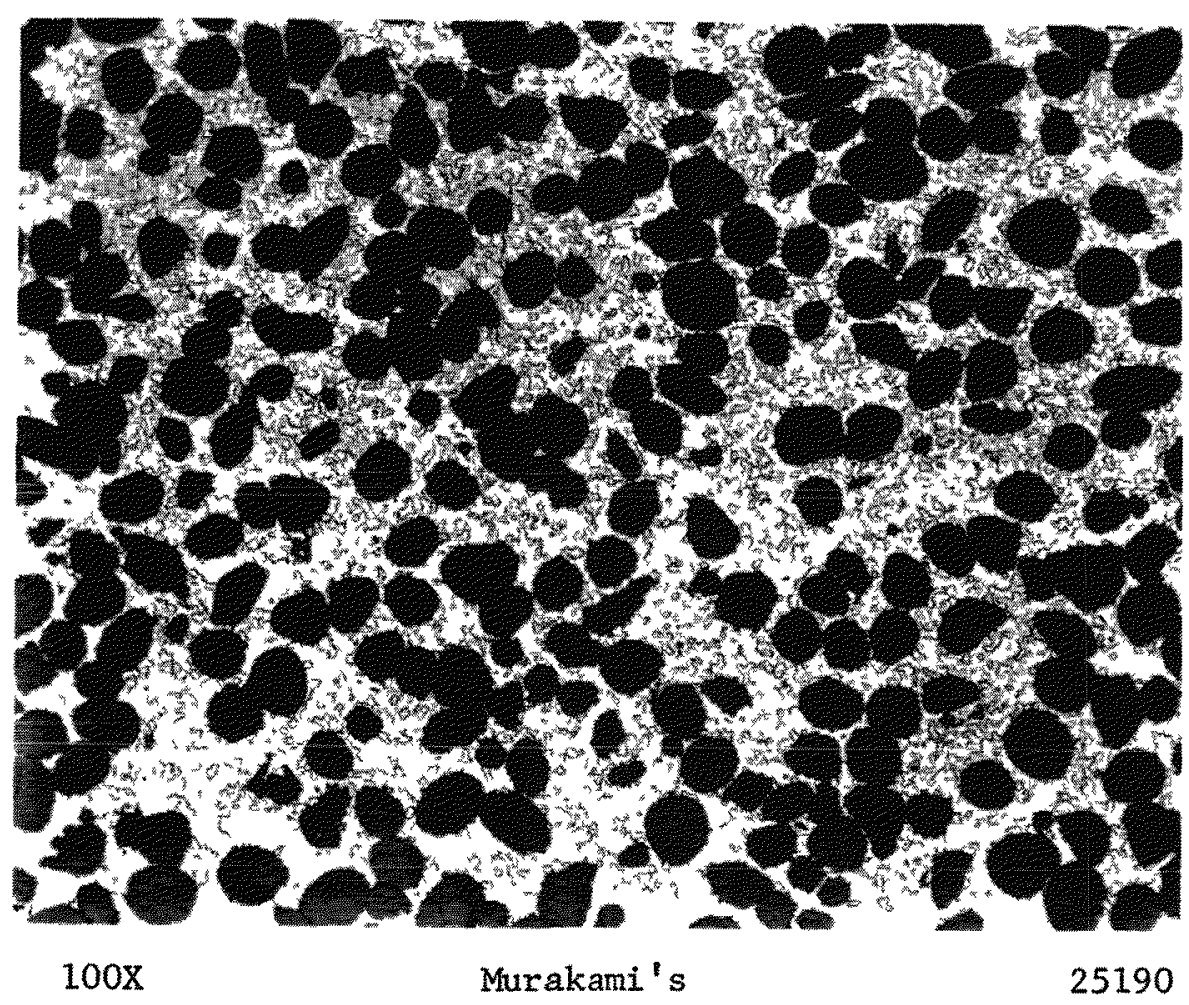

FIGURE 11. FUEL FORM FABRICATED BY EXPLOSIVE COMPACTION

The structure shown is after the cladding cycle. 


\section{Fabrication, Cycling, and Evaluation} of Thermal-Cycle Specimens

The primary evaluation technique for clad fuel pellets fabricated during this study was thermal cycling and subsequent examination. During the thermal cycles, measurements and weights were taken so that the weight loss and growth could be determined. The optimum fuel pellet would exhibit no fracturing and have a minimum of growth and weight loss during thermal cycling 100 times to $2000 \mathrm{~K}$. From the data obtained by these evaluations, a cladding material, fuel form, and fabrication technique for producing a clad fuel pellet most closely meeting these requirements were selected.

First Thermal-Cycle Evaluation

The first thermal-cycle evaluation consisted of two pellets clad with tungsten. These pellets were thermal cycled five times and were found to be severely cracked. A detailed account of these specimens is given below.

Fuel-Pellet Fabrication. The fabrication of the fuel pellets consisted of three distinct areas. These are fuel form fabrication, clad fabrication, and bonding and machining.

The fuel form consisted of $\mathrm{UO}_{2}$ coated with approximately 6 microns of tungsten by vapor deposition. Fine tungsten powder ( 0.88 mircon) was blended with the coated particles using a Parawax binder to bring the fuel loading to 50 volume percent. The pellets were cold pressed to 72 percent density, vacuum treated, and then hydrogen treated at $1500 \mathrm{~F}$ for $1 \mathrm{hr}$ prior to loading into a molybdenum container for hot isostatic pressing. These pressing conditions were $2850 \mathrm{~F}$ and $10,000 \mathrm{psi}$ for $3 \mathrm{hr}$. After HIP, the 
pellets were leached from the containers. One specimen had to be ground on the $O D$ to fit the cladding materials. The three tungsten-UO fuel forms were then vacuum treated at $500 \mathrm{~F}$ for $1 \mathrm{hr}$ to remove any moisture from leaching or grinding.

The cladding materials consisted of a tungsten tube $0.530 \mathrm{OD} x$ 0.470 ID $\times 1.150-$ in. Iong, and tungsten end plugs 0.020 and $0.1 .25-$ in. thick by 0.465-in. diameter. The interior of the tube was in the as-EDM'd condition. These components were vacuum treated at $2000 \mathrm{~F}$ for $\mathrm{I} \mathrm{hr}$ prior to assembly with the fuel forms. After assembly and welding in molybdenum containers the assemblies were gas-pressure bonded at $2850 \mathrm{~F}$ and 10,000 psi for $3 \mathrm{hr}$. FollowIng bonding, the containers were removed by leaching.

The specimens were then ground on the OD to provide the type specimen shown in Figure 3b. The final dimensions of these pellets were 0.500-in. diameter by 1.088 -in. long with a shoulder diameter of $0.516 \mathrm{in}$.

Thermal cycling. Two of the three specimens, the best appearing and one that contained a small defect, were selected for thermal cycling. The defect area in the one specimen consisted of poor bonding in one area between the thin end plug and the tungsten tube. The thermal cycle consisted of heating from room temperature to $2000 \mathrm{~K}(1727 \mathrm{c})$ in $10 \mathrm{~min}$, holding five min, and then cooling as rapidly as possible. Furmace cooling was used to $1000 \mathrm{C}$ at which time a steady flow of helium was purged through the furnace chamber. Then at $500 \mathrm{C}$, a direct blast of helium onto the specimens shortened the time necessary to reach a temperature below $50 \mathrm{C}$. The entire cycle required approximately $45 \mathrm{~min}$. 
After the first cycle, one specimen showed no change while the other specimen, which showed the defect initially, had a 40-mil blister on the 20-mil end plug end. In addition, the original defect area was slightly enlarged.

Since the xyglo and helium leak check tests showed no cracking, the pellets were submitted to four additional cycles. Upon inspection, longitudinal cracking was apparent in both specimens. The blistered pellet had two such cracks as well as a transverse crack in the area where the core meets the 1/8-in. end plug. Almost complete separation of the thin end plug from the tube had occurred. The other specimen possessed three longi-. tudinal cracks. These specimens are shown in Figures 12 and 13.

Metallographic sections of these two specimens were made transversely through the center of the specimen and longitudinally through the remaining end pieces. Evaluation of these sections showed extensive intergranular fracturing of the core in both the $\mathrm{UO}_{2}$ and the tungsten. Cracks that were observed on the surface of the pellet penetrated the core. A photomicrograph of a crack into the fuel form is shown in Figure 14. Small cracks initiating on the inside surface of the clad tube were noted as shown in Figure 15. For comparison, the as-bonded pellet was sectioned to obtain initial conditions of the clad pellet. The core did not appear to densify an additional amount during the cladding operation but the $\mathrm{NO}_{2}$ itself did. Good core-to-clad bonding was observed while clad-to-clad bonds were only fair. Very fine grain size was found on the exterior half of the tube whereas large grains were observed on the interior half. Photomicrographs of the fuel form which was not thermal cycled and a fuel form after cycling is shown in Figure 16. 

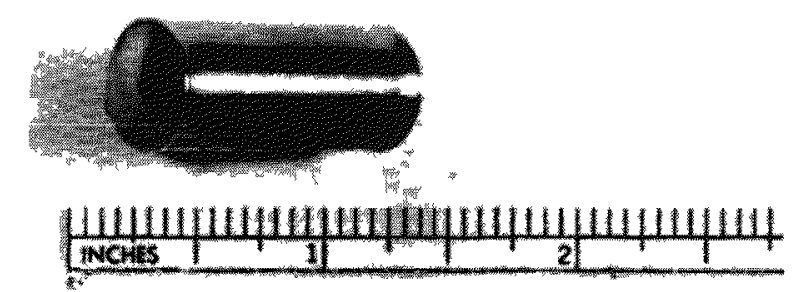

$$
\begin{aligned}
& \text { (3) }
\end{aligned}
$$

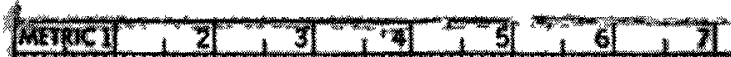

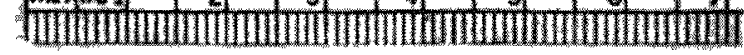

$1 \mathrm{x}$

FIGURE 12. SPECIMEN AFTER FIVE THERMAL CYCLES

This specimen showed no defects after one thermal cycle. 


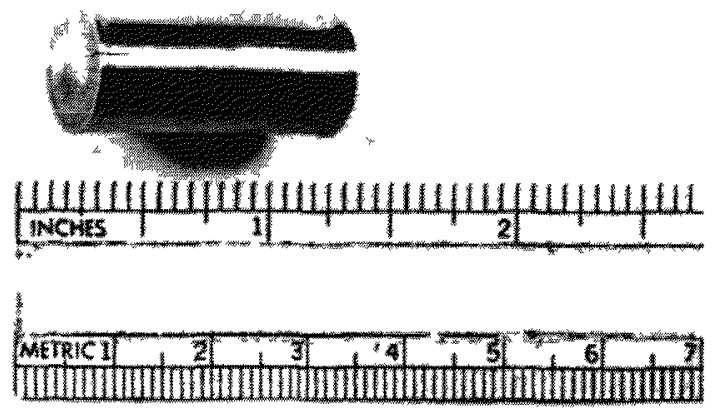

FTGURE 13. SPECTMEN CONTAINING DEFECT AREA AFTER FIVE THERMAL CYCLES

Note the lack of bond between the end plug and the tungsten cladding. 


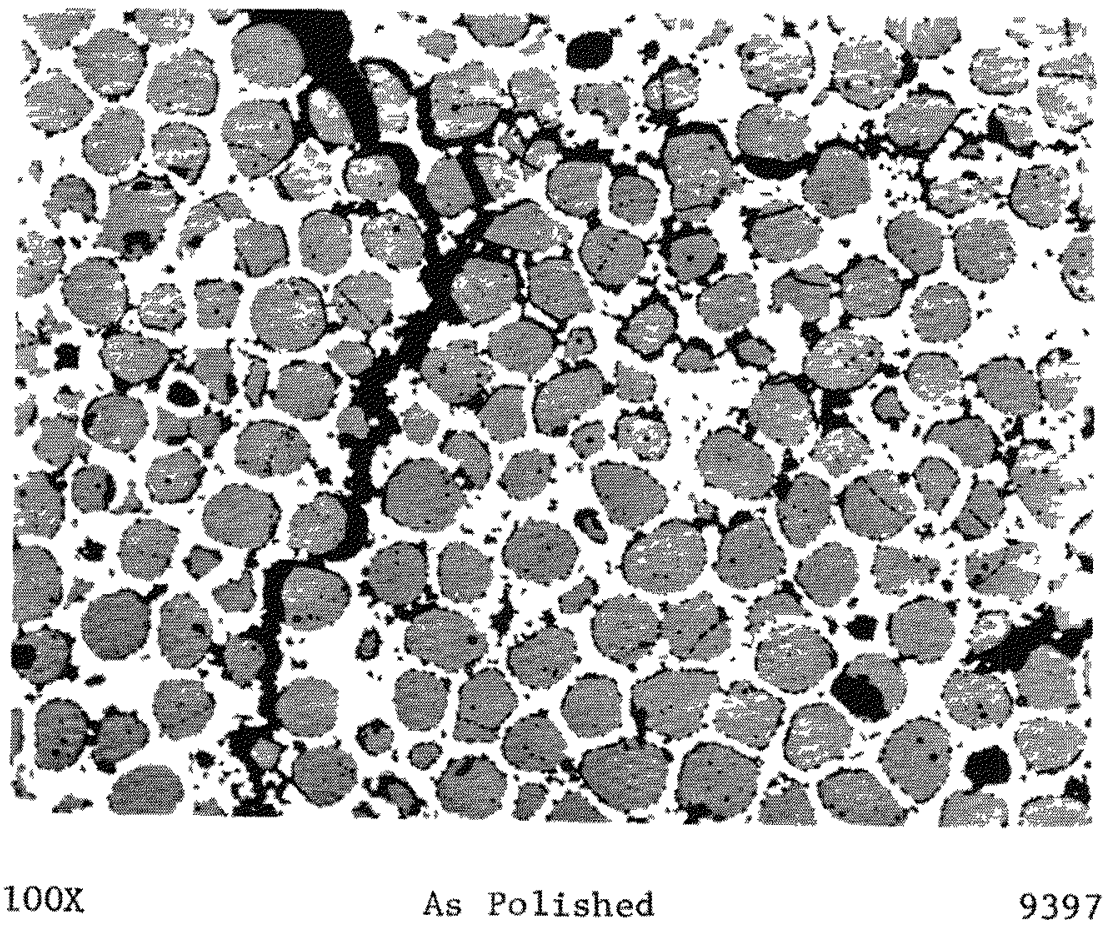

FIGURE 14. CRACK IN FUEL FORM AS A RESULT OF THERMAL CYCLING This is the specimen shown in Figure 12. 


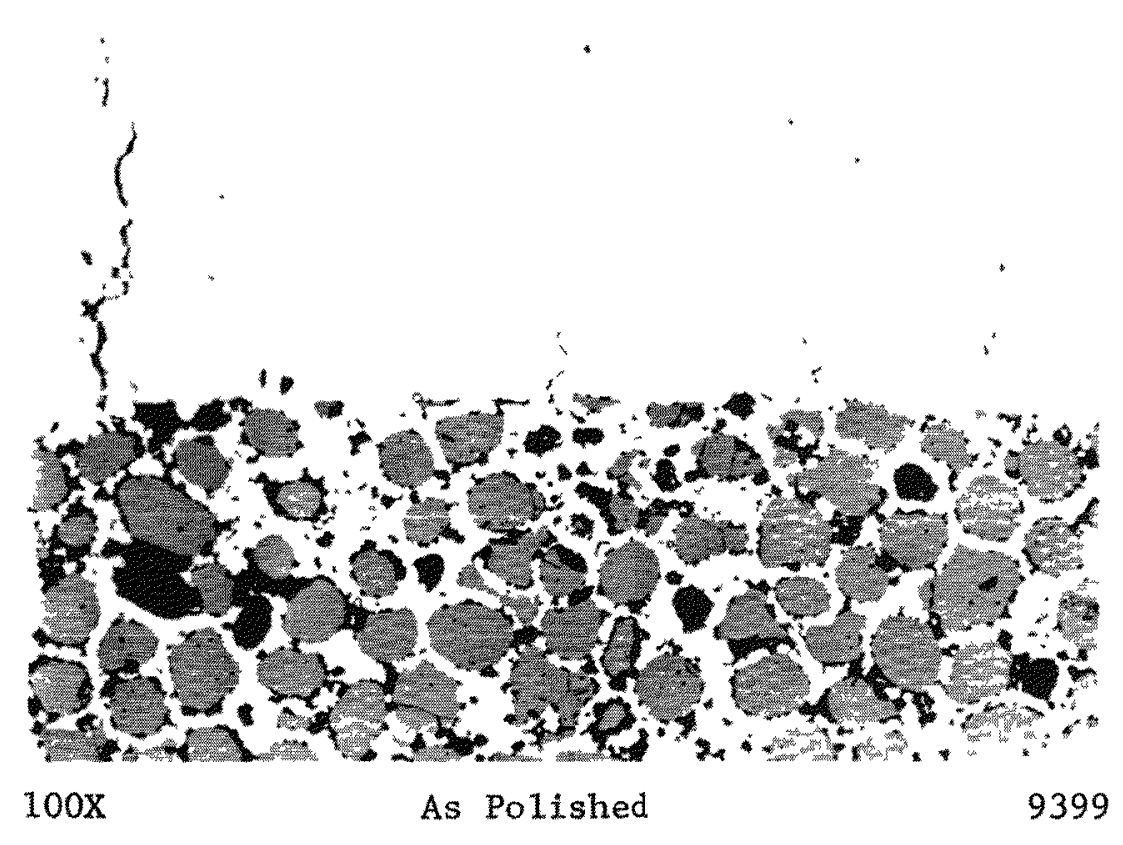

FIGURE 15. MICROCRACKS INITIATING AT THE INSIDE SURFACE OF THE TUNGSTEN CLADDING 


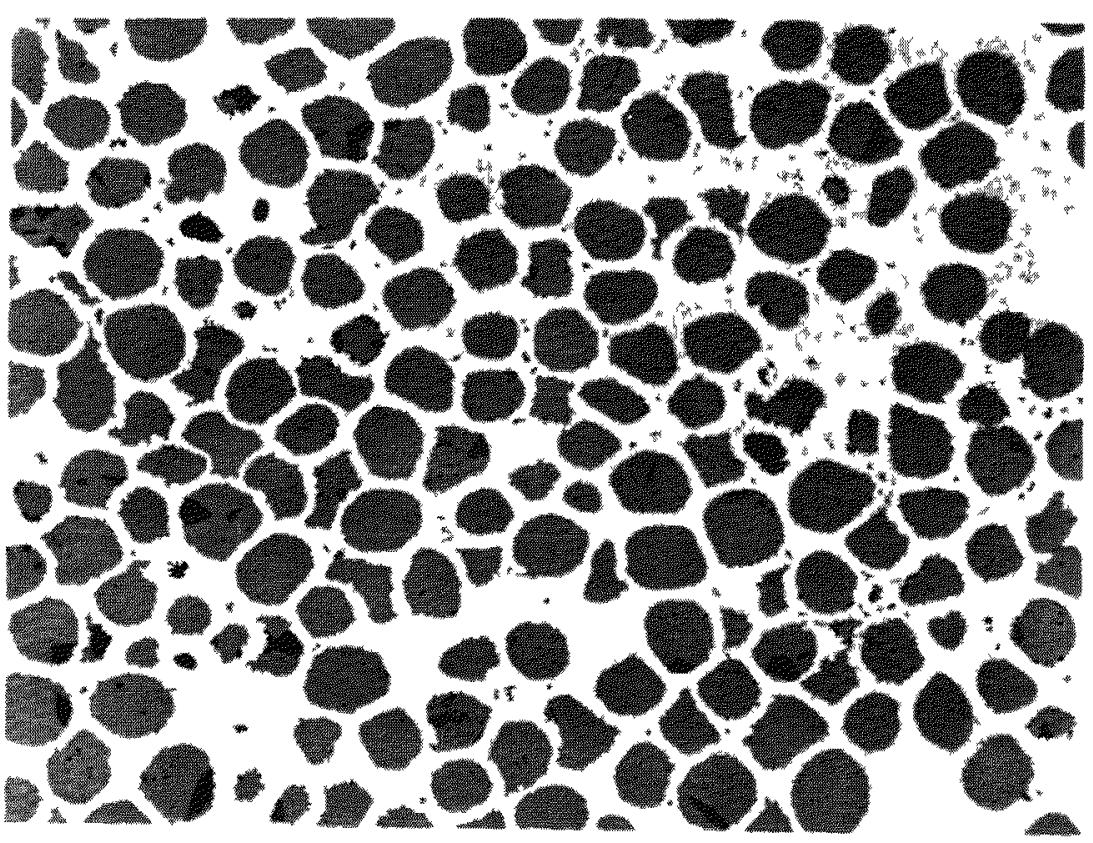

a. Fuel Form Not Thermal Cycled.

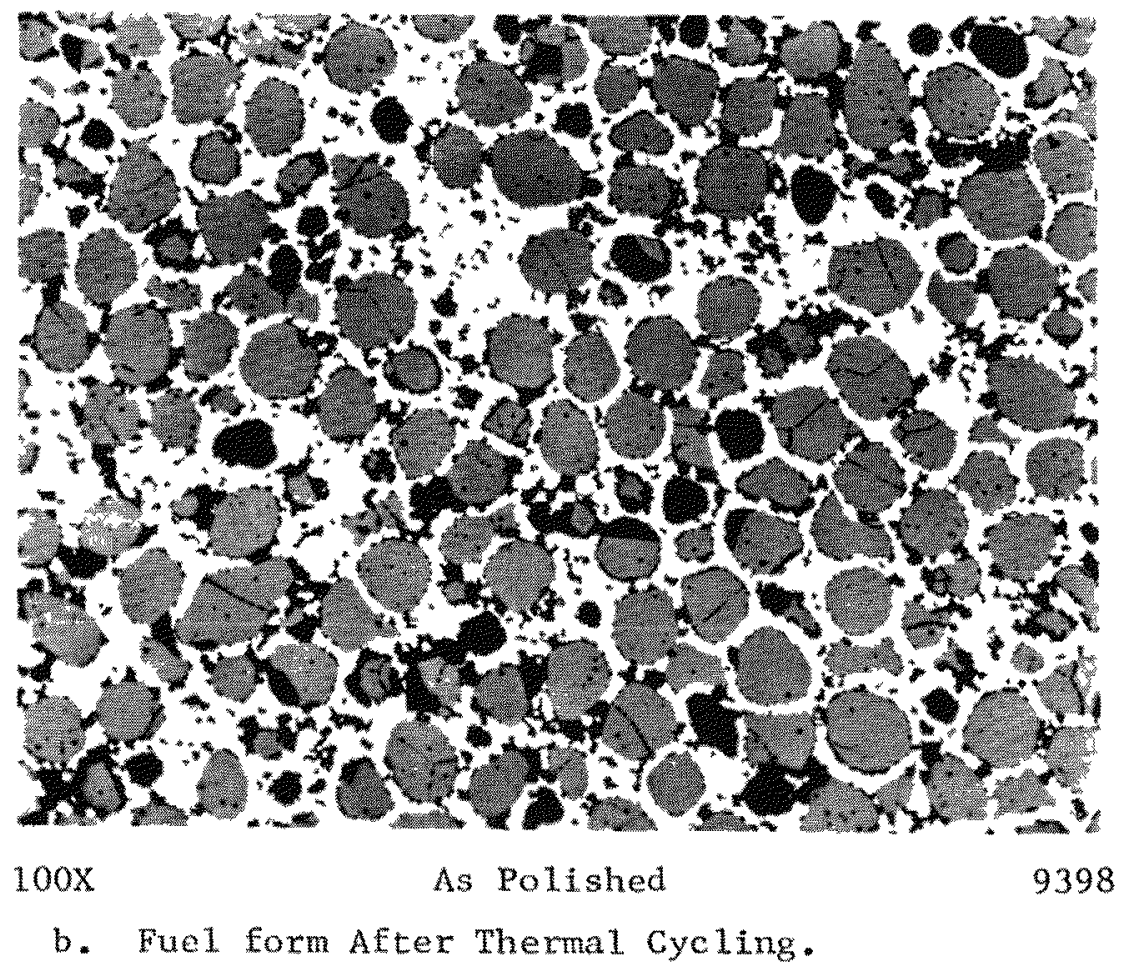

FIGURE 16. COMPARISON OF FUEL FORM MICROSTRUCTURE BEFORE AND AFTER THERMAL CYCLING 
Analysis of these results prompted the thernal cycling of a tungsten cladding tube and an unclad fuel pellet. After cycling, these components were examined metallographically. No cracks were found in the fuel form and the degree of core disintegration was less than had been noted with the cycled clad fuel pellets. Microcracks were apparent on the ID of the tungsten tube. Further examination of other tubes indicated that these microcracks were caused by the electrical discharge machining of these tubes. No dimensional changes were noted in either components but a weight loss of 0.28 percent was observed in the fuel form as a result of the five thermal cycles.

Second Thermal Cycle Experiment

Additional thermal cycle specimens were prepared to more fully evaluate the behavior of the clad fuel pellet during thermal cycling. Generally the fabrication procedure was the same as before except more care was taken in cleanup of the components at the various stages of processing and the bonding temperature for the cladding operation was increased.

Fuel Pellet Fabrication. The fuel form consisted of $\mathrm{UO}_{2}$ coated with $50 \mathrm{w} / \mathrm{O}$ tungsten. Tungsten fines were added with a 0.2 percent Parawax binder to bring the fuel loading to $50 \mathrm{v} / 0 \mathrm{UO}_{2}$. The cold-pressed pellets were vacuum outgassed at $1800 \mathrm{~F}$ for $1 \mathrm{hr}$ prior to HIP in molybdenum containers. The pressing parameters were $2900 \mathrm{~F}$ and $10,000 \mathrm{psi}$ for $3 \mathrm{hr}$. The fuel forms were ground to a diameter of $0.450 \mathrm{in}$. and leached in dilute $\mathrm{HNO}_{3}$ to remove any smeared $\mathrm{UO}_{2}$. 
The clad components were fabricated as before with one exception. The EDM operation was done in two steps with the final sizing to 0.470-in. diameter being done very slowly to minimize cracking. The clad components and $t$ he fuel forms were vacuum treated at $2000 \mathrm{~F}$ for $1 \mathrm{hr}$ prior to assembly. Because the fuel forms were slightly undersize, more clearance was present in the assembly than would normally be desirable. The components after sealing in the molybdenum containers were gas-pressure bonded at $3200 \mathrm{~F}$ and 10,000 psi for 1-I/2 hr. Pressure was released while at the bonding temperature to permit relaxation of the tungsten.

After bonding, the two peliets were machined to a diameter of approximately $0.490 \mathrm{in.} \mathrm{to} \mathrm{provide} \mathrm{a} \mathrm{clad} \mathrm{thickness} \mathrm{of} 0.020 \mathrm{in}$. The length was ground just enough to cleanup and the resulting length was 1.045 in. The diameter of the shoulders was 0.505 in.

Thermal Cycling. The thermal cycle used for these pellets consisted of heating to $2000 \mathrm{~K}(1727 \mathrm{C})$ in $10 \mathrm{~min}$, holding for $5 \mathrm{~min}$, and then cooling. Cooling was similar to that used previously except that the heating cycle was initiated after reaching $150 \mathrm{C}$. Inspection of the pellets was made by dyepenetrant inspection and helium leak detection after Cycles 1, 2, 3, 4, 5, and 10. The helium leak test consisted of pressurizing the pellets with helium gas, transferring the pellets to a vacuum chamber, and then checking the pump effluent with a helium leak detector to determine if helium had been retained in any cracks or voids present in the specimens.

After Cycles 1 and 2, no change was noted in the pellets except for some growth both on the length and diameter. This growth continued through the cycling treatment. Visual observation of these pellets after the tenth cycle showed that both had cracked claddings, primarily in the tube 
poxtion of the clad. These cracks were more or less random in orientation, although at least one was found to be completely circumierential. This failure did not occur without warning, however, because an identical pattern was observed on the specimens during xyglo evaluations after the fourth and fifth cycles. The fact that the clad pellets were still leak tight suggests that a grain-boundary widening was taking place without actual cracking. One of the failed pellets was submitted for metallographic examination. It was readily apparent that the cracking was intergranular in nature. To point out the weakness of the grain boundaries, whole grains of tungsten were pulled out of the cladding during metallographic polishing. Both the cracking and pull-out are shown in Figure 17 which shows the cladding in a transverse section. Notice that to the right and left of the crack are grain boundaries which appear to have voids along a certain length. These are more clearly shown in Figure 18. These voids were examined at high magnification under bright and polarized light to determine if they were actually voids or microscopic inclusions of some sort. All areas examined proved to be voids. There is no doubt that these small voids represent the early stages of the intergranular cracking. The mechanism by which these voids are formed is not known thoroughly, but it is probably related to vacancy diffusion and the grain-boundary widening effects observed in tungsten of large grain size. With regard to the clad bonding, satisfactory leak-tight bonds were produced during the pressure bonding cycle. Although some isolated voids still remain along the original interface, as shown in Figure 19, grain growth provided a gas-tight seal. Figure 20 is a photomicrograph of a bond after thermal cycling. Notice that although the voids are still present, no cracking occurred along this plane. Since the pellets grew 


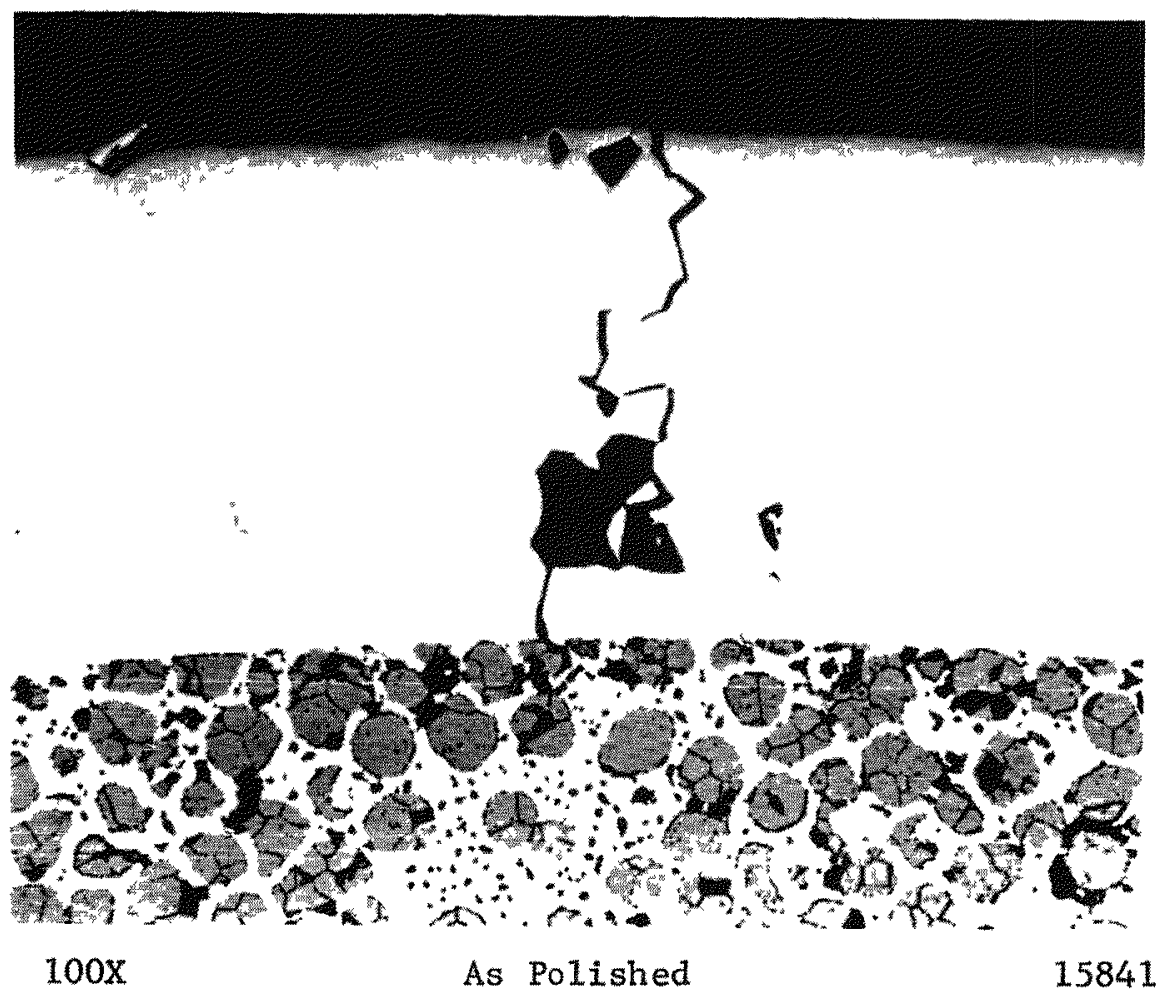

FIGURE 17. TRANSVERSE SECTION OF CLADDING FAILURE

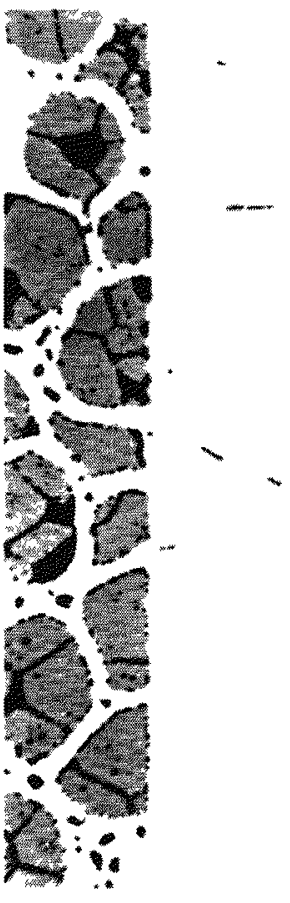

$175 \mathrm{X}$

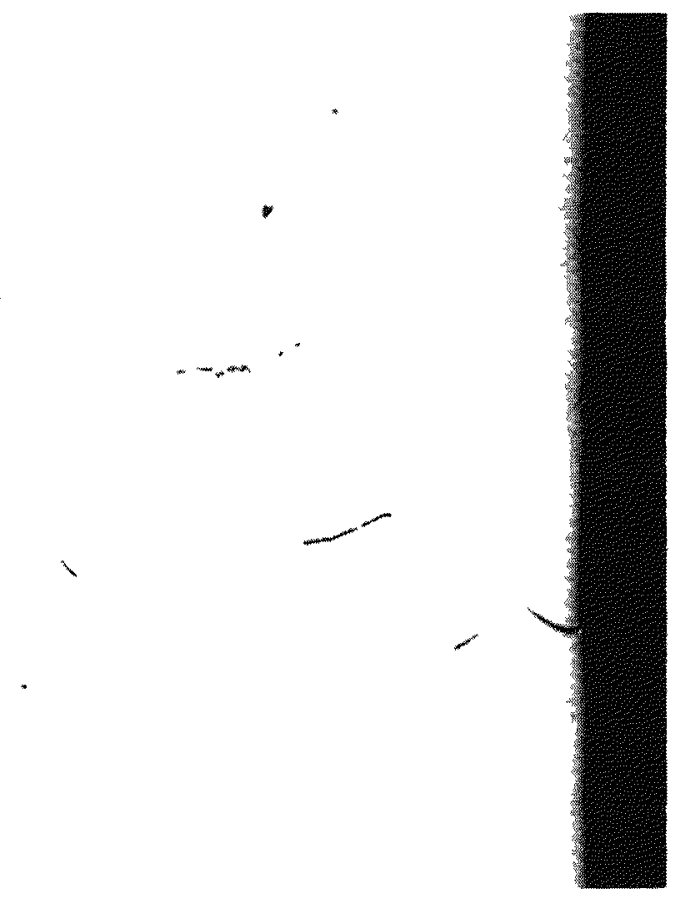

As Polished

FIGURE 18. LONGITUDINAL SECTION OF CLADDING FAILURE 
41
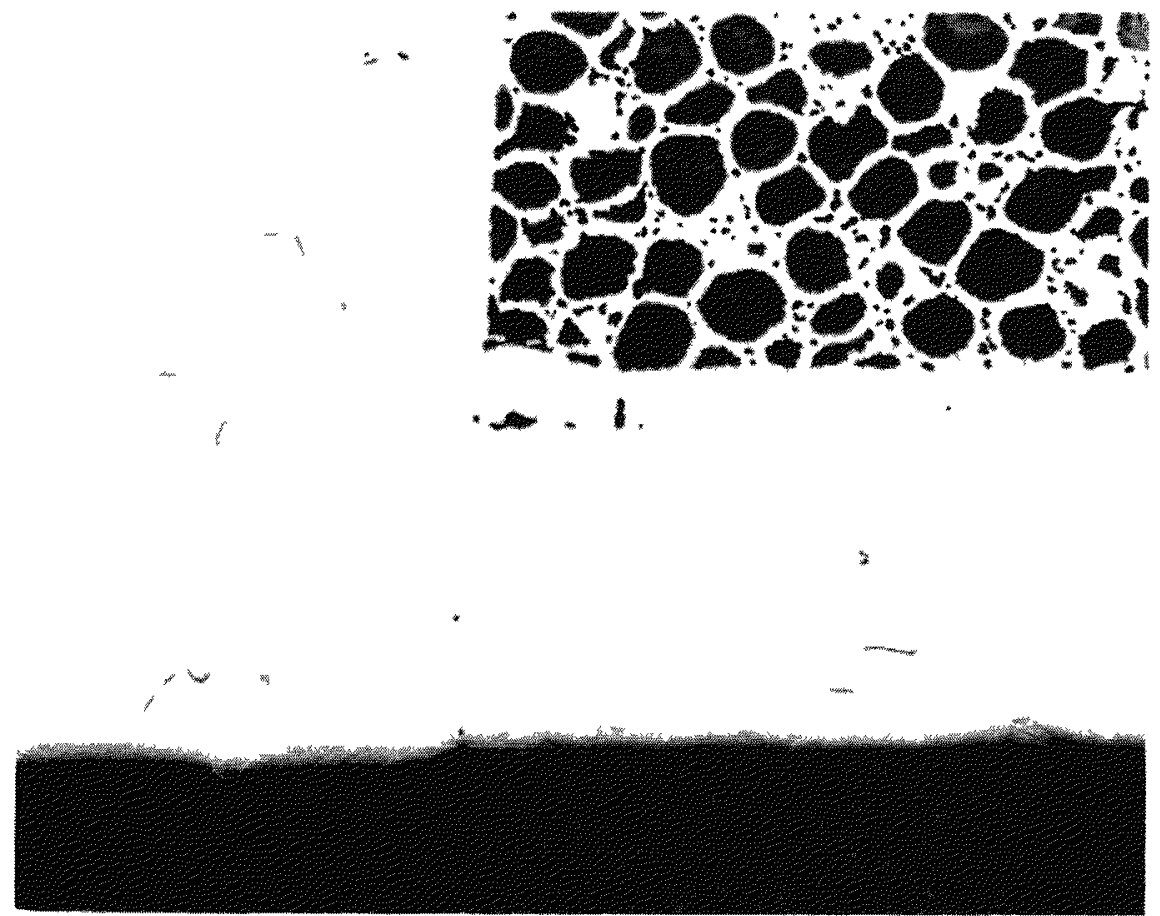

$100 \mathrm{X}$

As Polished

15848

FIGURE 19. LONGITUDINAL SECTION OF BOND IN AS-BONDED PELIET

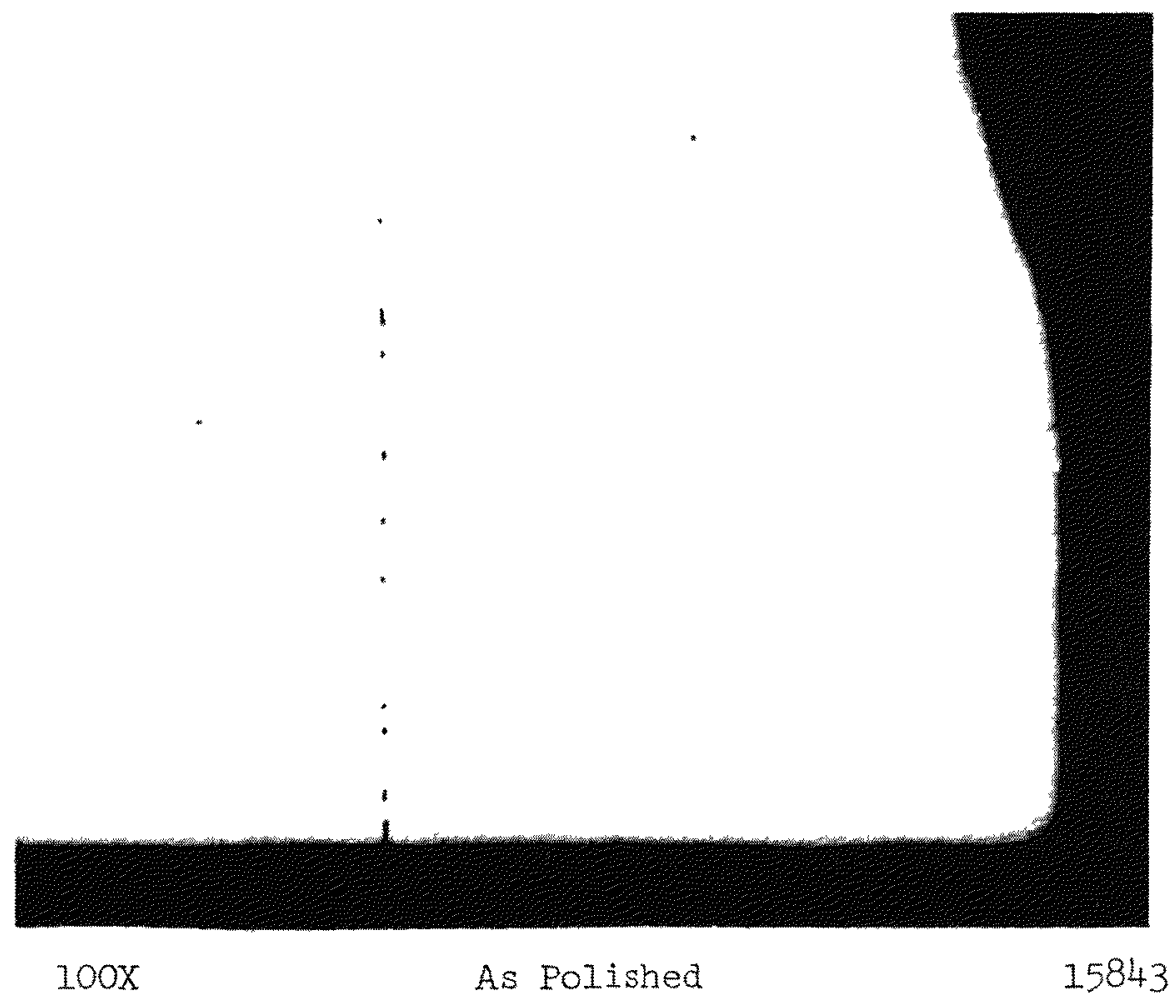

FIGURE 20. IONGITUDINAL SECTION OF THICK END PLUG BOND AFTER THERMAL CYCLING 
dimensionally by about I percent during cycling, this suggests that the bond line is not weaker than the tungsten grain boundaries themselves. In addition, the bond between the clad and the core was of excellent quality and showed no signs of failure.

The appearance of the cermet core was similar to that of previous pellets in that there was general disintegration of both the $\mathrm{UO}_{2}$ and tungsten as a result of grain growth and grain-boundary separation. Typical examples are shown in Figures 17, 18, and 19. Although some of the larger voids in the $\mathrm{UO}_{2}$ area are due to pullout during metallographic polishing, the smaller voids apparent in the $\mathrm{UO}_{2}$ grain boundaries and in the tungsten are real. Many of the voids seen in the cycled core (Figures 17 and 18) were inherent to the core as a result of bonding (Figure 19). A contributing factor in the behavior of the cermet core during cycling may be the high fluorine content of the vapor deposited tungsten. Analysis of these particles indicated that the fluorine content was approximately $1100 \mathrm{ppm}$. This amount of fluorine in the tungsten coating has been shown to result in the formation of voids during high-temperature treatment.

Because of the failure of these pellets to withstand thermal cycling for an acceptable number of cycles, the program was re-directed to investigate new cladding materials and pellet fabrication techniques. These were investigated in the next two thermal cycle experiments.

Third Thermal Cycle Experiment

In this thermal cycle experiment, three different cladding materials were evaluated. These were tungsten, tungsten-25 rhenium, and 1 pèrcent thoriated tungsten. Also, different procedures were used in the heat treatments 
of the fuel form and the cladding materials prior to bonding. Improved machining procedures were used in the preparation of the cladding components. These refinements resulted in improved thermal cycling behavior, particularly for the tungsten and tungsten-rhenium clad pellets.

Fuel Pellet Fabrication. The fuel forms were fabricated from the same Lot of coated particles and in the manner as those prepared in the second thermal cycle experiment. The only change in procedure was a high-temperature hydrogen stress relief prior to the cladding operation. Following machining of the fuel form and removal of any smeared $\mathrm{UO}_{2}$ by a dilute nitric acid dip, the fuel forms were hydrogen treated at $1750-1800 \mathrm{C}$ for $1-1 / 2 \mathrm{hr}$. Heating and cooling rates of $500 \mathrm{c} / \mathrm{hr}$ were used. A preliminary study of this treatment indicated that very little dimensional change or weight loss resulted. The tungsten structure did show slightly greater porosity, but this was not felt to be deleterious.

The cladding materials used for this study were tungsten, tungsten25 rhenium, and I percent thoriated tungsten. Improved procedures were used in the preparation of these components. Rather than using the electrical discharge machined surface for bonding, the EMD'd surface was cleaned up by honing about 0.005 in. from the surface to remove any microcracks. A slip fit with the fuel form was provided. The end plugs were prepared by grinding from 0.130-in.-thick sheet and 0.030-in.-thick sheet. Following machining and prior to assembly for gas-pressure bonding, the clad components were given the same hydrogen heat treatment that was given to the fuel form. The clad materials and the fuel forms were assembled, placed in molybdenum containers and gas-pressure bonded. In this bonding cycle, a higher pressure, 25,000 psi was used. The run conditions consisted of a temperature of $3150 \mathrm{~F}$ and a gas pressure of 25,000 psi for a period of $1-1 / 2 \mathrm{hr}$. The gas 
44

in the autoclave was then bled off at a rate not exceeding $100 \mathrm{psi} / \mathrm{min}$ to a pressure of 100 psi while maintaining temperature to permit relaxation of the tungsten. The total time at temperature was about $4 \mathrm{hr}$.

Following bonding, the specimens were leached from the bonding containers and ground to the required dimensions. These were a cladding thickness of $0.020 \mathrm{in.}$ on the diameter and one end and a clad thickness of $0.125 \mathrm{in}$. on the thicker end. The clad pellets were inspected for cracks by dye-penetrant inspection and for possible defects by the helium leakdetection technique described previously.

Thermal Cycling. These three pellets were subjected to the same thermal cycle as that described previously. Inspection was made after Cycles $1,2,3,4,5,10,25,50,75$, and 100. All three pellets were cycled the full 100 cycles.

Pellets 2 and 4 did not change in physical appearance at all during the 100 cycles but Pellet 6 , having the thoriated tungsten clad, did crack. During an intermittent macroscopic examination after 35 cycles, the surface appeared dull and grainy as a result of extensive grain growth in the cladding. Then, after 50 cycles, the zyglo test indicated apparent grain-boundary cracking almost identical to that observed during the previous thermal-cycle test with tungsten clads. Since the cracking appeared to be initiating on the exterior surface, thermal cycling of the pellet was continued. By the end of the 100 cycles, the entire clad surface was cracked, and some had propagated over the machined shoulder and into the thin end plug. Upon reaching the bond area between the clad tube and the end plug, the crack propagated circumferentially along the bond line. 
During the inspections of the pellets, accurate dimensions were taken as well as weights. These data were tabulated and then plotted so that percent change was a function of the number of thermal cycles. Figure 21 compares the data for the three pellets with regard to growth on the diameter and length and to the weight loss of the total specimens. The diametrical growth of the pellets was so minute during the first 25 cycles that the calculated percent growth was still within the accuracy with which the measurements could be taken.

As can be seen, however, the pellets all began to show indications of growing after 10 cycles. Pellets 2 and 4 continued to increase but began to reach a stable point after 75 cycles. The inflection point at which the rate of growth changes from increasing to decreasing is at about 35 cycles. Pellet 6 , on the other hand, did not reach any inflection point but rather continued to grow at a linear rate after 25 cycles. One important point regarding the diametrical growth is that on all three pellets there was 0.2 percent growth or less at the machined shoulders. The major growth was recorded in the area between the shoulders. Although the diameter at the center tended to be larger than those next to the shoulders, the overall change was very near the established measurement accuracy. Therefore, for simplicity, the three center diameters were averaged for producing the curves shown.

The growth produced in the lengths was somewhat different. In all three cases, the rate of growth decreased after the initial cycles as shown by the second set of curves in Figure 21. The tungsten-clad pellet (2) exhibited the least amount of growth with the majority being produced during the first two cycles. By the end of the tenth cycle, the pellet grew at a rate of about 

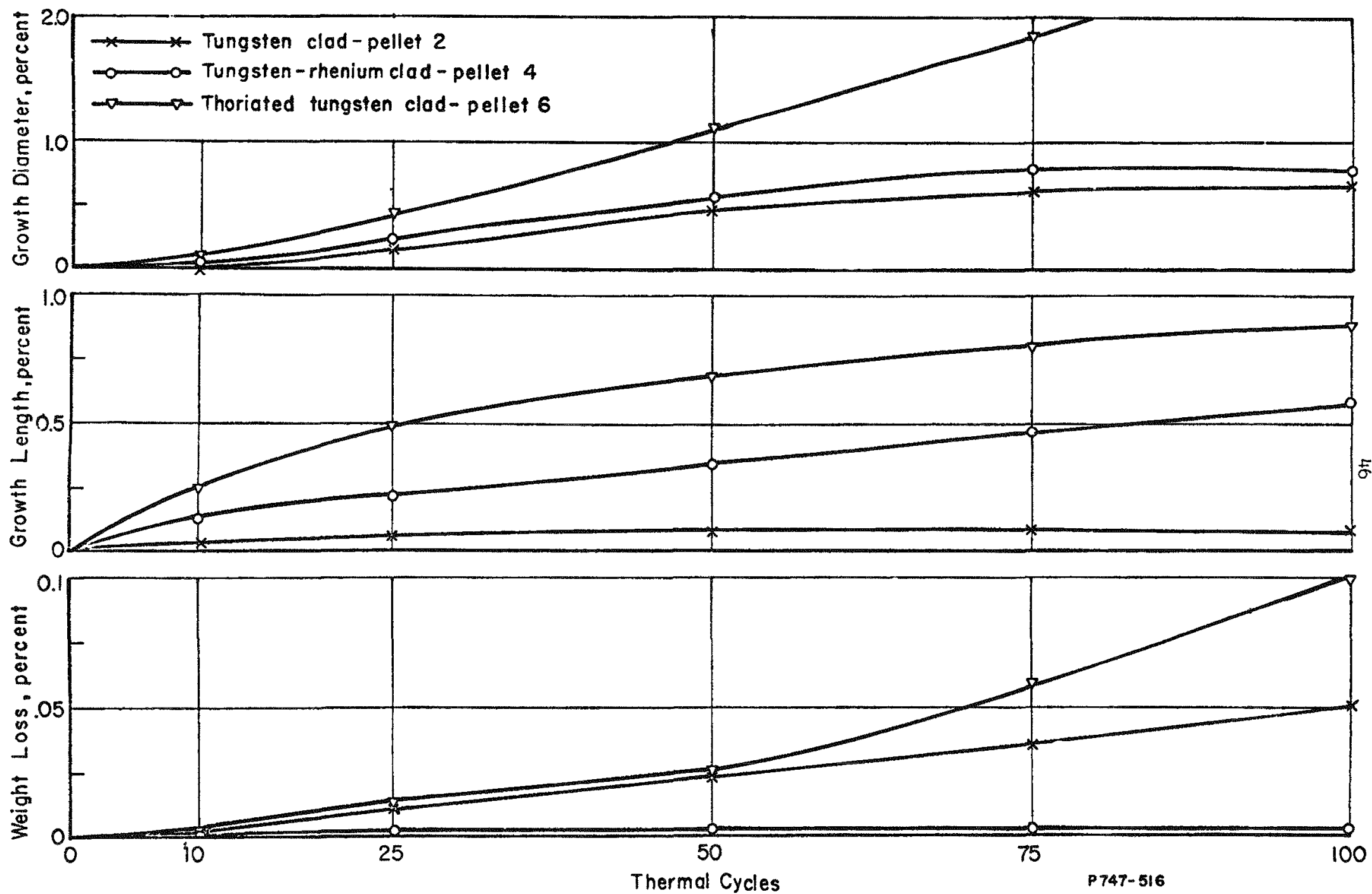

FIGURE 21. PERCENT GROWTH AND WEIGHT LOSS CURVES FOR THIRD THERMAL CYCLE EXPERIMENT 
1 mil every 40 cycles. Pellets 4 and 6 , on the other hand, showed considerably more growth than 2; the thoriated-tungsten-clad pellet (6) had about twice the amount of growth as the tungsten-rhenium-clad pellet (4). In comparing this data with that of diametrical growth, it is interesting to note that there is no inflection point for the length-growth curves.

The last set of curves in Figure 21 shows the accumulative weight loss of the three pellets. As shown, Pellet 4 had a negligible loss. It should be noted here that these percent values were calculated on the basis of the weight of the whole pellet both core and clad. The weight-loss curves are to show qualitative results only. However, they are indicative of the quantitative results since the weights of all three core pellets were within 0.3 percent. Percent loss calculated on the basis of the core weight will increase the values on these curves by a factor of about 1.55. Pellets 2 and 6 had almost identical losses until about the fiftieth cycle. Then, Pellet 6 began to lose at a much faster rate. This is evidently due to the cracking of the clad and resulting exposure of $\mathrm{UO}_{2}$ to the vacuum.

Figure 22 shows the exterior of the thermal-cycled pellets prior to sectioning. Metallographic examination of the tungsten-clad pellet (2) revealed the best structure produced on this program to date. As show in Figure 23, disintegration of the $\mathrm{NO}_{2}$ and tungsten matrix was much less than in previous specimens. The $\mathrm{UO}_{2}$ grain boundaries were not enlarged nor was there extensive pullout at the $\mathrm{UO}_{2}$-tungsten interface. Figure 24 demonstrates the excellent core-to-clad bonding which was achieved. Similarly, figures 25 and 26 show the bonds produced between the cladding components. Although some spherical isolated voids existed at the interface, there was no indication of these creating a path for crack propagation. 


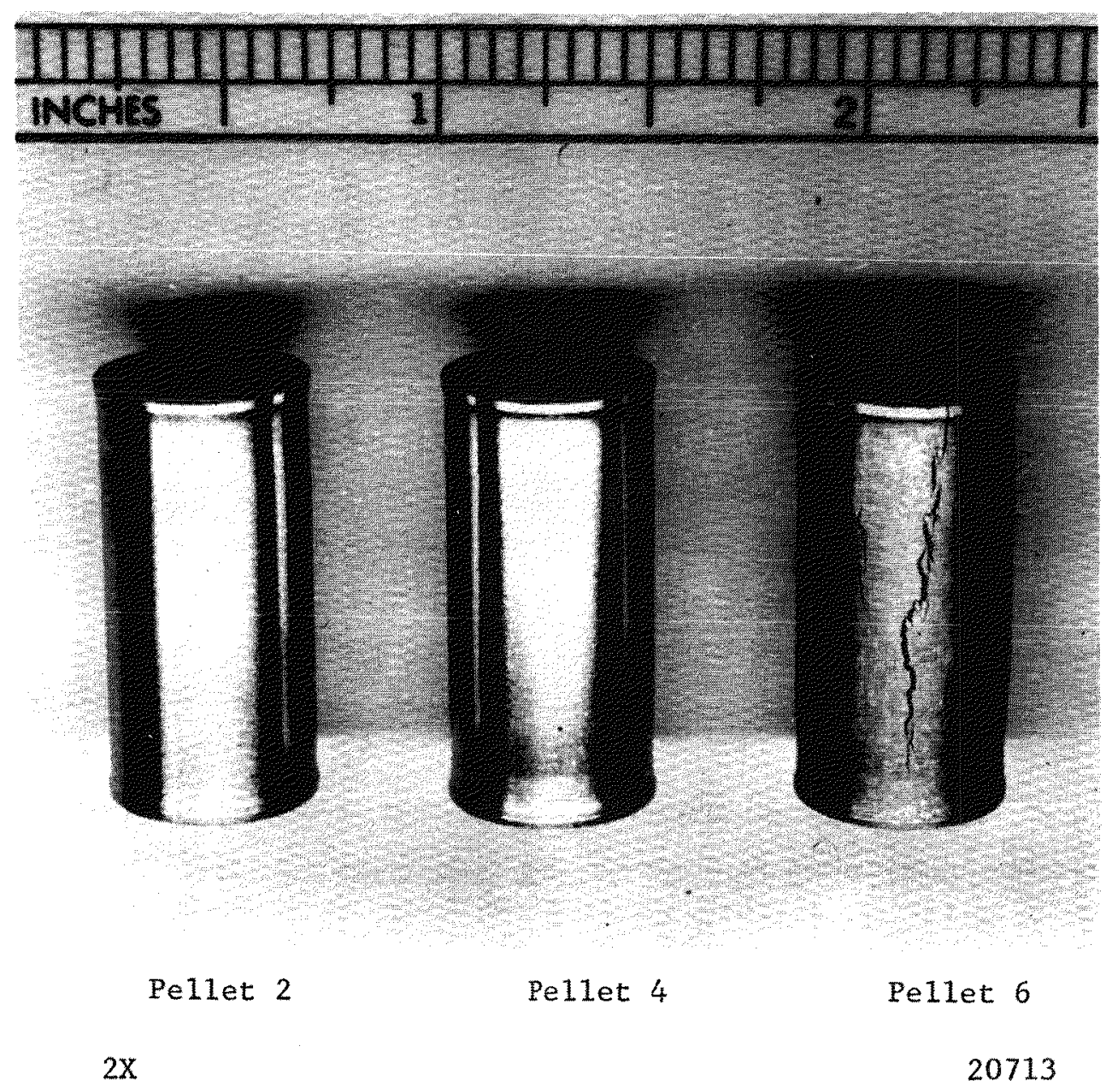

FIGURE 22. CLAD FUEL PELLETS AFTER 100 THERMAL CYCLES 


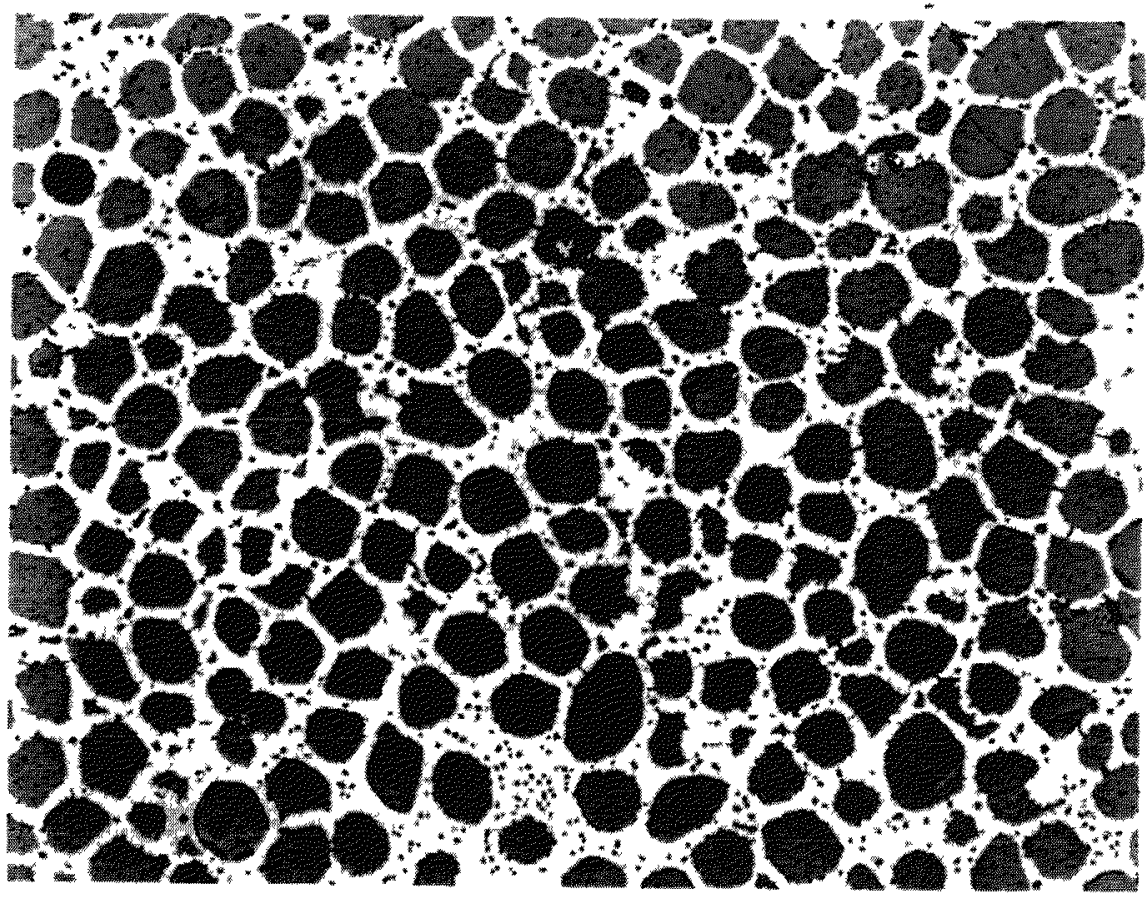

$1.00 \mathrm{x}$

Murakami's Etch

21231

FIGURE 23. TUNGSTEN CLAD: TYPICAL CORE STRUCTURE
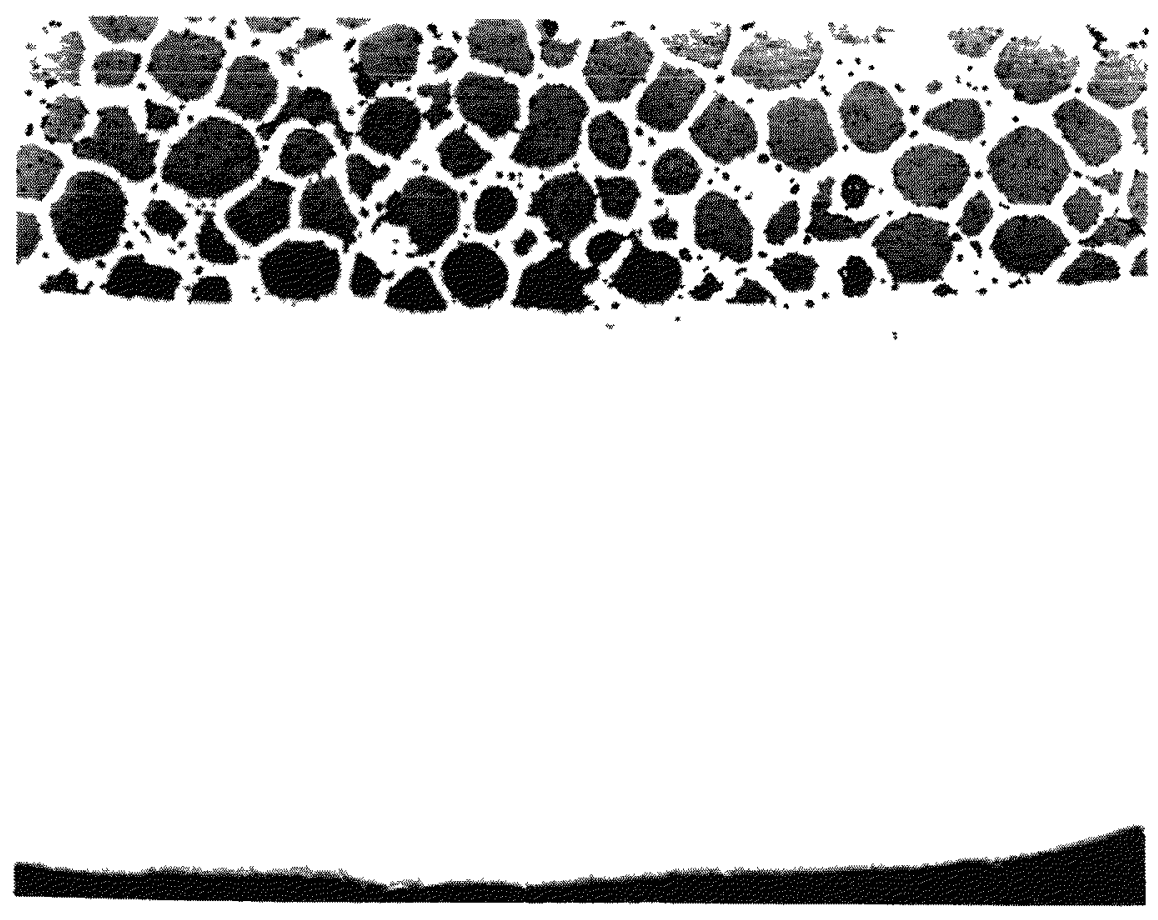

FIGURE 24. TUNGSTEN CLAD: CORE-TO-CLAD BOND 

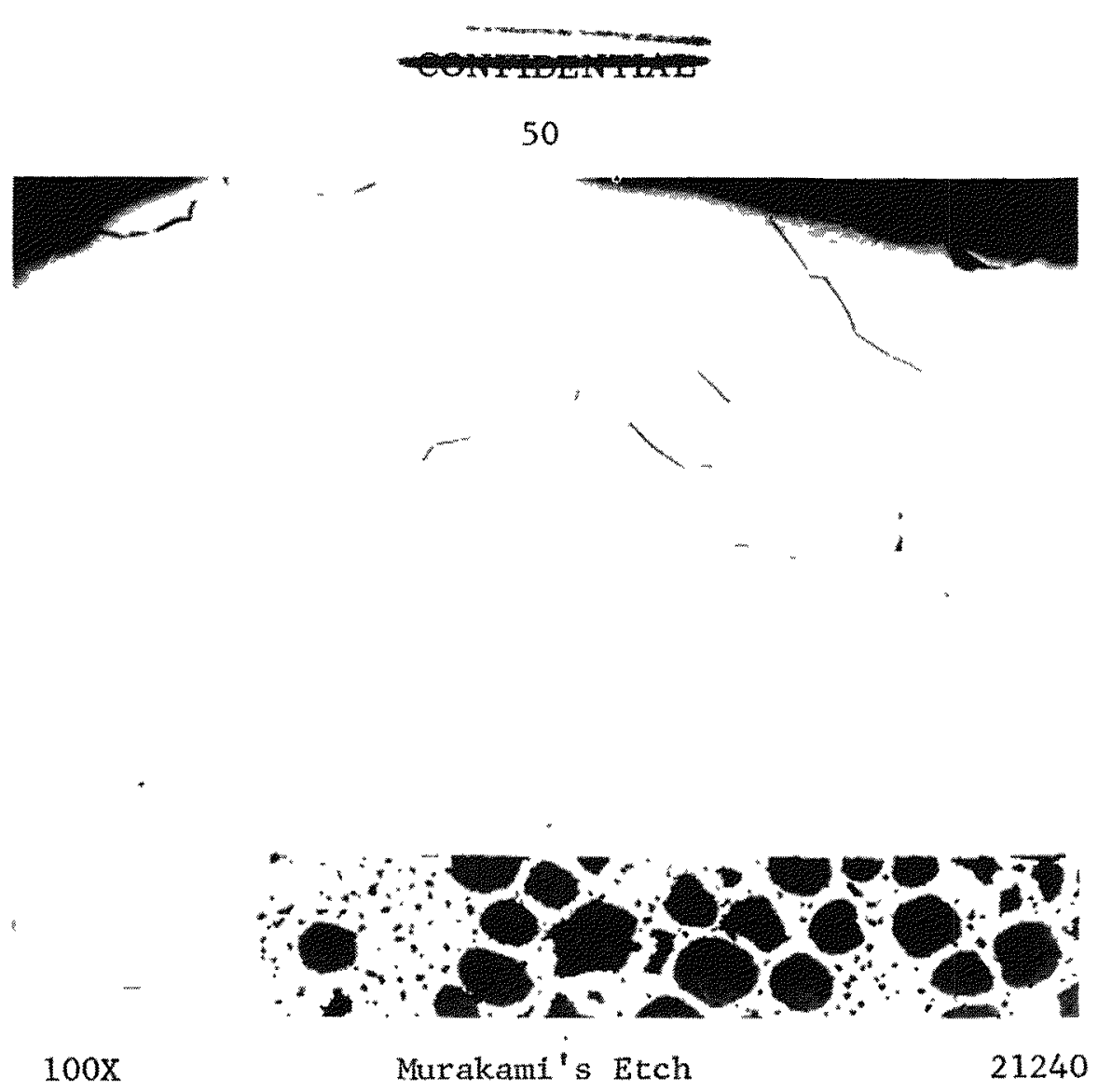

FIGURE 25. TUNGSTEN CLAD: BOND BETWEEN THIN-END PLUG AND CLAD TUBE
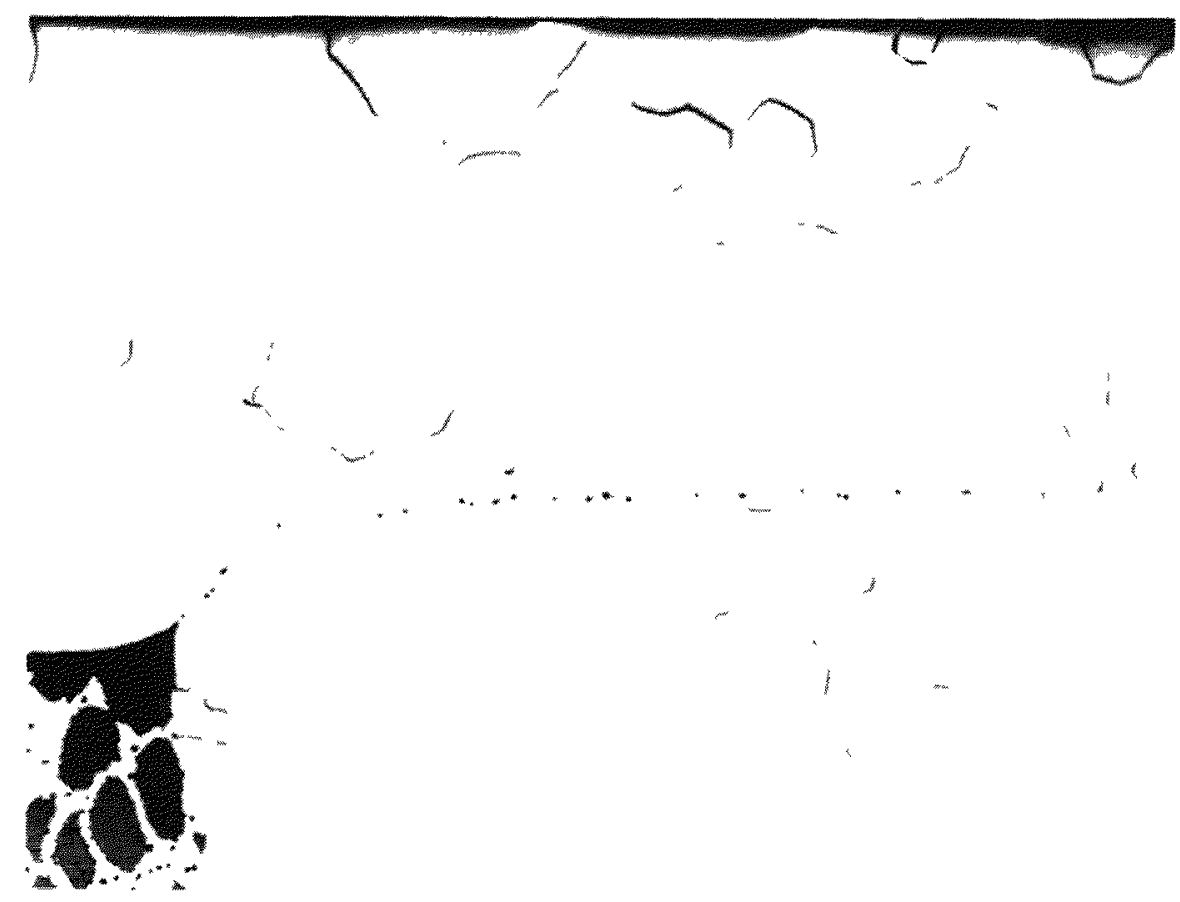

$100 \mathrm{x}$

Murakami's Etch

21236

FIGURE 26. TUNGSTEN CLAD: BOND BETWEEN THICK-END PLUG AND CLAD TUBE 
Figures 27, 28, 29, and 30 show the same views of the tungstenrhenium-clad pellet (4). For all practical purposes, the microstructures of Pellets 2 and 4 are identical although the photomicrographs of Pellet 4 show more tungsten-rich areas than those of Pellet 2. These isolated areas were noted in both pellets. Good core retention, core-to-clad bonding, and clad-to-clad bonding were observed in all metallographic sections.

This was not the case with the thoriated-tungsten-clad pellet (6), however. As shown in Figure 31, the core disintegration was much more pronounced than in the other two specimens. However, it was still an improvement over the structures of previous thermal-cycled specimens. Figure 32 shows the good core-to-clad bonding achieved but it also points out the large radial grain boundaries which existed in the cladding. These large grain boundaries were the areas where cracking initiated. The thoria has remained uniformly dispersed despite the large grains and the time at the cycling temperature. Figures 33 and 34 show the bonds in Pellet 6. As mentioned earlier, a longitudinal crack had propagated over the shoulder and into the bond between the thin end plug and the clad tube. This crack in the bond is shown in Figure 33. The bond produced between the thick end plug and the clad tube was not cracked but it is obvious that there was not much grain growth across the interface. This result is expected if the material is already at an equilibrium grain size plus the effect of the thoria pinning the grain boundaries.

In summary, Pellets 2 and 4 were definitely satisfactory. The fact that the tungsten-clad pellet grew less during thermal cycling in conjunction with its good core condition implies that it would be the most desirable. 


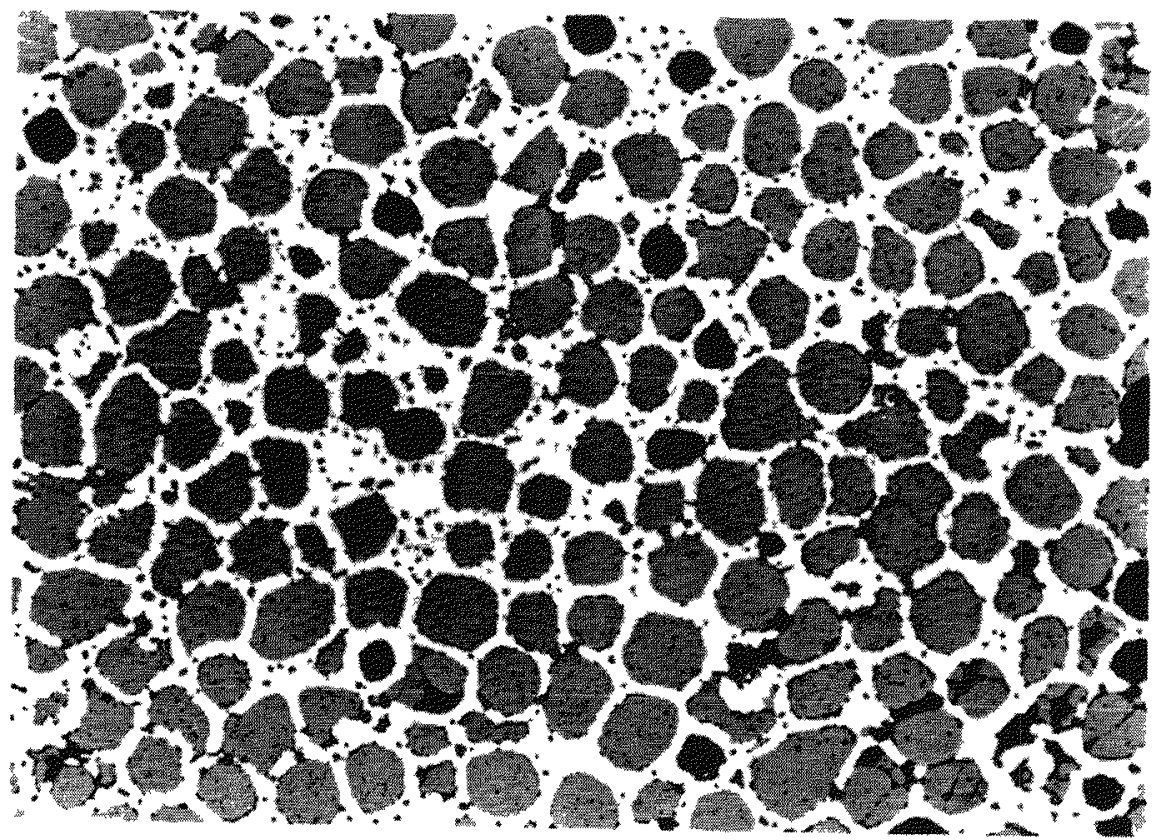

$100 x$

Murakami's Ltech

21229

FIGURE 27. TUNGSTEN-RHENIUM CLAD: TYPICAI CORE STRUCTURE
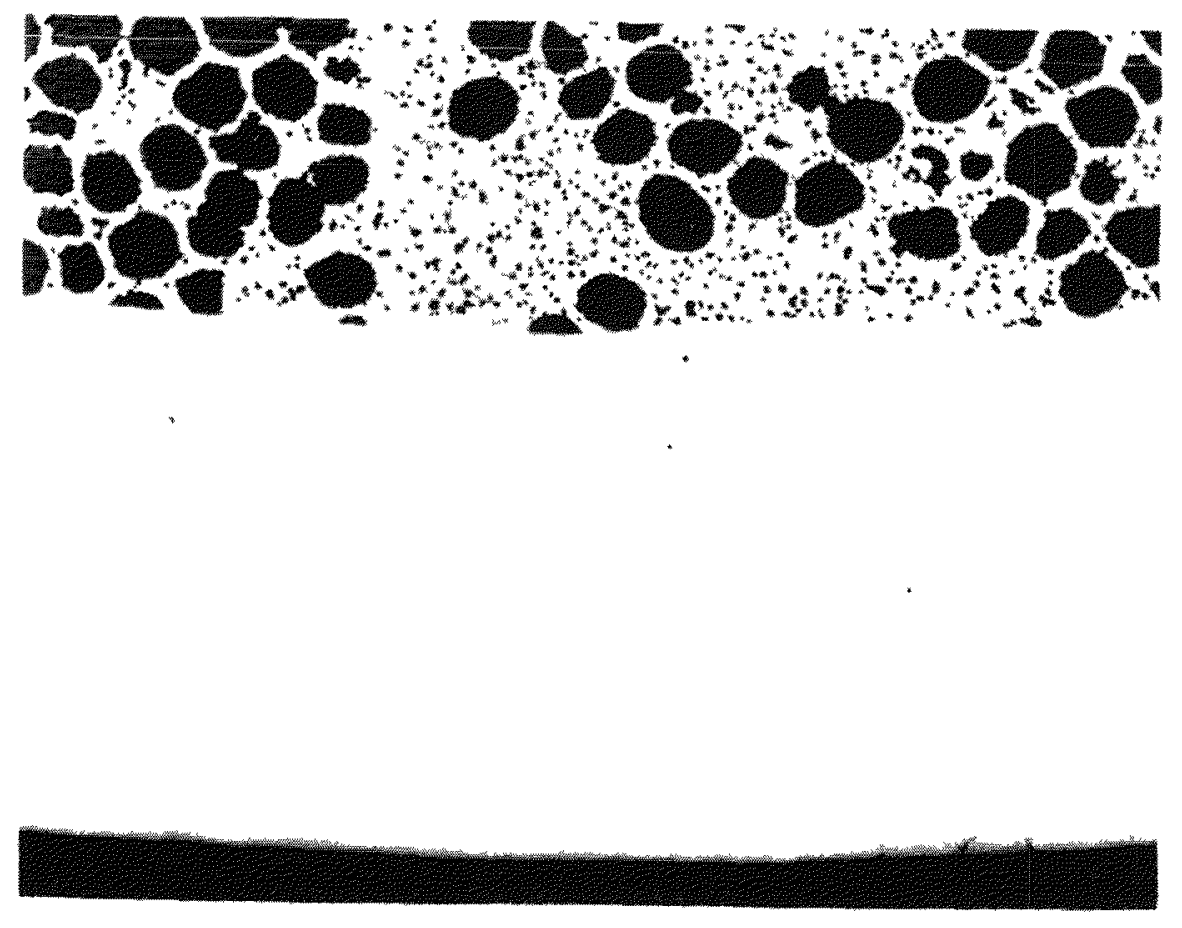

H'TGURE 28. TUNGSTEN-RHENIUM CLAD: CORE-TO-CLAD BOND 


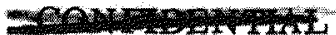

53

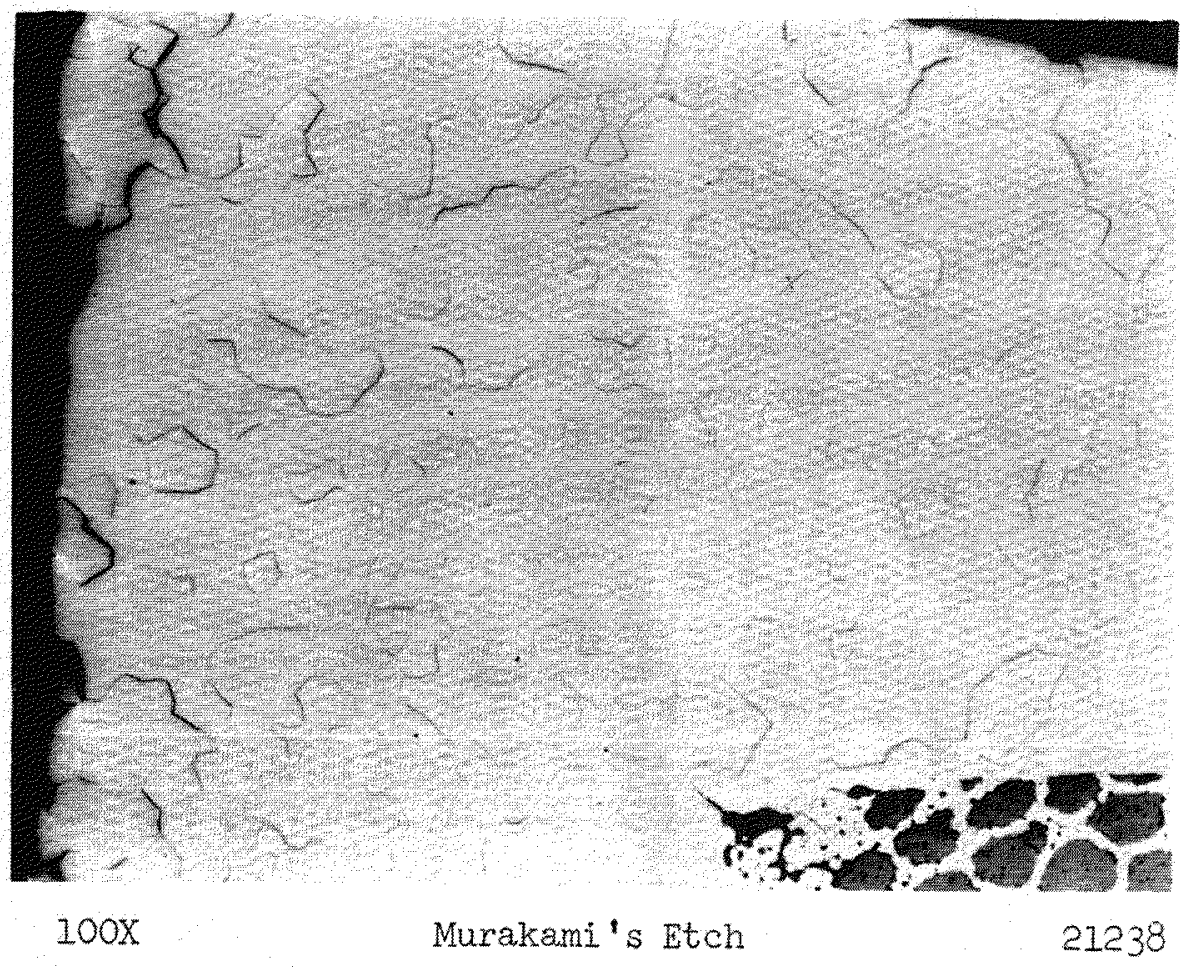

FIGURE 29. TUNGSTEN-RHENIUM CLAD: BOND BETWEEN THIN-END PLUG AND CLAD TUBE

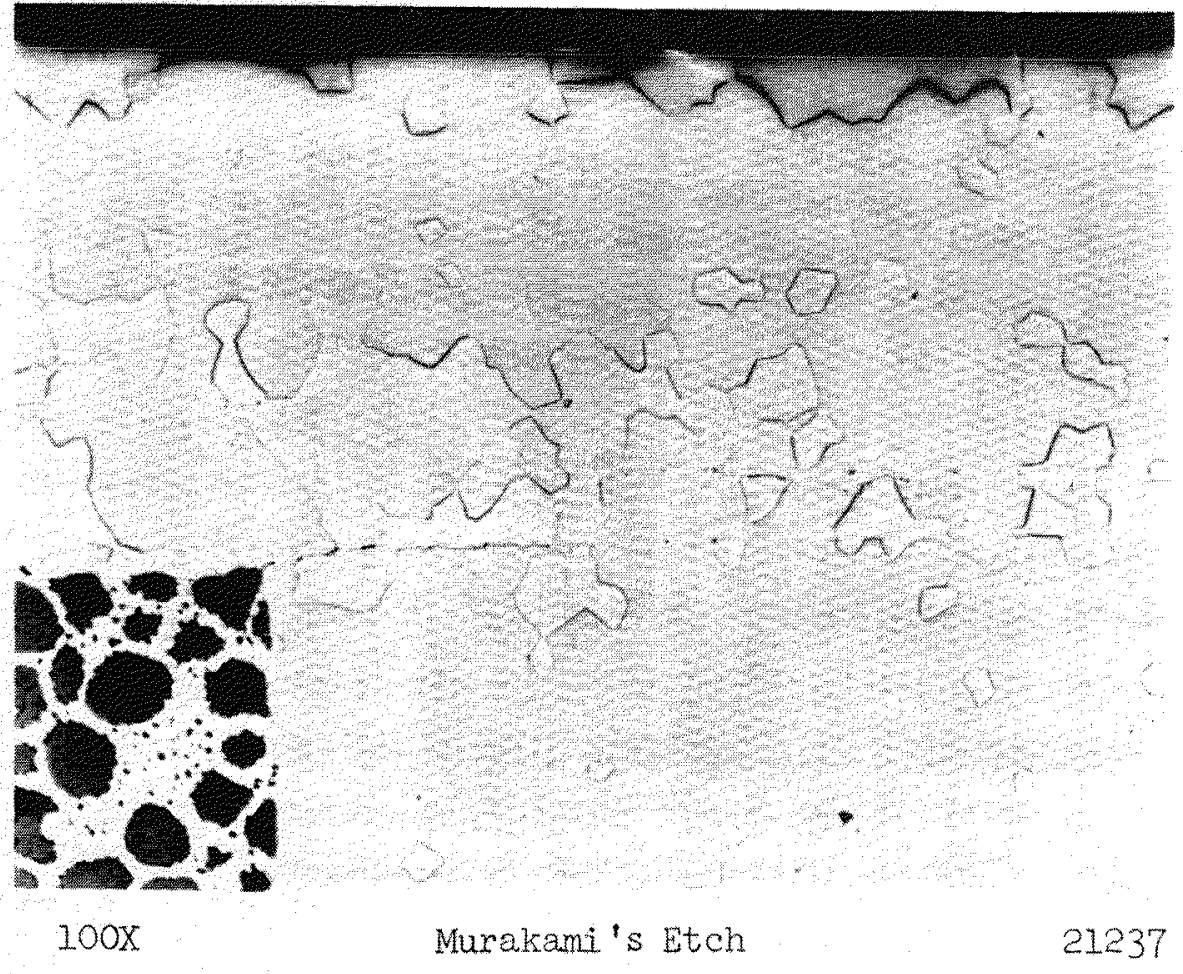

FIGURE 30. TUNGSTEN-RHENIUM CIAD: BOND BETWEEN THICK-END PLUG AND CLAD TUBE 


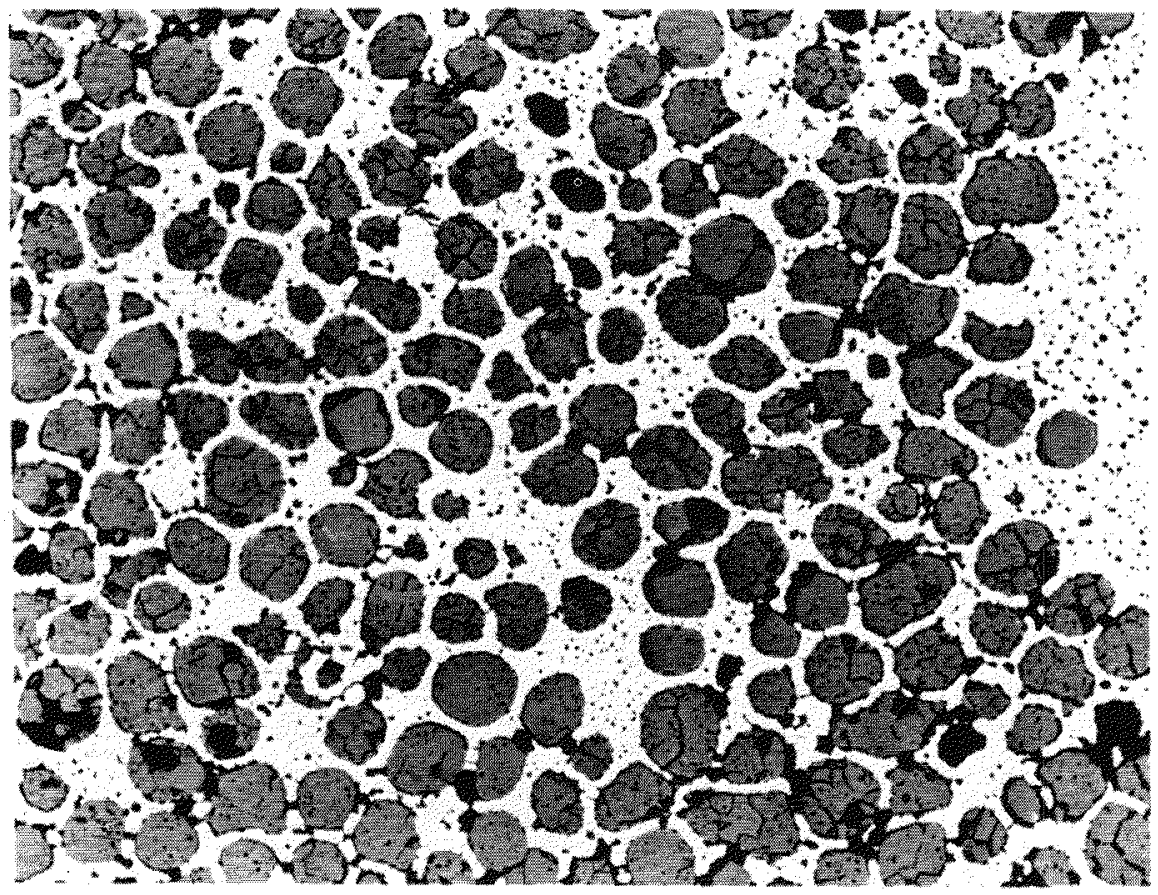

FIGURE 31. THORIA-TUNGSTEN CLAD: TYPICAI CORE STRUCTURE
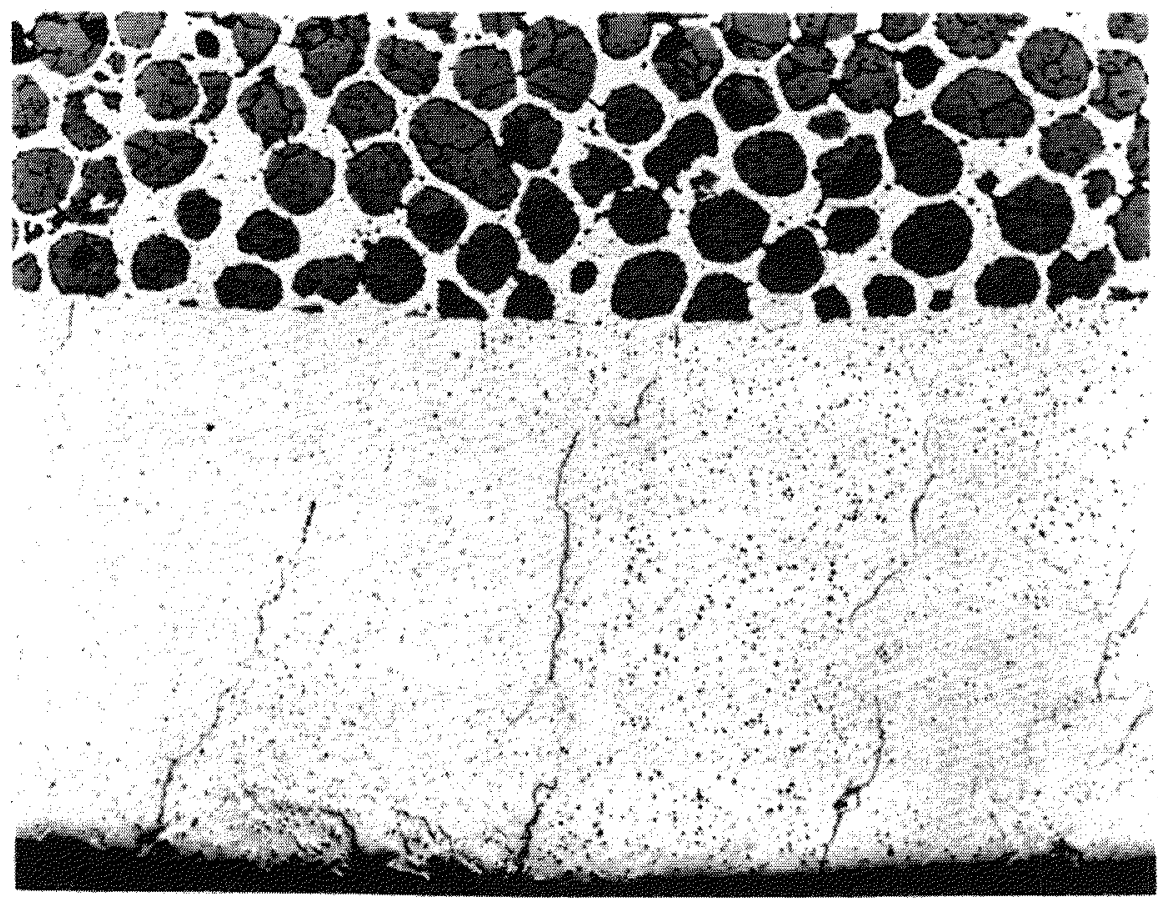

FIGURE 32. THORIA-TUNGSTEN CLAD: CORE-TO-CLAD BOND 


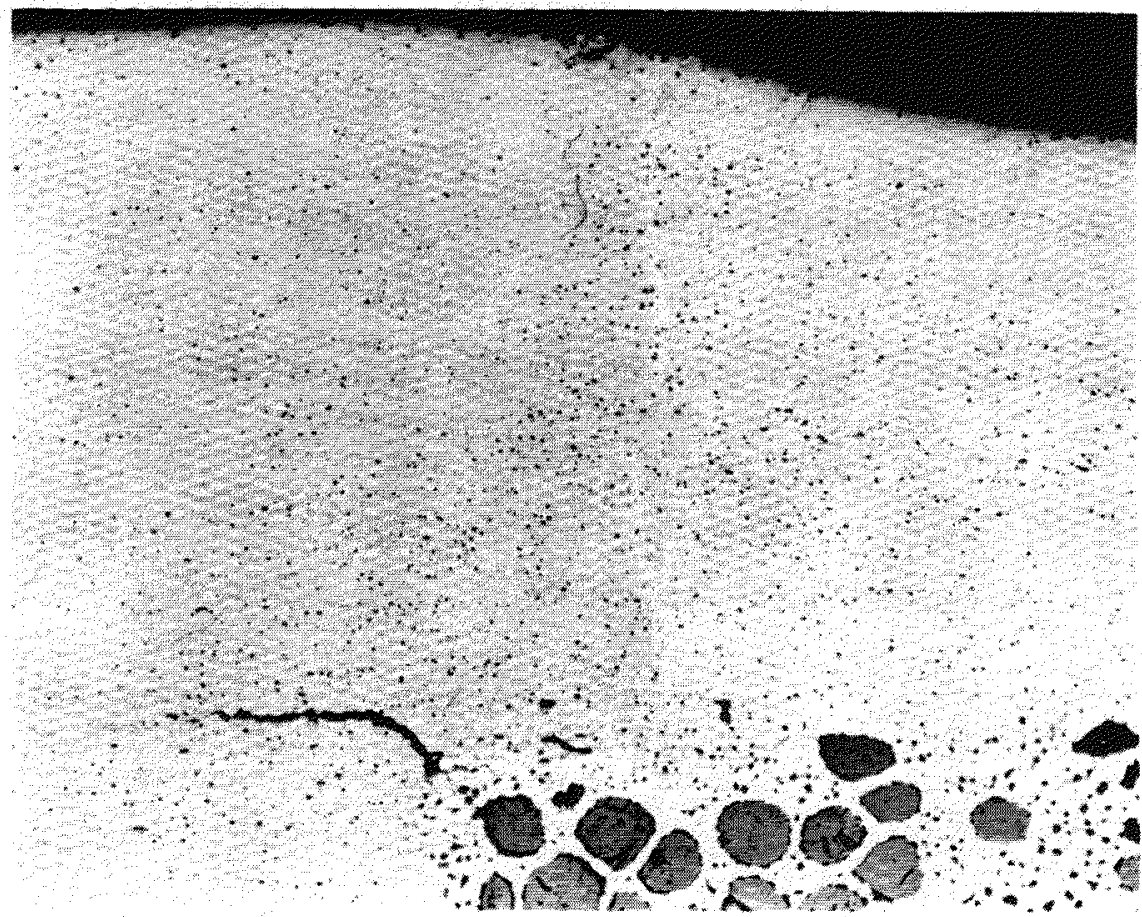

FTGURE 33. THORIA-TUNGSTEN CLAD: BOND BETWEEN THIN-END PLUG AND CLAD TUBE

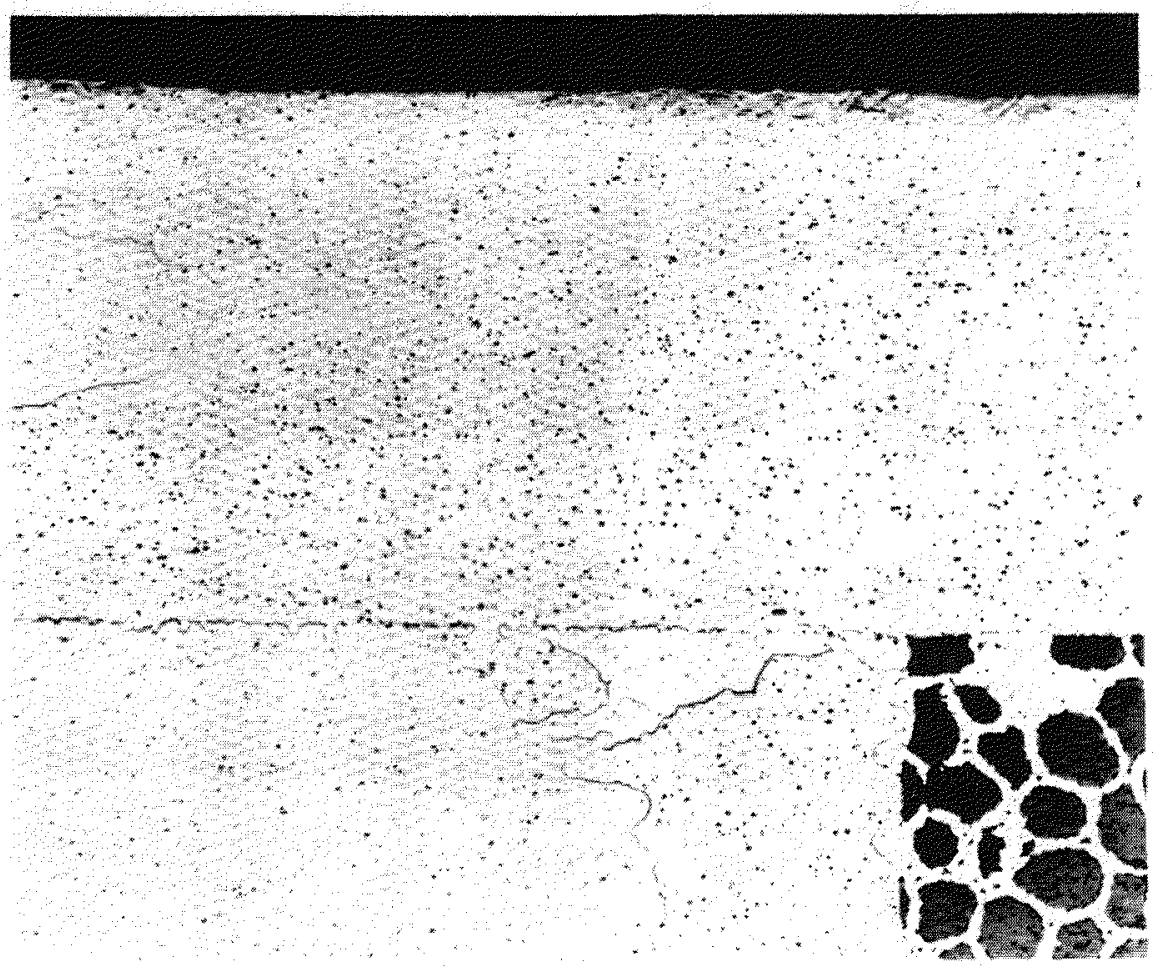


Fourth Thermal Cycle Experiment

Concurrent with the work on the third thermal cycle experiment clad pellets for an additional thermal cycle experiment were being prepared. Three different processing procedures were being evaluated for producing the fuel form. These were the blending of $\mathrm{UO}_{2}$ and thoriated tungsten powder for the fuel form rather than the use of coated particles blended with powder. The fuel forms prepared in this manner were then densified by explosive compaction or hot isostatic compaction. The thira approach was to evaluate the use of blending thoriated tungsten powder with coated particles rather than pure tungsten powder. Arc-cast tungsten clad material was used on all specimens.

Fuel Pellet Fabrication. The fuel forms for six of the seven specimens in this experiment were fabricated from a blending of 3 micron tungsten- $1 \mathrm{w} / \mathrm{O}$ thoria powder with spherical depleted $\mathrm{UO}_{2}$ having a nominal diameter of 60 microns. A slurry of this mixture was die pressed into pellets $0.520-$ in. diameter by 1.25 -in. Iong. The carrier was removed by vacuum outgassing. Three of these pellets were densified by HIP and three were densified by explosive compaction. The explosively compacted pellets had a density in excess of 95 percent of theoretical and were not isostatically sintered by HIP as originally intended. These explosively compacted pellets could be readily machined in the compacted condition. The three pellets that were densified by HIP were processed at $2900 \mathrm{~F}$ and $10,000 \mathrm{psi}$ for $3 \mathrm{hr}$. The seventh pellet was fabricated from coated particles $\left(50 \mathrm{w} / 0 \mathrm{VO}_{2}\right.$ ) blended with sufficient thoriated tungsten powder to obtain the desired fuel loading of $50 \mathrm{v} / \mathrm{O} \mathrm{VO}_{2}$. The processing for this specinen, except for the use of thoriated tungsten powder, was the same as previous fue]. forms. 
The fuel forms were under the desired size and therefore after machining there was excessive clearance between the fuel form and the clad material. No chemical cleaning of the blended fuel forms was done prior to the heat treatment because of the lack of a protective coating over the $\mathrm{UO}_{2}$ particles.

The cladding material was arc-cast tungsten for all pellets. Holes were EDM'd in rod stock and honing was used as previously to remove any damaged material. End plugs were machined the same size as the fuel forms since these were undersize. To prevent extrusion of the molybdenum canning material into the gap between the end plug and the tube, a tungsten wafer was placed over each end. The material was also heat treated at the same time as the fuel forms. Because of a leak in the hydrogen furnace, slight oxidation of the first specimen to be treated resulted in the decision to use vacuum as the atmosphere for the stress relief. Therefore, all seven fuel forms and their cladding components were stress relieved in vacuum at a temperature of $1750-1800 \mathrm{C}$ for $1-1 / 2 \mathrm{hr}$ using heating and cooling rates of $500 \mathrm{c} / \mathrm{hr}$

The specimens were then assembled in their molybdenum containers and gas-pressured bonded at $3200 \mathrm{~F}$ and $15,000 \mathrm{psi}$ for a period of 2 hr. The pressure was reduced while maintajning temperature. After removal of the bonding containers, one specimen containing an explosively compacted core and one containing a blended core consolidated by HIP were selected for metallographic examination. The remaining five pellets were ground to provide a 0.020 -in.-thick clad on the OD at one end and a thickness of 0.125 in. on the thicker end. Shoulders having a diameter $0.015 \mathrm{in}$. larger than the oD were provided at each end as usual. After final machining, these pellets were dye- 
penetrant inspected and helium-leak checked to determine the integrity of the clad. All pellets were found to be satisfacotry for thermal cycling.

Thermal Cycling. Prior to thermal cycling, two pellets having blended cores, one explosively compacted and one HIP core, were subjected. to the brazing cycle used for the joining of the thermocouple wells to the pellet. To simulate the final setup, pieces of tantalum-10 weight percent tungsten rod were brazed to the pellets on the thick end plug. The brazing cycle was: heat to $4500 \mathrm{~F}$ in a vacuum in no less than $2 \mathrm{hr}$, hold for $5 \mathrm{~min}$, and furnace cool. The first attempt to braze the pellets using pure columbium as a braze was unsuccessful because a furnace element burnt out at $4450 \mathrm{~F}$. No brazing occurred so the pellets were subjected a second time with this try being successful.

After brazing of these two pellets, the five pellets scheduled for evaluation were thermal cycled. The thermal cycle used was: room temperature to $500 \mathrm{C}$ in $10 \mathrm{~min}, 500 \mathrm{C}$ to $1727 \mathrm{C}$ in $10 \mathrm{~min}$, hold for $5 \mathrm{~min}$, and $\mathrm{cool}$ as rapidly as possible using an argon flow when specimens had reached black heat. After 5 cycles, considerable growth was observed with all specimens except for the control pellet which contained the coated particles blended with thoriated powder.

The average diametral growth for the four pellets at this point was $1 / 2$ to $I$ percent. This rate of growth continued through the 10 th and $15 \mathrm{th}$ cycles before tapering off to a 2 percent growth after 25 cycles.

The coated pellet snowed no growth until the 25th cycle. At the end of 50 cycles, the average of the first four was 2.5 percent, while Pellet 16 was only at 1.25 percent. At the end of 75 cycles, there was considerable 
scatter of data due to failures in the clad; however, the control pellet had the least growth. It was the only specimen which grew in a similar manner to the specimens cycled in the previous test.

All pellets grew at a fairly consistent rate on length except the brazed pellet with an explosively compacted core. This pellet grew approximately 2 percent within the first five cycles. All pellets ended up with a final growth of approximately 3 percent, however, The other explosively compacted pellet was removed from testing after 50 cycles because of excessive cracking on the thin end plug. The control pellet did show the minimum growth on length through the first 30 cycles.

Surprisingly, the weight-Ioss data on all five specimens was comparable to that produced by the tungsten-clad specimen in the earlier test. All specimens had final weight losses of less than 0.1 percent, and the average value was 0.054 percent. It is not unusual to have specimens which show growth but still be low on weight loss, because this occurred during the previous test when the tungsten-rhenium-clad specimen grew more than the tungsten-clad specimen but yet had less weight loss. The growth and weight loss data are sumarized in Figure 35 which also identifies the pellets by number.

Typical structures of the blended fuel form pellets are shown in Figures 36 and 37. Figure $36 \mathrm{a}$ shows the explosively compacted fuel form in the as-compacted form and Figure $36 \mathrm{~b}$ shows this same core after gas-pressure bonding. Figure $37 \mathrm{a}$ shows the blended core after HIP and Figure $37 \mathrm{~b}$ shows the same core after the cladding cycle.

Each of the five pellets cycled was sectioned into five pieces by removing a 1/8-in.-thick transverse piece from the center of the specimens and then sectioning each end Iongitudinally through the center. This technique 


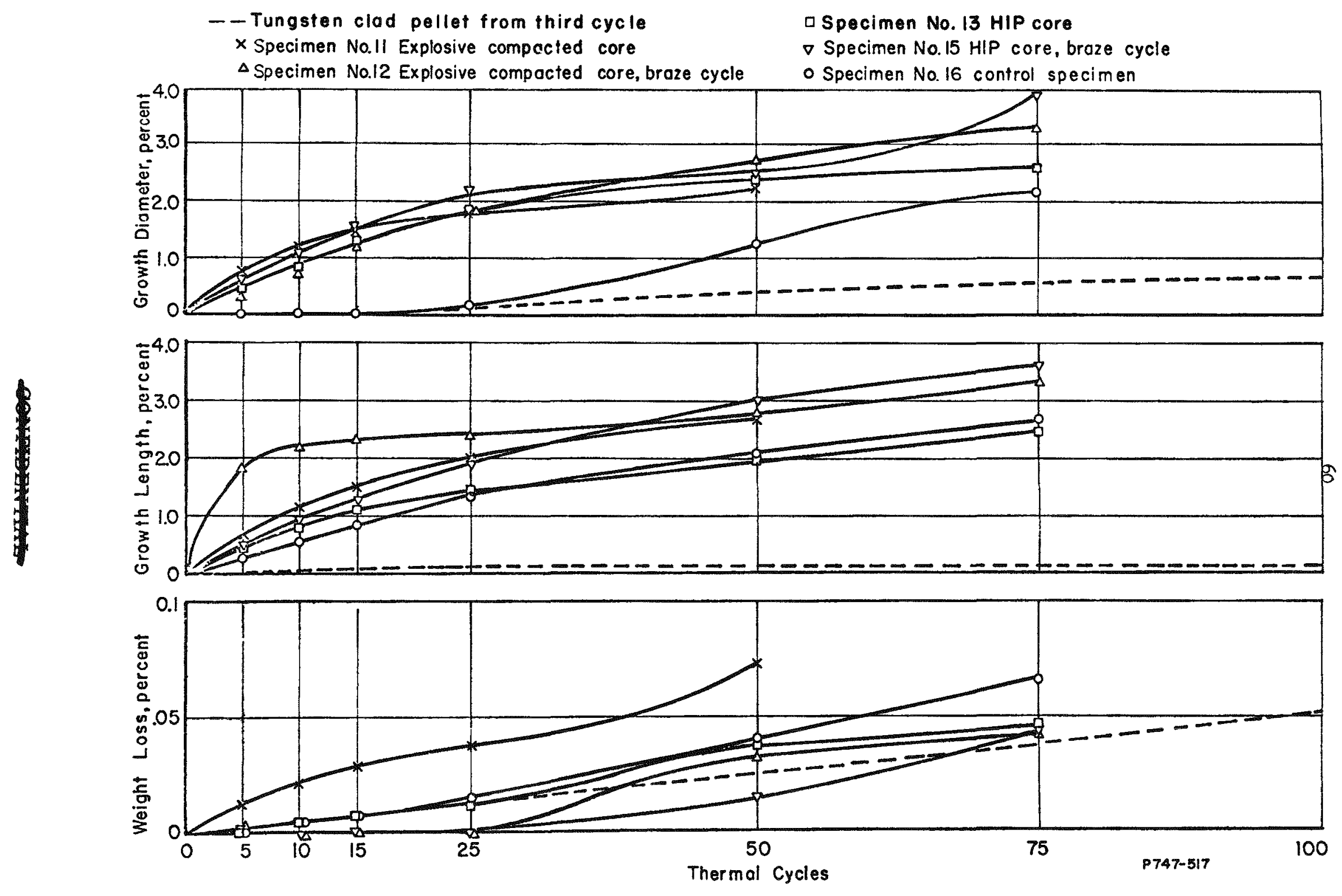

FIGURE 35. PERCENT GROWTH AND WEIGHT LOSS CURVES FOR FOURTH THERMAL CYCLE EXPERIMENT 
61

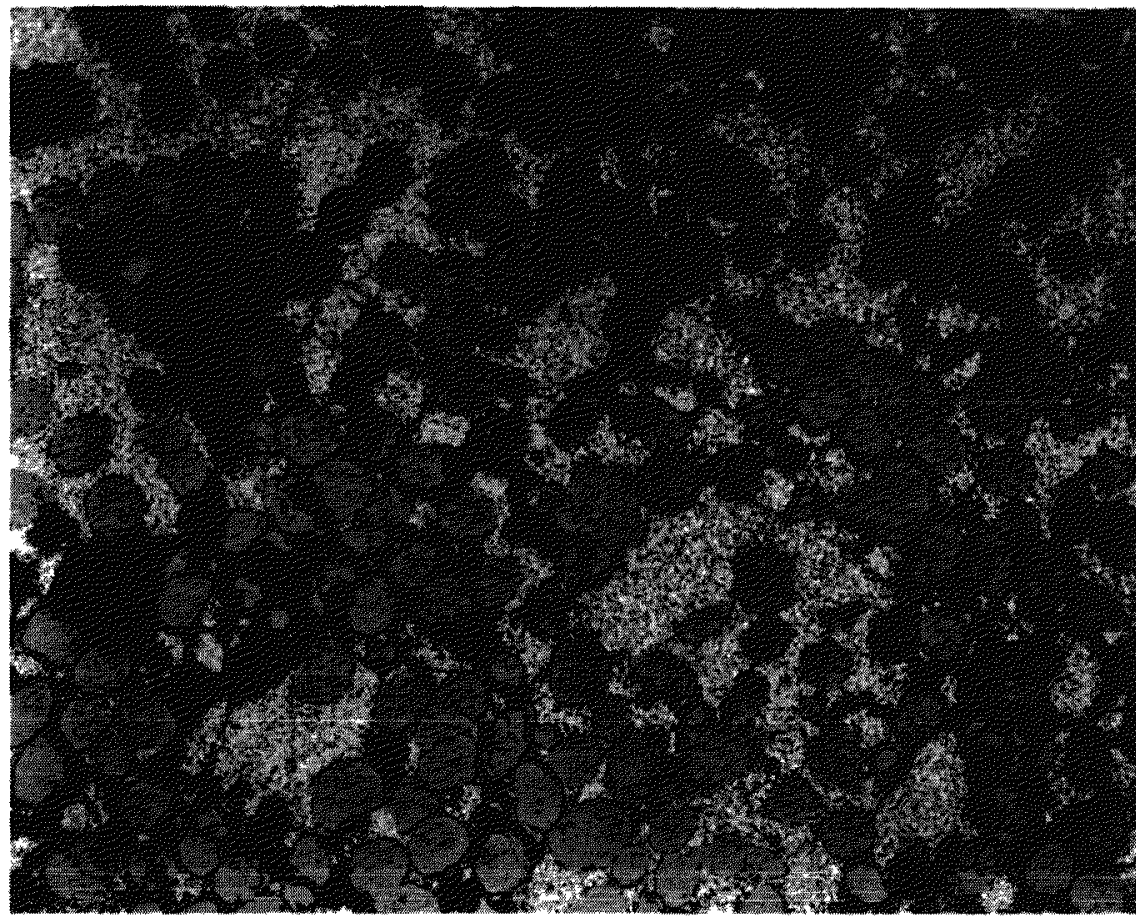

$100 \mathrm{X}$

Murakami's Etch

25188

a. As-compacted

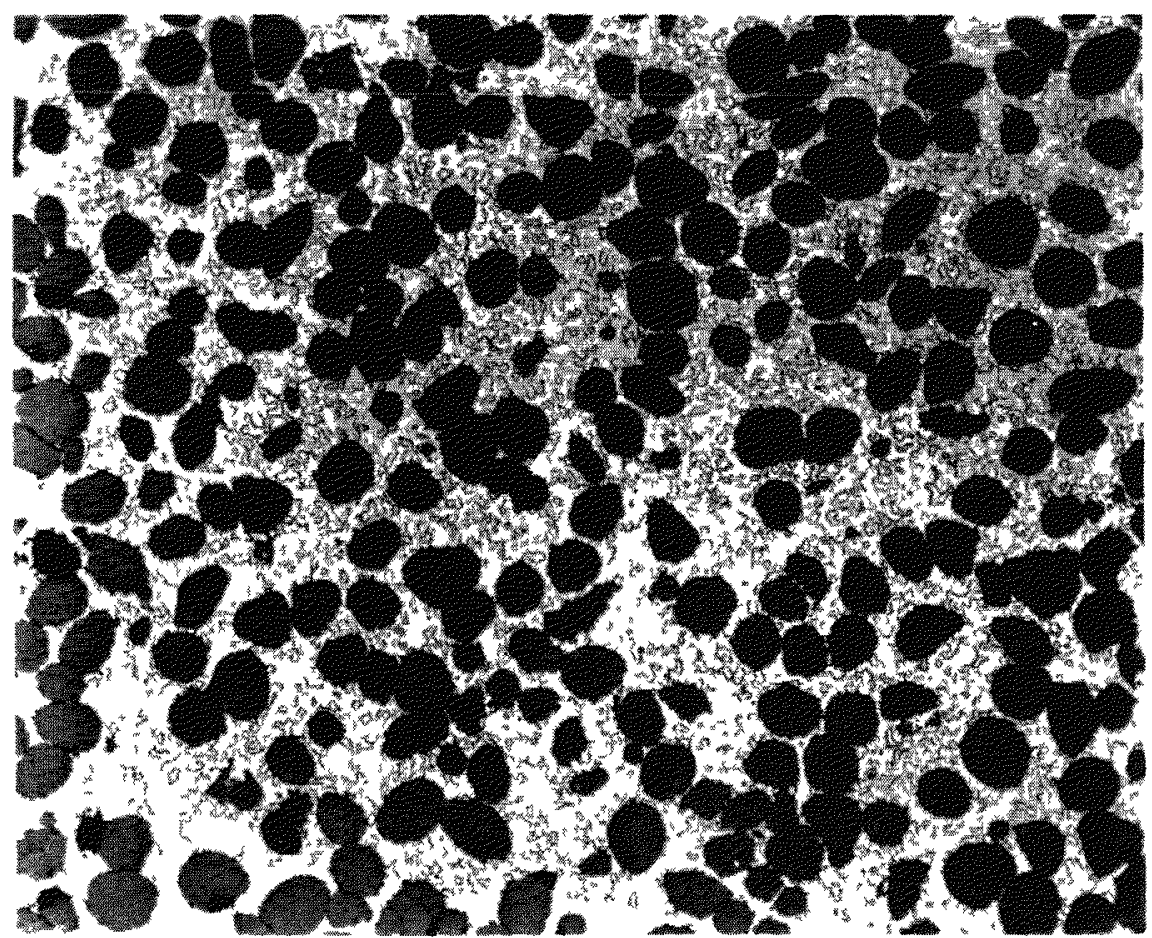

$100 \mathrm{X}$

Murakani's Etch

25190

b. After Cladding Cyclo

FTGURE 36. MICROSTRUCTURE OF EXPLOSIVELY COMPACTED PELIET AT VARIOUS STAGES OF FABRICATION

Explosivo compaction followed by pressure bonding. 
62
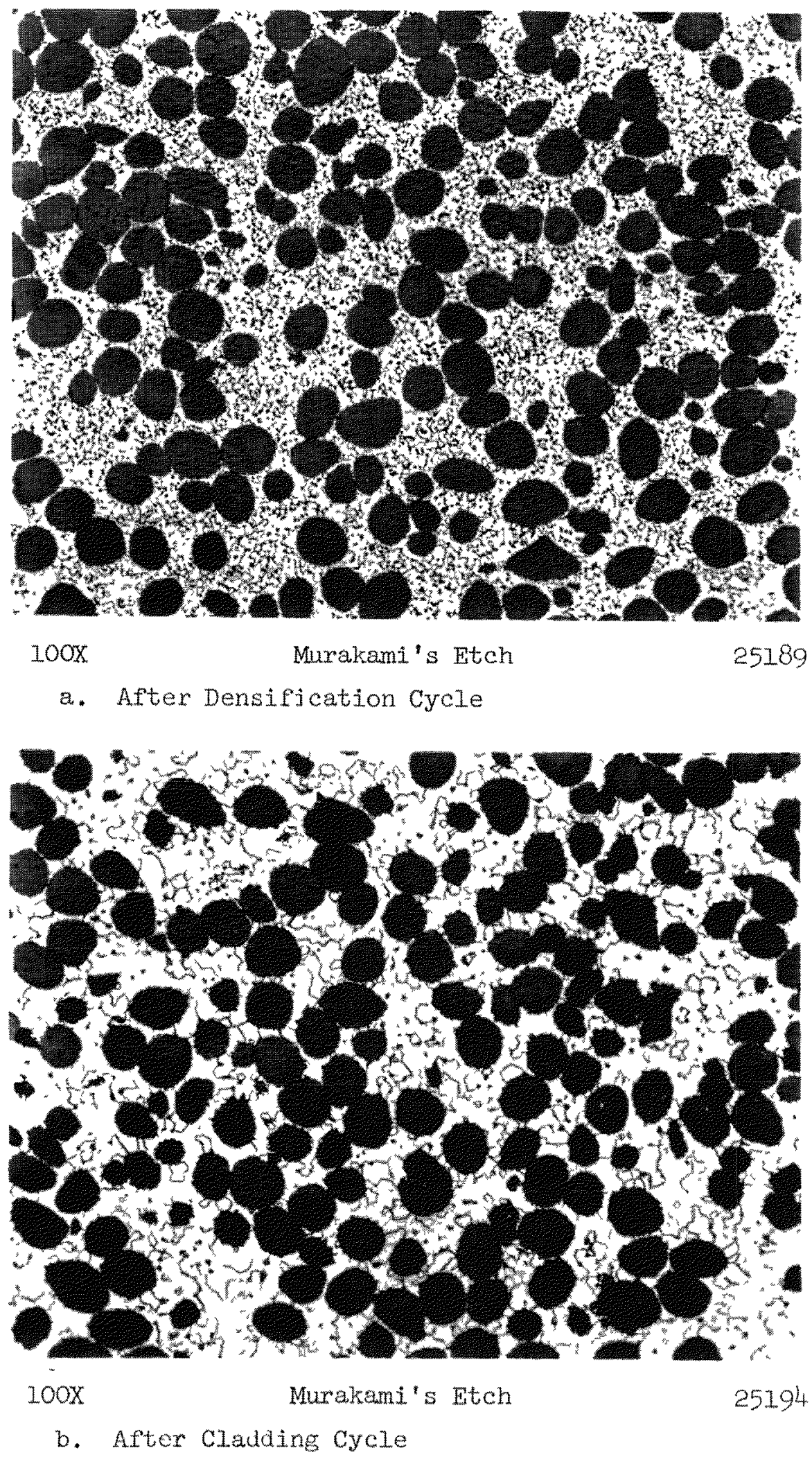

FIGURE 37. MTCROSTRUCTURE OF HOT ISOSTATICALLY PRESSED PELIET AT VARIOUS STAGES OF FABRICATION 
was used on previous specimens since it allows examination of clad bonding, core-to-core bonding, core-to-clad bonding, and core structure. Figures 38, 39, 40, 41, and 42 are typical photomicrographs of the core-to-clad bonds and core structures for Specimens 11, 12, 13,15, and 16, respectively. The first four figures do not vary in appearance much except for voids in the core. Most of the variation is a result of pullout of the $\mathrm{UO}_{2}$ during metallographic polishing. One characteristic which is evident is that the void space between $\mathrm{UO}_{2}$ particles and the matrix are larger in Pellets 12 and 15 than they are in Pellets 11 and 13. This is evidently due to the greater expansion of the $\mathrm{UO}_{2}$ during the $4500 \mathrm{~F}$ brazing cycle, causing a larger fuelparticle void. Another point is that Pellet 17 has a more dense matrix than Pellet 12 which had gone through the brazing cycle. The fact that Pellet 12 survived the 75 cycles better than Pellet 11 suggests that the increased density is not necessarily beneficial. A third observation is that the $\mathrm{UO}_{2}$ In the explosively compacted pellets, 11 and 12 , is more dense than those fabricated by pressure bonding.

The control specimen, Figure 42, is basically of similar quality to Pellets 13 and 15 except, of course, the $\mathrm{UO}_{2}$ dispersion is much more desirable as a result of using coated particles. Void formation and $\mathrm{UO}_{2}$ density are of equal proportions to the other specimens.

Core-to-clad bonding was excellent in all five specimens. The only variation in cladding material was the larger grain size in Pellets 12 and 15 as a result of the high-temperature vacuum treatment required for brazing.

Figure 43 shows the two types of failures observed on the specimens. The top photo is of the "H" type crack which occurred in Pellet 11 at the thin eng-plug end. Notice that the end plug has bowed and that the crack protrudes 
64
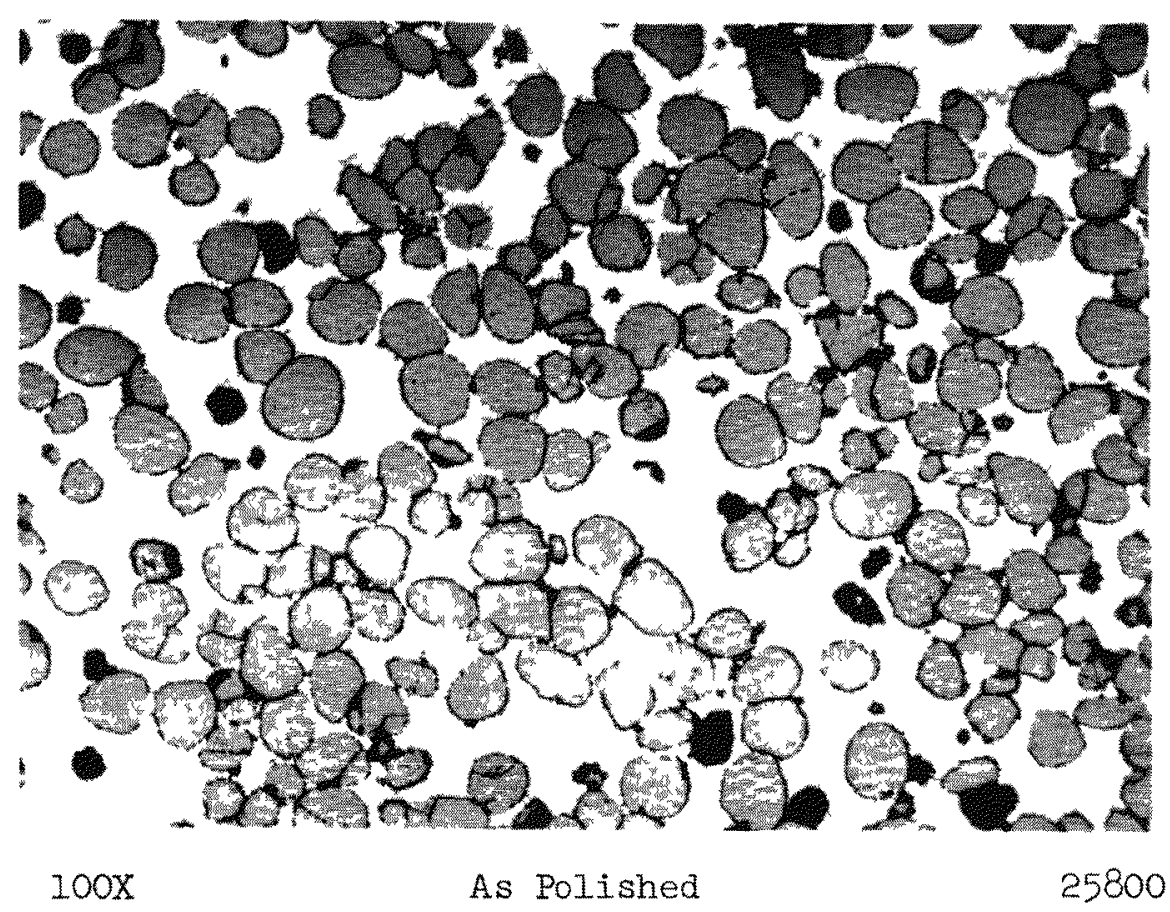

a. Core structure

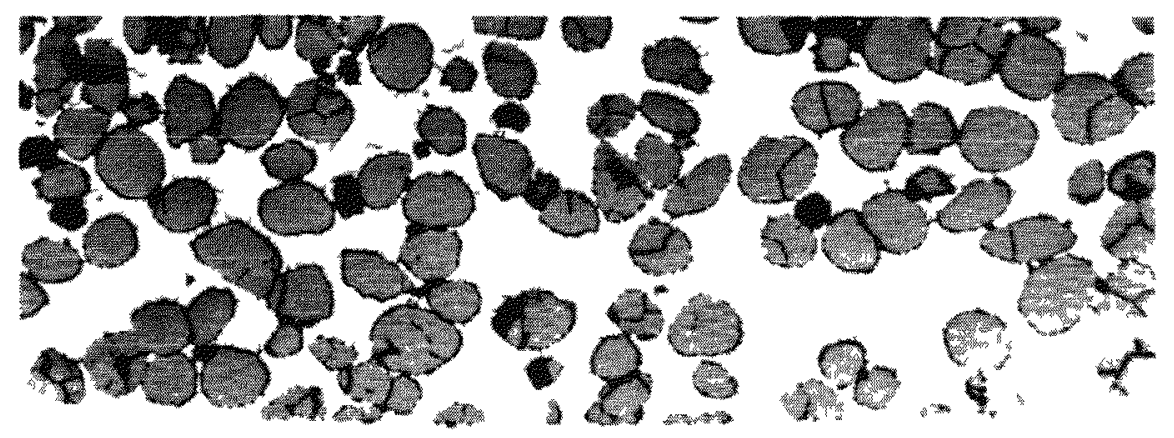

100X As Polished 25801

b. Core-to-clad Bond Structure

FIGURE 38. TYPICAL CORE AND CORE-TO-CLAD BOND STRUCTURES FOR SPECIMEN 11 Explosive compacted core, clad by pressure bonding, and thermal cycled. 


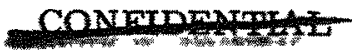

65

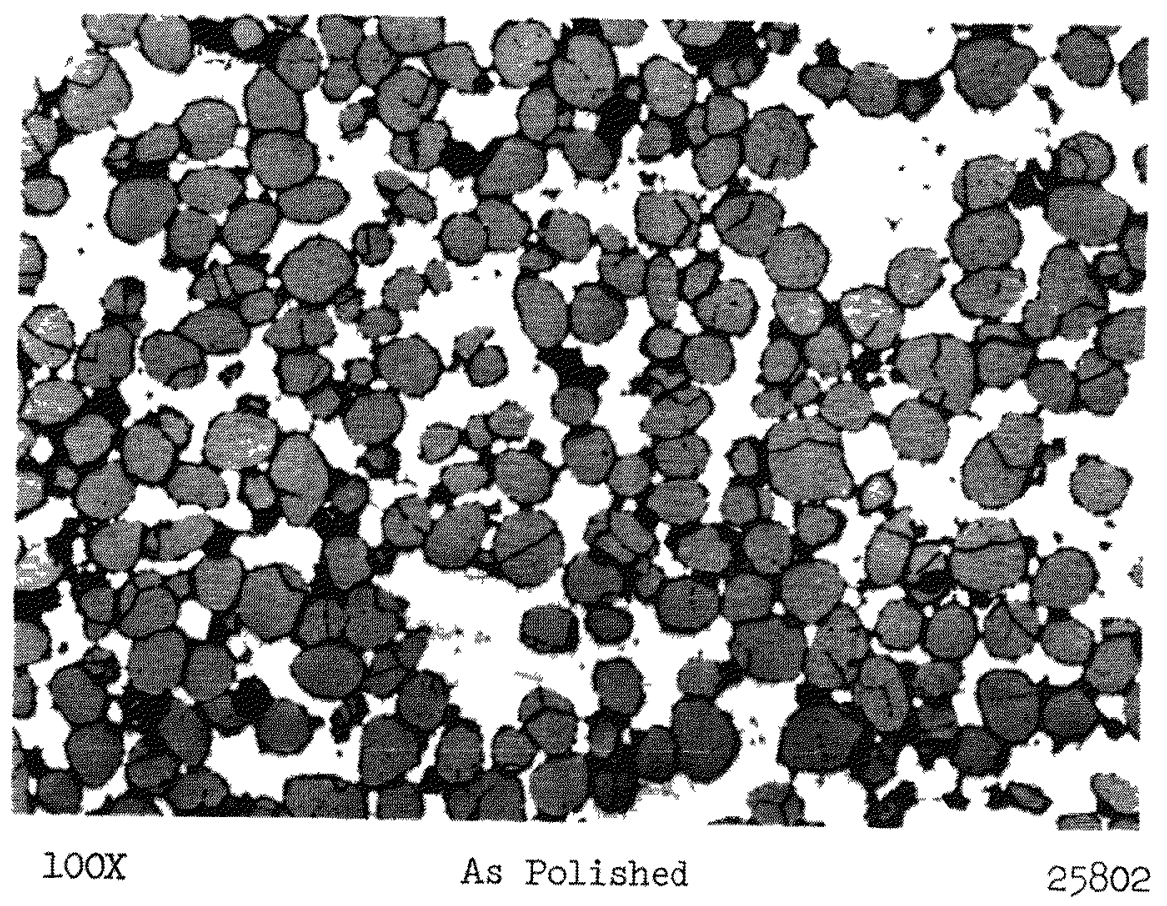

a. Core structure

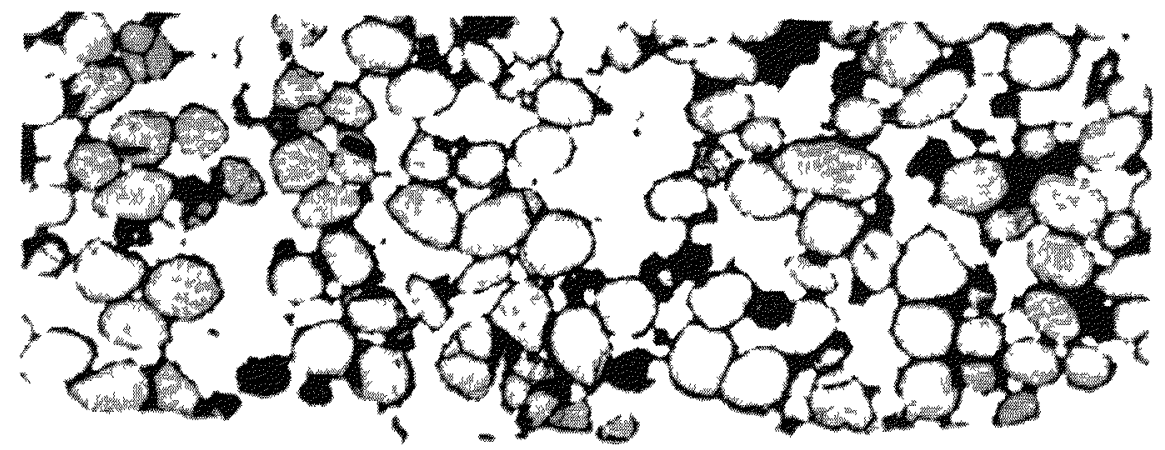

100X As Polisher 24,803

b. Core-to-Clad Bond Structure

FIGURE 39. TYPICAL CORE AND CORE-TO-CLAD BOND STRUCTURES FOR SPECIMLN 12 Explosive compacted core, lidd by pressure bonding, submitted to brazing cycle, and thermal cycled. 

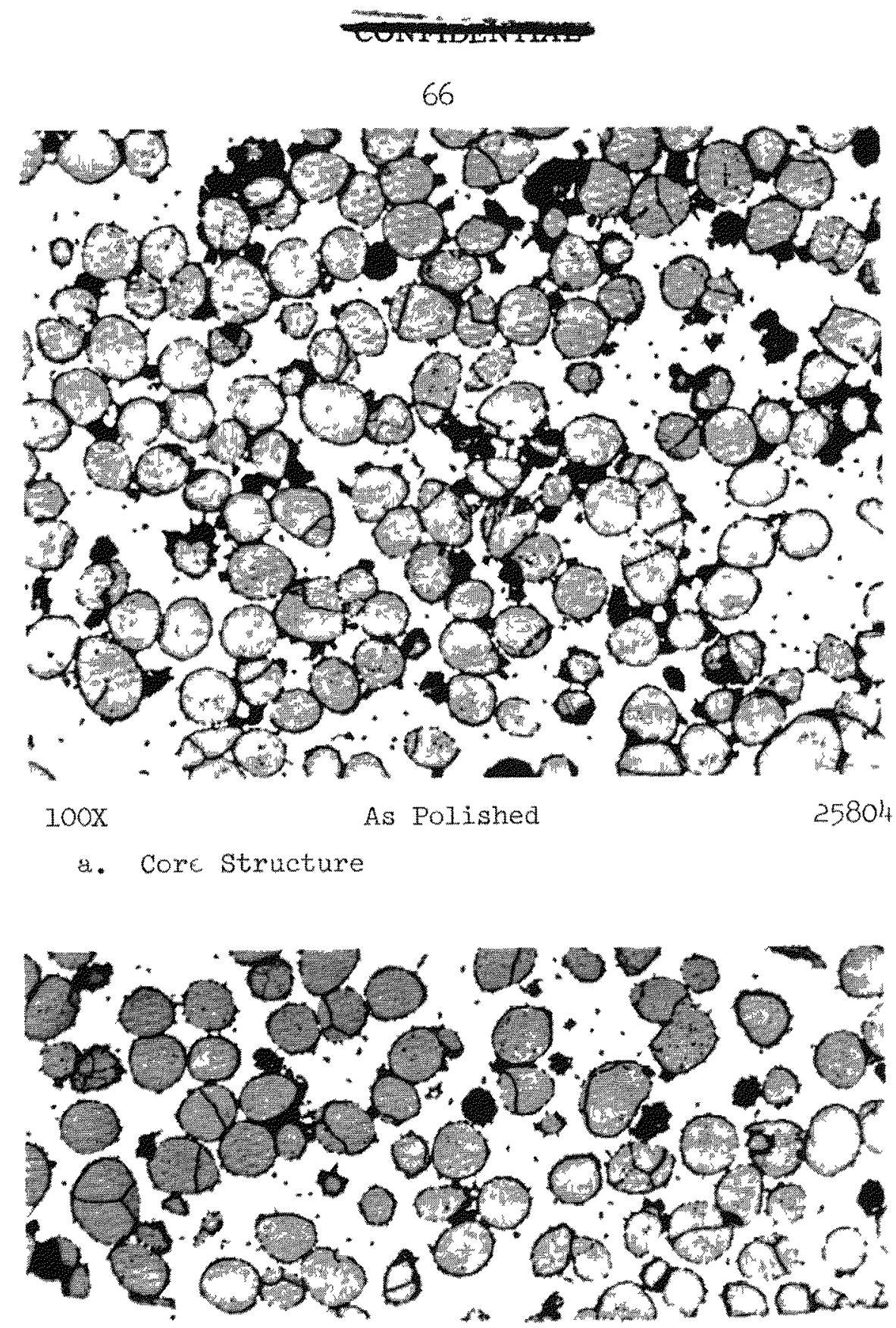

100x As Polished 25605

b. Core-to-cldd Bond Strueture

FIGURE 40. TYPICAL CORE AND CORE-TO-CLAD BOND STRUCTUURES FOR SPECIMEN 13 Pressure-bonded core, clad by proware bonding, and thermal cycled. 


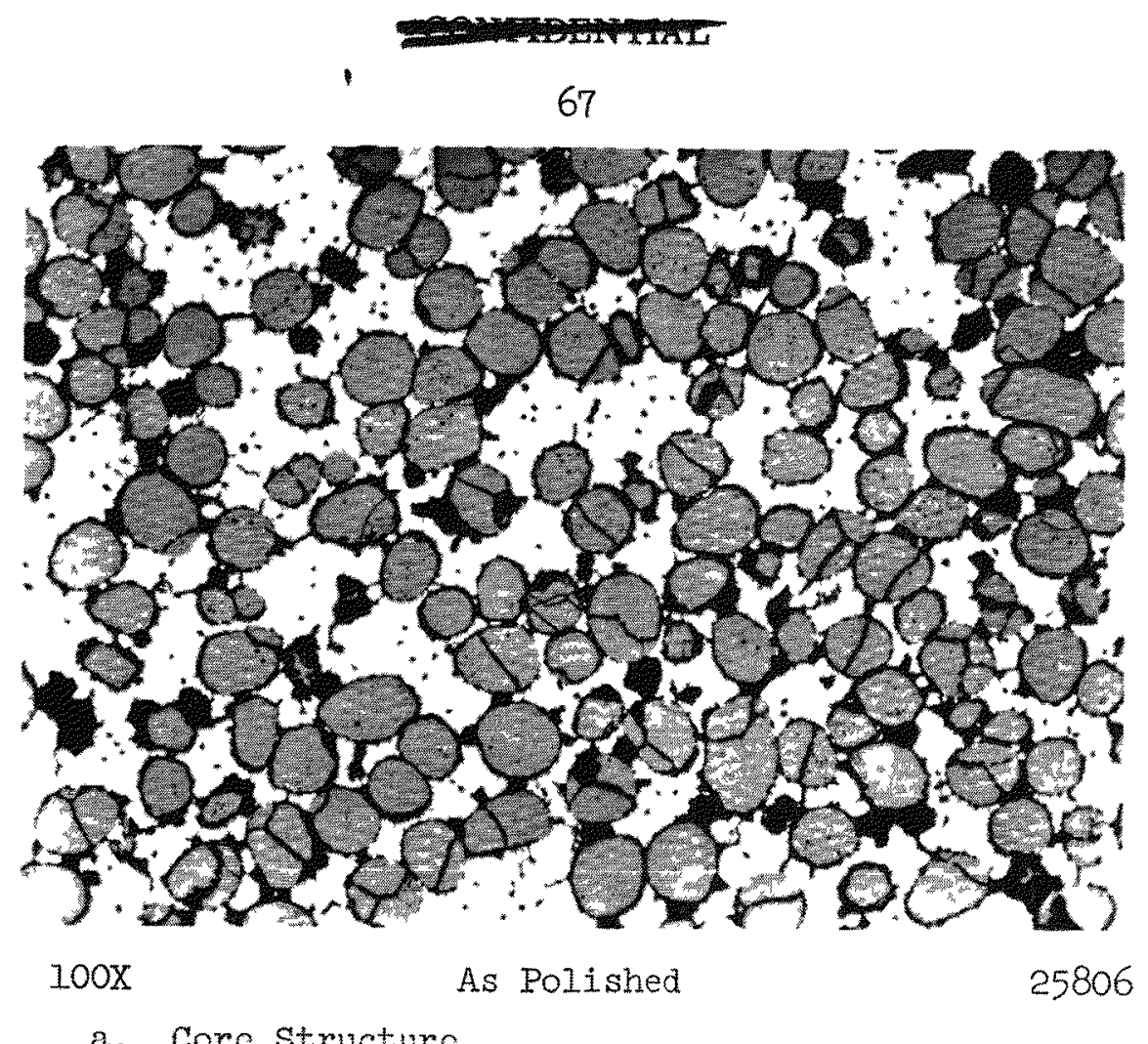

a. Coro Structurc
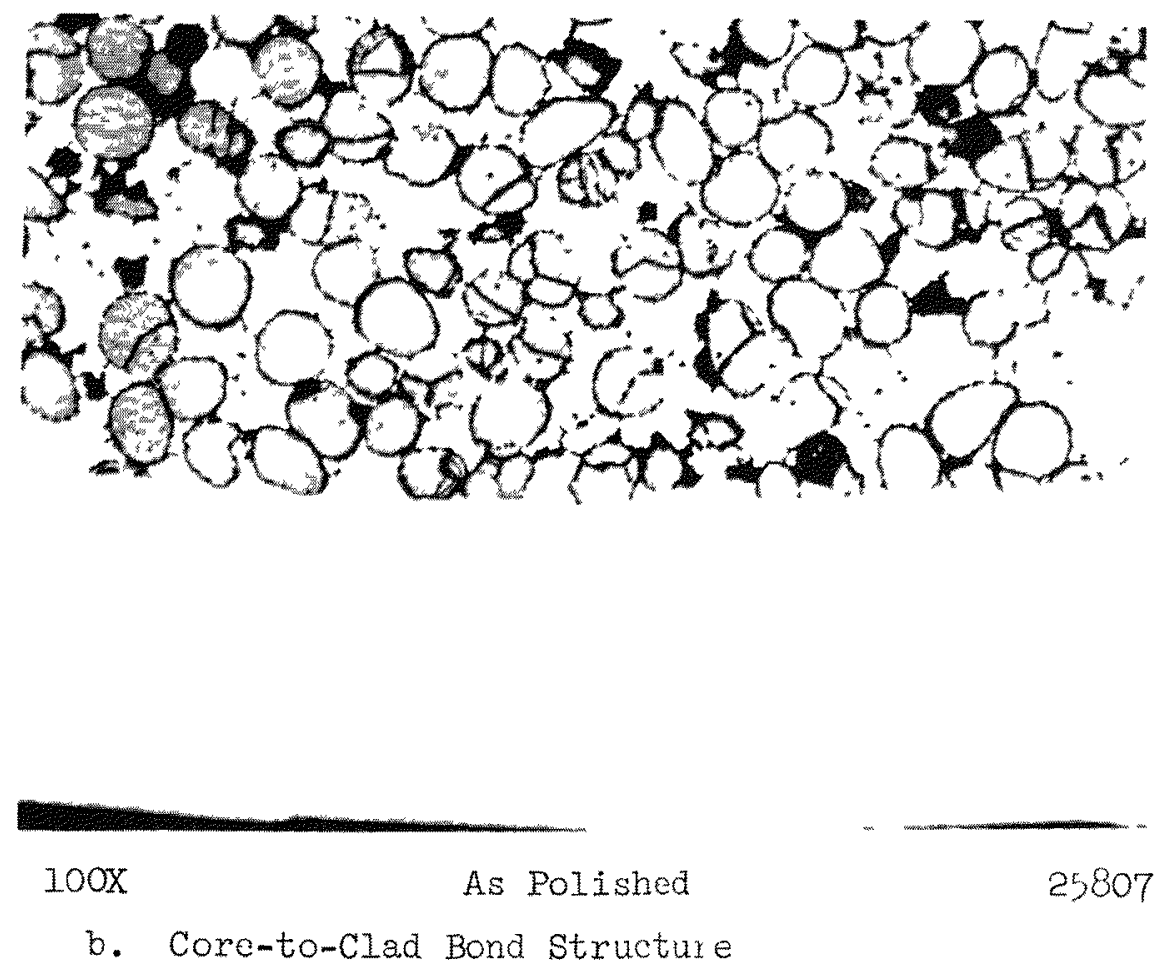

FIGURE 41. TYPICAI CORE AND CORE-TO-CLAD BOND STRUCTURES FOR SPECIMEN 15 Pressure-bonded core, clad by pressure bonding, submitted to brazing cycle, and thermal cycled. 

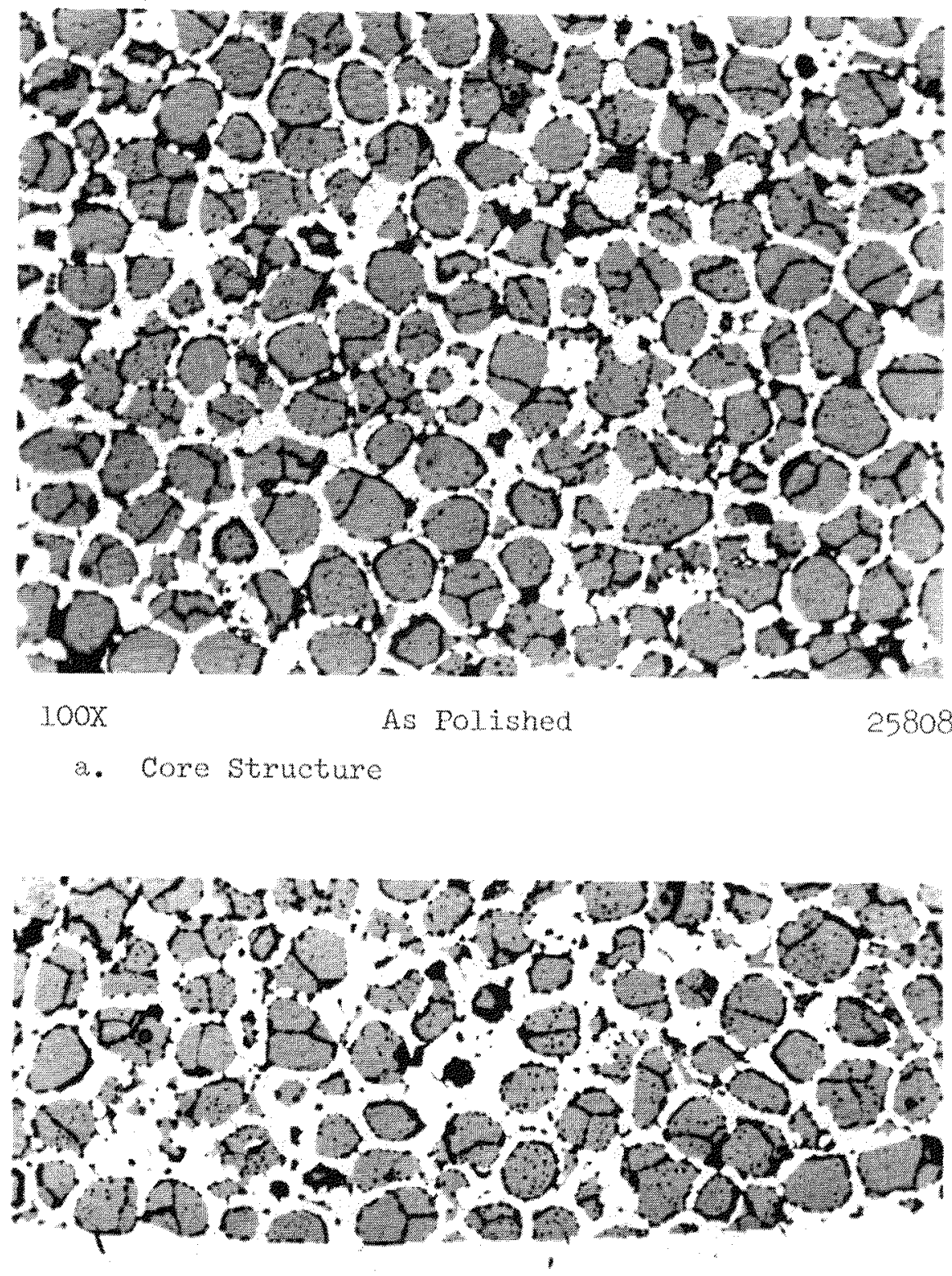

100x As Polished 25809

b. Core-to-clad Bond Structure

FTGURR 42. TYPICAL CORE AND CORE-TO-CLAD BOND STRUCTURES POR SPECIMEN 16 Pressure-bonded core, clad by pressure bonding, and thermal cycled. 


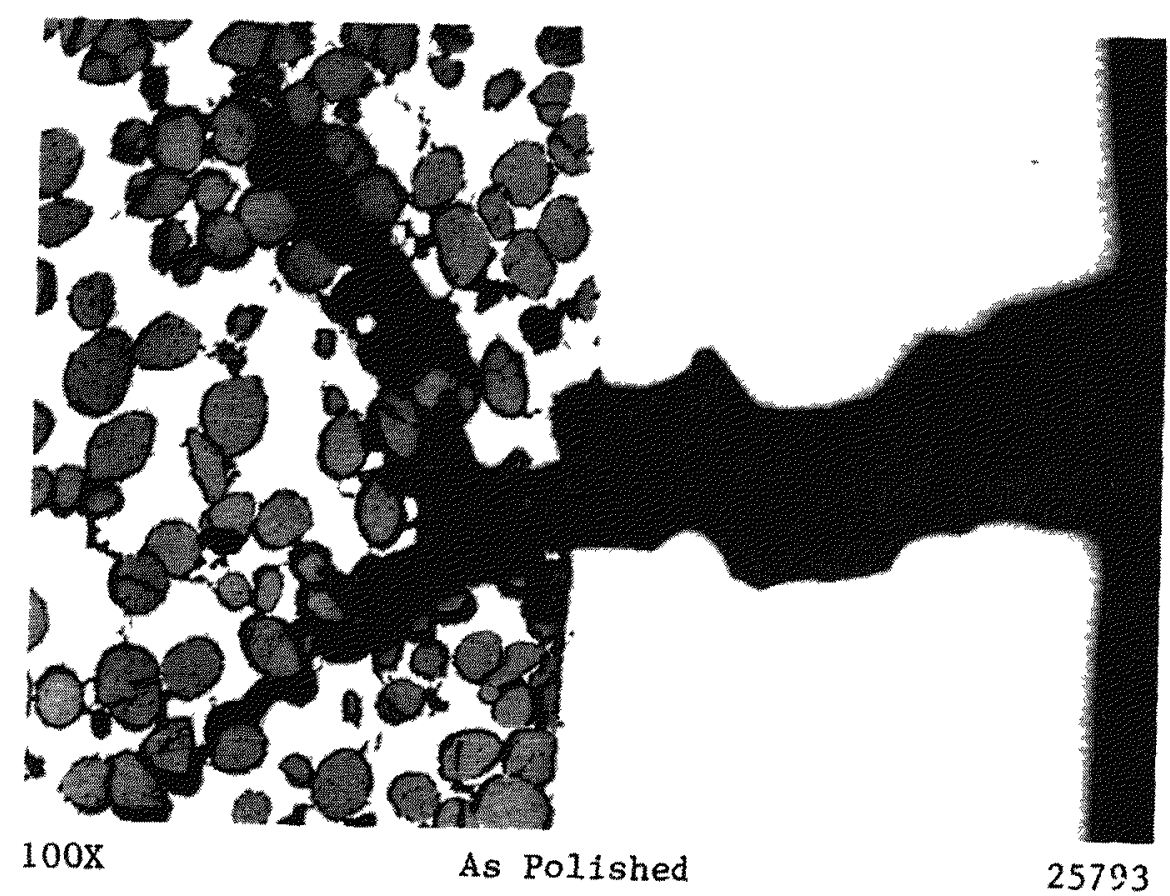

a. Thin End Plug Crack in Specimen 11

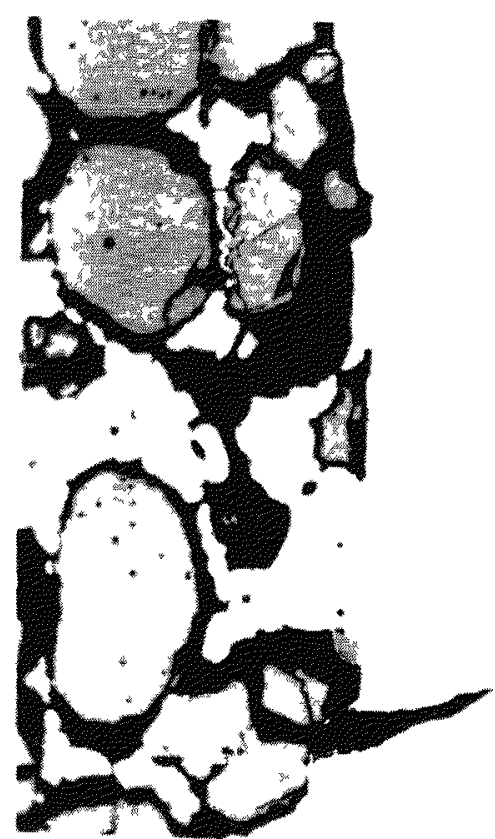

$250 \mathrm{x}$
As Polished

b. Typica1 Clad Crack in Specimen 15

FIGURE 43. Typical Failures of Therma1-cycled Pellets. 
into the core rather than propagating at the core-to-clad interface. The crack is intergranular and is evidently due to excessive growth which created large tensile stresses in the cladding. The lower photo is of the intergranular cracks which were apparent on the other four speciliens, particularly those pellets which had been submitted to the brazing cycle. Note how the grains have displaced at the grain boundary creating steps on the clad surface. The frequency of these failures was greater in the brazed pellets due to their larger grain size and resulting poor grain-boundary strength.

Failure of the fourth sexies of thermal cycle specimens was believed to have been caused primarily by altering the stress-relieving atmosphere from hydrogen to vacuum rather than the introduction of thoriated tungsten powder as the matrix material. It was agreed that coated particles should be used in all subsequent work since the control specimen (Pellet 16) showed a more desirable growth pattern. As previously decided, all future pellets would use unalloyed arc-cast tungsten rod as the cladding material.

As a result of these studies, Battelle and NASA personnel agreed to initiate fabrication of the enriched fuel pellets.

Preparation and Evaluation of Enriched $\mathrm{UO}_{2}$ Fuel Pellets

The results from the thermal cycle experiments indicated that the desired pellet assembly would consist of a tungsten-50 v/0 UO fuel form clad with unalloyed tungsten. The fabrication procedure for this type of pellet had been established and the decision was made by NASA to initiate fabrication of the enriched fuel pellets. Ten fuel pellets were made of which four were thermal cycled to determine the growth and weight loss characteristics of these pellets. 
Enriched Fuel Pellet Fabrication. The $\mathrm{UO}_{2}$ used for the enriched pellets had been initially coated with $50 \mathrm{v} / 0$ tungsten early in the program. This coating was also high in fluorine. As improved pellet fabrication procedures were developed, it was necessary to remove the tungsten coating and re-coat the $\mathrm{UO}_{2}$ with $50 \mathrm{w} / \mathrm{o}$ tungsten. This new coating also contained lower fluorine ( $167 \mathrm{ppm}$ ). Because of some losses during processing, two of the ten pellets contained $\mathrm{UO}_{2}$ from another lot material. $\mathrm{All}$ the $\mathrm{UO}_{2}$ met the requirements of the contract which specified a spherical particle size of 60-100 microns, a density of 92-95 percent, and full enrichment (see Table 3).

Following coating with $50 \mathrm{w} / \mathrm{O}$ tungsten, the coated fuel was blended with sufficient 0.8 micron tungsten powder to bring the fuel loading to 50 $\mathrm{v} / \mathrm{O} \mathrm{UO}_{2}$. The analysis of the coated fuel is given in Table 4. Parawax ( 0.2 percent) was used as a binder. The pellets were pressed to about 75 percent density, outgassed at $1500 \mathrm{C}$ for $1 / 2 \mathrm{hr}$ to remove the binder and loaded into molybdenum containers for consolidation. Porous molybdenum spacers were placed at each end of the container to insure uniform deformation of the pellet. HIP conditions of $2900 \mathrm{~F}$ and 10,000 psi for $3 \mathrm{hr}$ were used to densify the pellets to an approximate density of 95 percent of theoretical. The molybdenum containers were selectively leached from the fuel form and the resulting fuel form was cleaned up in dilute sodium hydroxide. The fuel forms were then ground to 0.462-in. diameter by 1.000-in. Iong. Prior to hydrogen stress relieving at 1750-1800 $\mathrm{c}$ for $1-1 / 2 \mathrm{hr}$, the fuel forms were dipped in dilute $\mathrm{HNO}_{3}$ to remove any smeared $\mathrm{UO}_{2}$. Following the hydrogen treatment the pellets were weighed. 
TABLE 4. ANALYSIS OF ENRICHED UO 2 PARTICLES AFTER COATING WITH $50 \mathrm{w} / 0$ TUNGSTEN

\begin{tabular}{|c|c|}
\hline Element & Impurity Level - ppm \\
\hline $\mathrm{Al}$ & $<10$ \\
\hline $\mathrm{Bi}$ & $<5$ \\
\hline $\mathrm{B}$ & $<0.3$ \\
\hline $\mathrm{Ca}$ & 10 \\
\hline $\mathrm{Cr}$ & $<5$ \\
\hline $\mathrm{Cu}$ & $<1$ \\
\hline $\mathrm{Fe}$ & 10 \\
\hline $\mathrm{Pb}$ & $<5$ \\
\hline $\mathrm{Mg}$ & $<2$ \\
\hline $\mathrm{Mn}$ & 2 \\
\hline Mo & $<$ \\
\hline $\mathrm{Ni}$ & 1 \\
\hline $\mathrm{P}$ & $<60$ \\
\hline Ti & $<1$ \\
\hline $\mathrm{Si}$ & 10 \\
\hline $\mathrm{sn}$ & $<5$ \\
\hline $\mathrm{V}$ & $<5$ \\
\hline $\mathrm{Zn}$ & $<20$ \\
\hline $\mathrm{H}_{2}$ & $<10$ \\
\hline $\mathrm{N}_{2}$ & $<10$ \\
\hline$F$ & 167 \\
\hline
\end{tabular}


The cladding materials were prepared as follows. Arc-cast tungsten rod (0.625-in. diameter) was cut and ground to a length of 1.200 in. These parts were then EDM'd to provide a through hole 0.445 in. in diameter. The tubes were then treated in vacuum at $2500 \mathrm{~F}$ for $1 \mathrm{hr}$ prior to honing the ID to 0.464-in. diameter. The OD was then ground to 0.530-in. diameter. End plugs 0.150 in. and 0.050-in. thick were machined from arc-cast tungsten bar stock which had been ground to a diameter of 0.462 in. The tubes and end plugs were dye-penetrant inspected before hydrogen treating at the same conditions as the fuel forms. After this treatment, the cladding components and the fuel forms were assembled and gas-pressure bonded at $3100+\mathrm{F}$ and $30,000 \mathrm{psi}$ for $2 \mathrm{hr}$. The pressurizing gas was removed while at temperature. Following the bonding operation, the pellets were ground to the specifications of NASA Drawing CF 351044.

Thermal Cycling of the Enriched Fuel.Pellets. Four pellets were selected for thermal cycling. These were designated at E4, E5, E7, and E8. Pellets E4 and E5 showed no defects by helium leak check and dye-penetrant inspection. Pellet E7 showed heat-check marks on the thick end and E8 showed heat-check marks on both ends. These were removed by abrading prior to thermal cycling and could not be detected by dye-penetrant inspection or helium leak check.

Pellet E8 showed a pattern of cracks on the thin end resembling the beat checking after one cycle. These became progressively worse during the cycles and at 25 cycles some cracking up the sides was evident. Pellet E4 showed a faint indication of a crack on the thin end at the periphery after 5 cycles. After 25 cycles, the crack extended about 0.06 in. into the thin 
end and about 0.04 in. along the $O D$. The crack did not increase in length during cycling but did show a tendency for an increase in width. Pellet E5 showed a crack about $0.09 \mathrm{in}$. long in the center of the thin end after 25 cycles. This crack did not increase in length but like the crack in Pellet E4 became wider during the remaining cycles. Pellet E7 showed no defects during the thermal cycles. The percent growth and weight loss curves are shown in Figure 44. Pellets E4, E5, and E7, which appeared satisfactory throughout the thermal cycling, showed nearly identical growth and weight loss. Pellet E8, which showed cracking after the first cycle, showed similar weight loss but considerably less growth. The thermal cycle for these specimens was the same as that for the previous group in which 20 min is taken to reach $2000 \mathrm{~K}$ rather than $10 \mathrm{~min}$ used in the early work.

Metallographic examination of these pellets indicated that E4, E5, and E7 appeared very similar in internal structure of the tungsten and the $\mathrm{UO}_{2}$. The tungsten was coarser grained and the $\mathrm{UO}_{2}$ more porous and fragmented than the other pellet, E8, which showed only 1.2 percent growth on the diameter. The $\mathrm{UO}_{2}$ in this pellet was from another lot that had not been decoated. Little or no fracturing of the $\mathrm{UO}_{2}$ was evident in this specimen after 100 thermal cycles. In Figures 45, 46, and 47 are shown typical sections from Pellets E4, E5, and E7. Metallographic sections of E8 are show in Figure 48. Areas of E8 showed complete lack of bond between the clad and the core after thermal cycling. Figure 49 shows photomicrographs of one of the pellets that was not thermal cycled.

Although the results of this thermal-cycle study were not as desirable as those obtained previously from a tungsten-clad specimen, the data for three of the specimens were very consistent both in growth and weight loss. 
$\times$ Specimen No. E 4

- Specimen No. E 5

- Specimen No. ET

$\triangle$ Specimen No. E 8

링

- Coincident Points
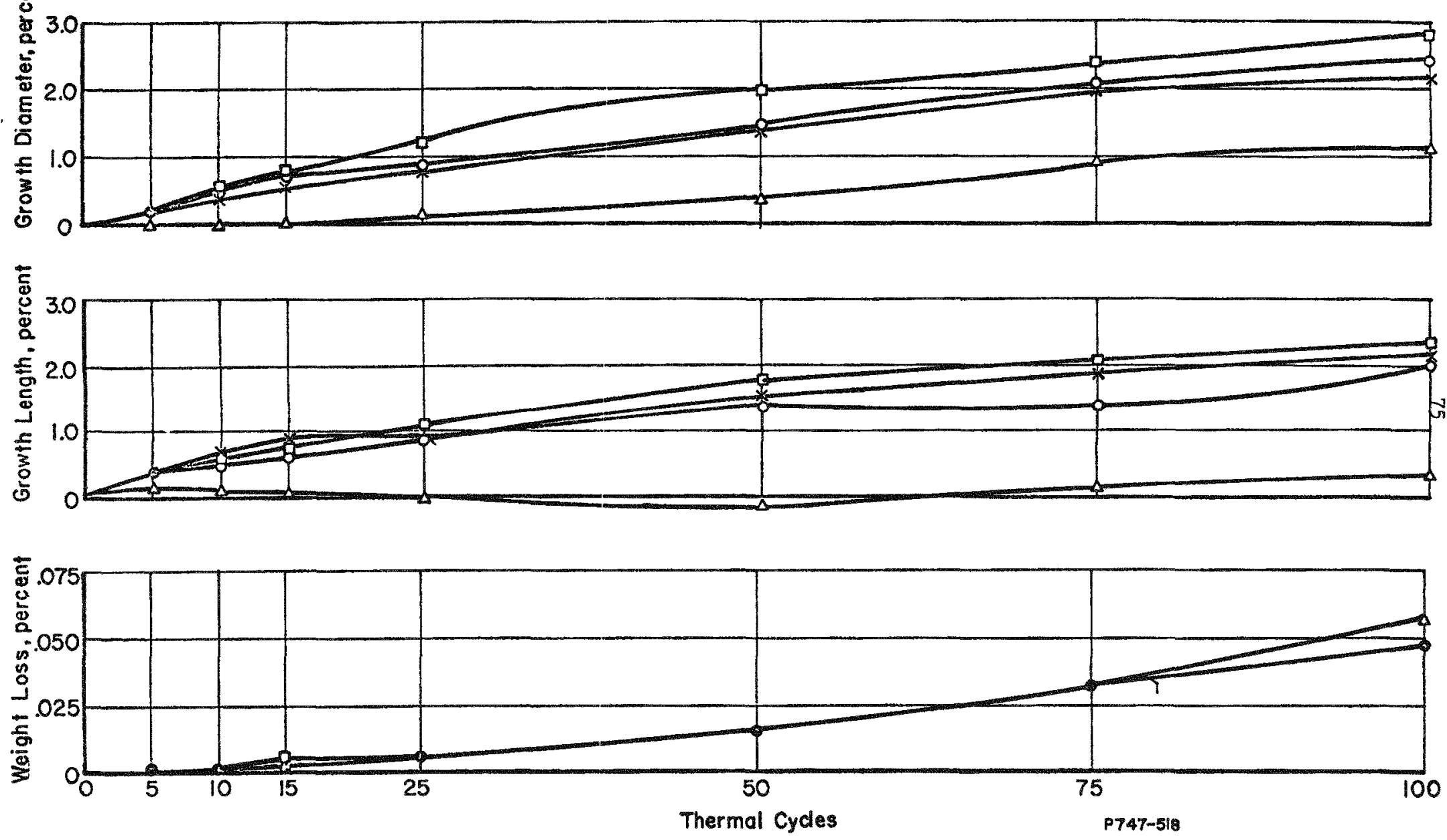

FIGURE 44. PERCENT GROWTH AND WEIGHT LOSS CURVES FOR ENRICHED THERMAL CYCLE SPECIMENS 


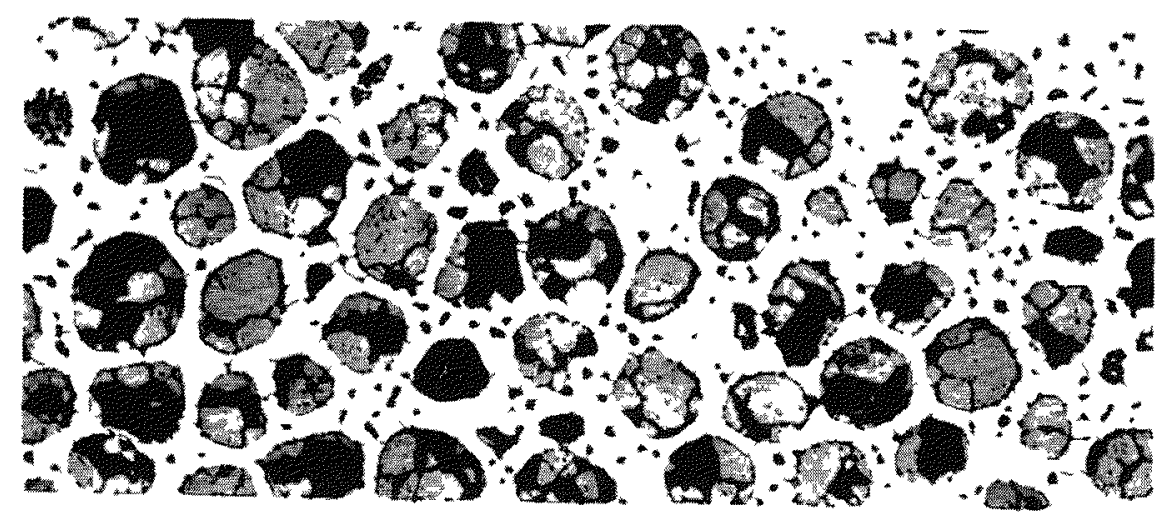

a. Clad and Core Structure

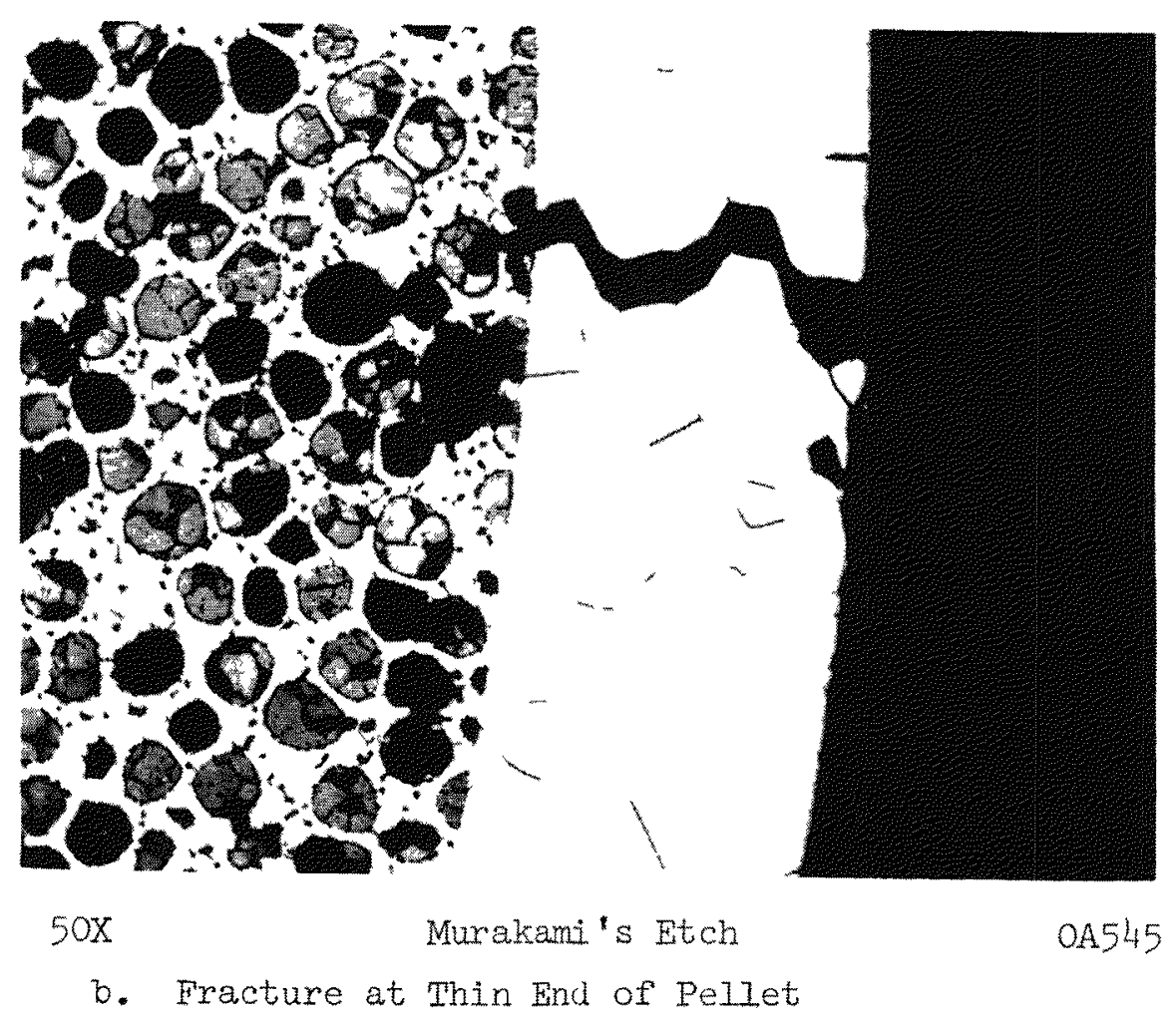

FIGURE 4\%. PELIET E4 AFTER I00 THERMAI CYCIES 


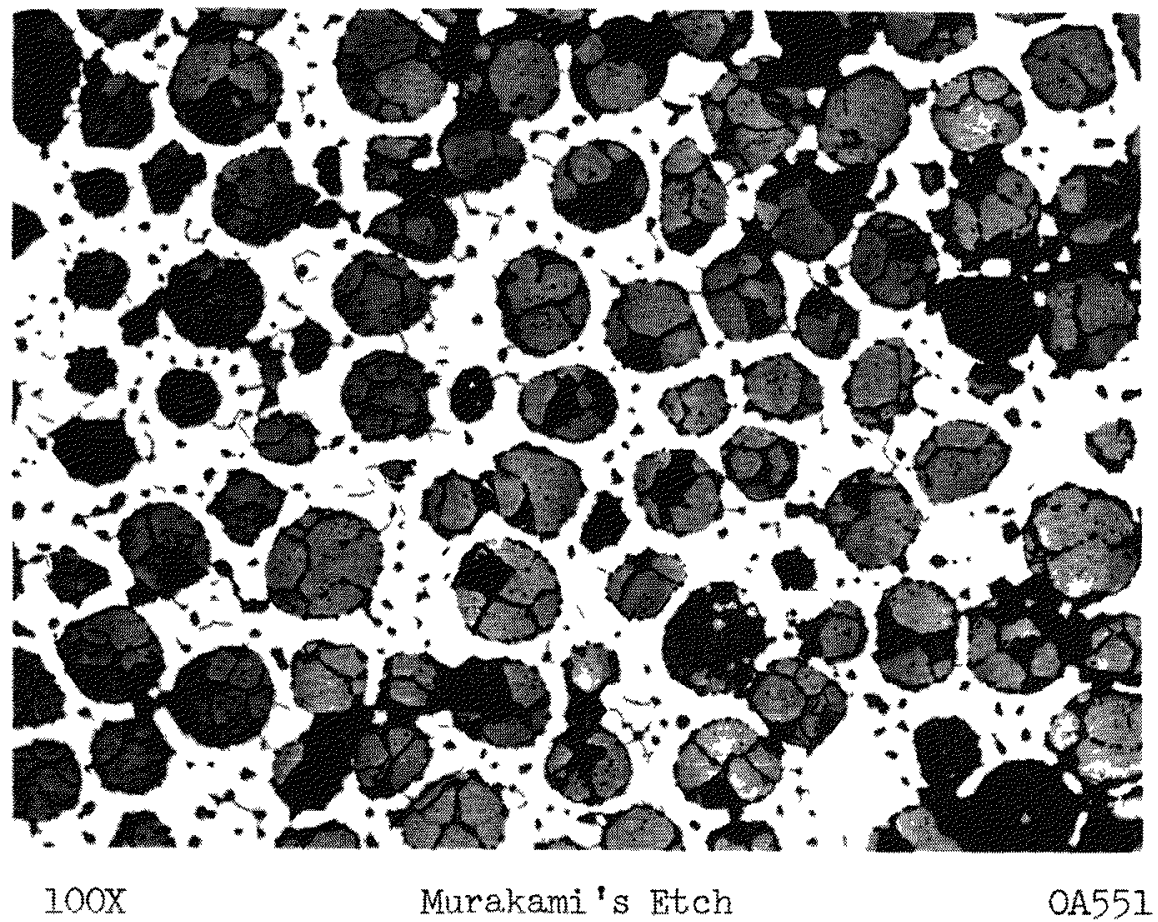

a. Typical Core Structure

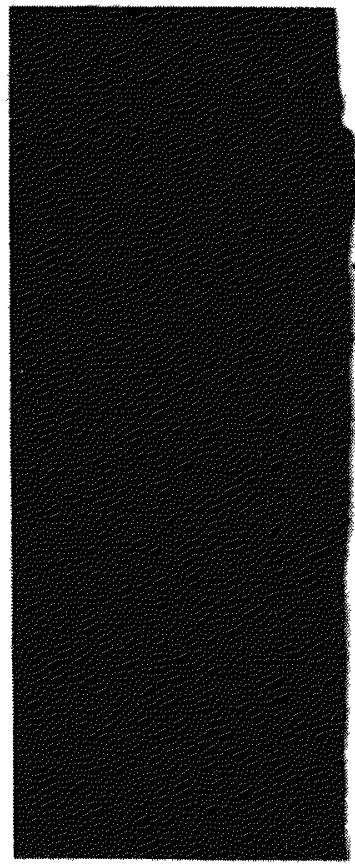

$100 \mathrm{X}$

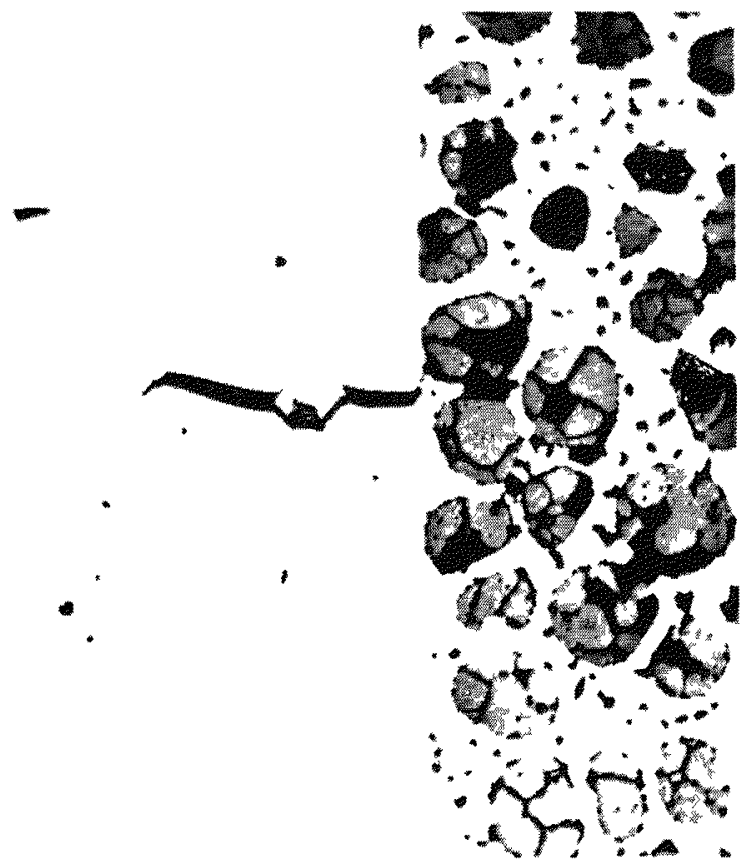

As Polished

$0 A 548$

b. Crack in Thin End of Pellet

FIGURE 46. PELIET E5 AFTER 100 THERMAL CYCTES 


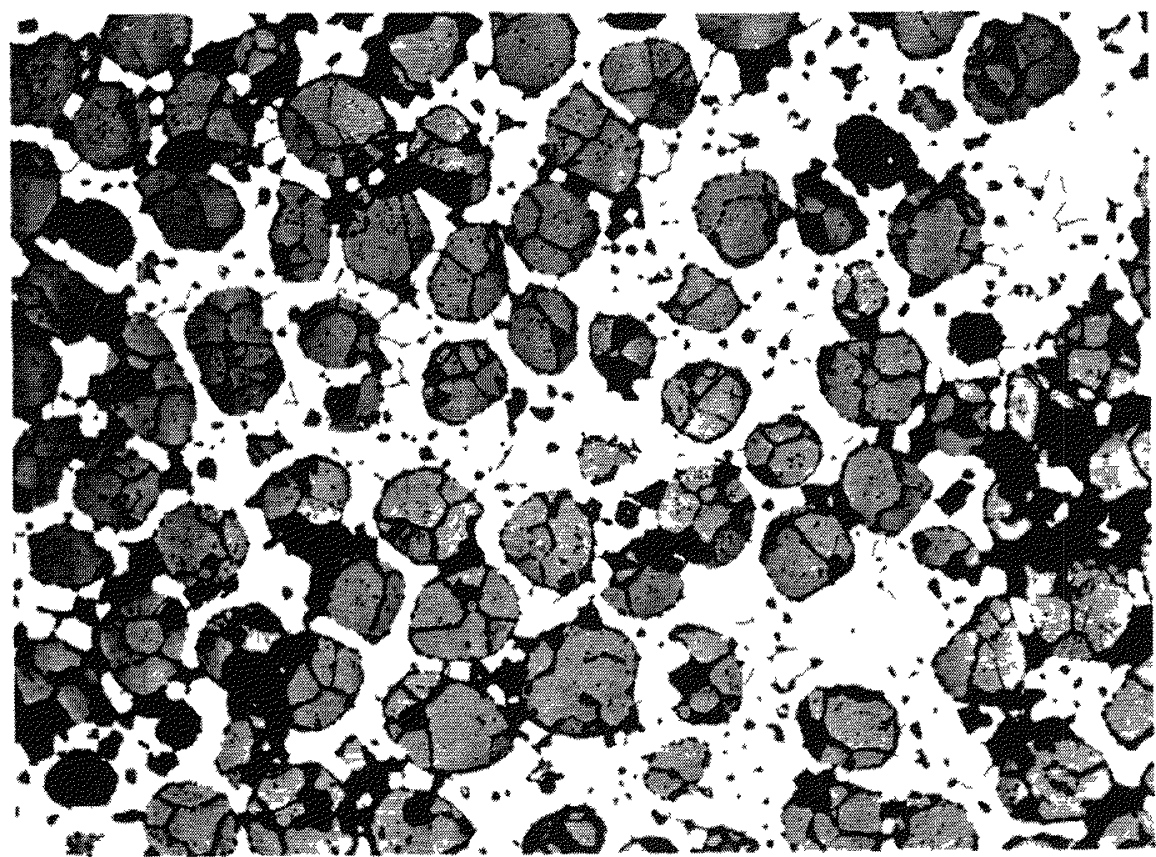

$100 x$

Murakami's Etch

a. Core structure

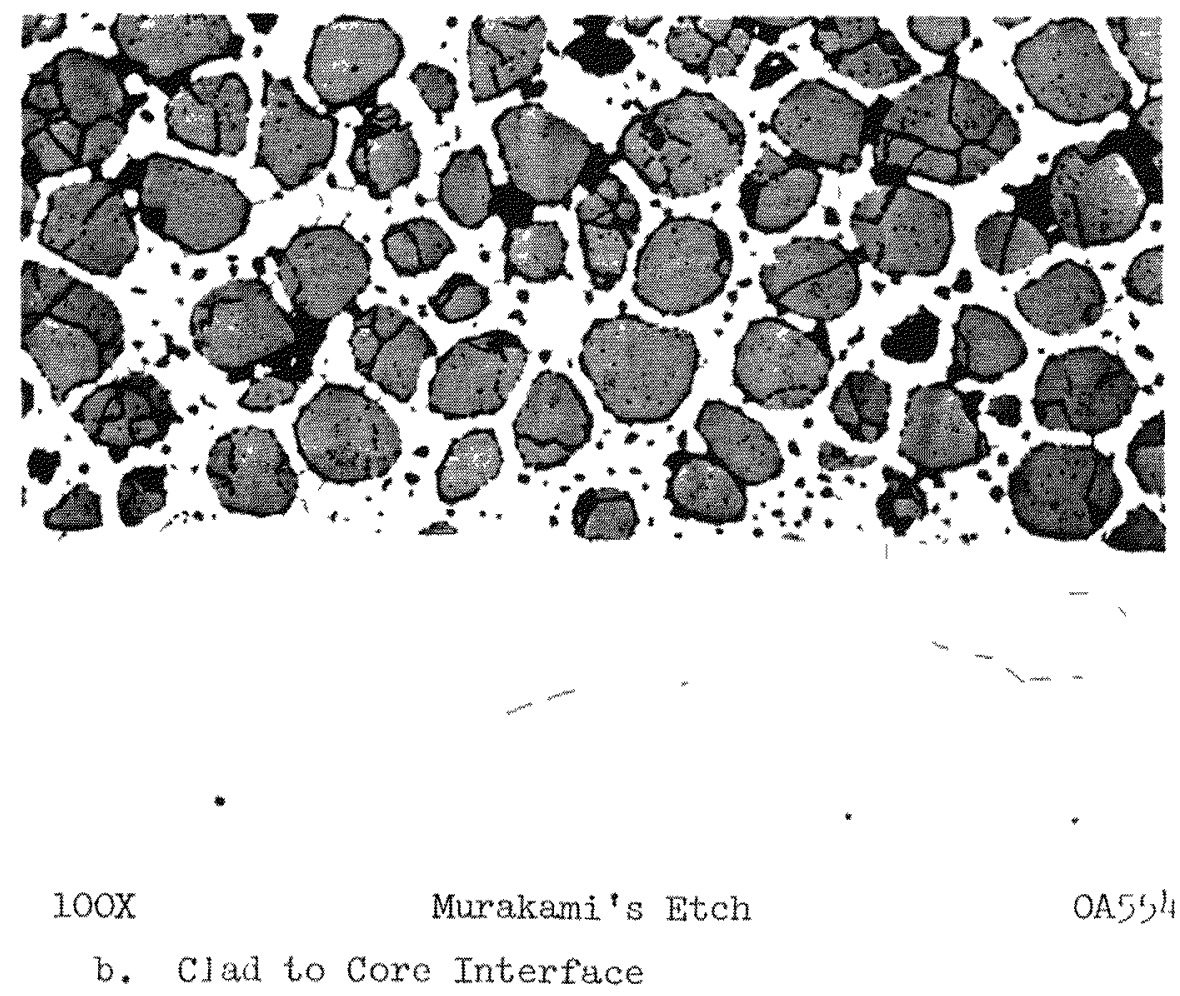

FIGURE 47. PELIET E7 AFTER 100 THERMAL CYCLES 


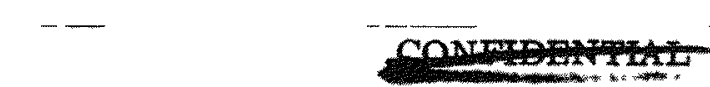

79

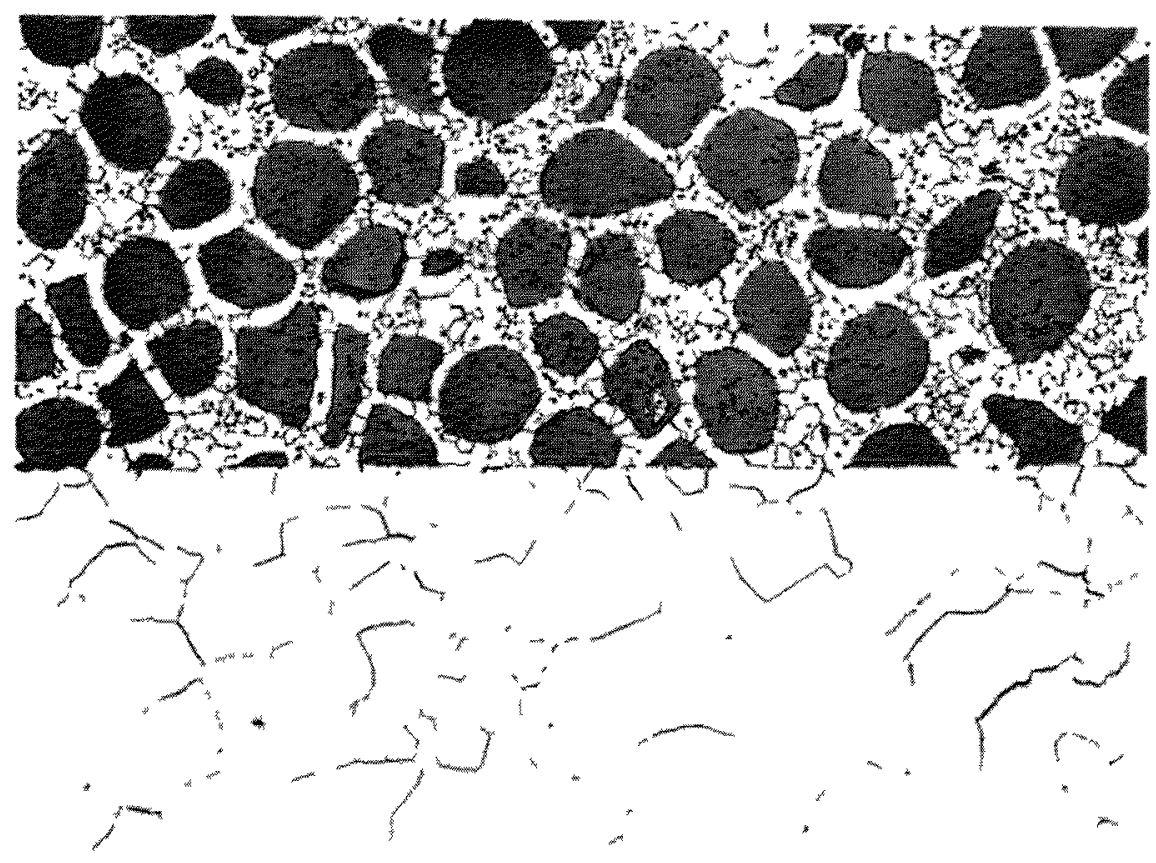

$100 x$

Murakami's Etch

$0 A 562$

a. Clad and Core structure

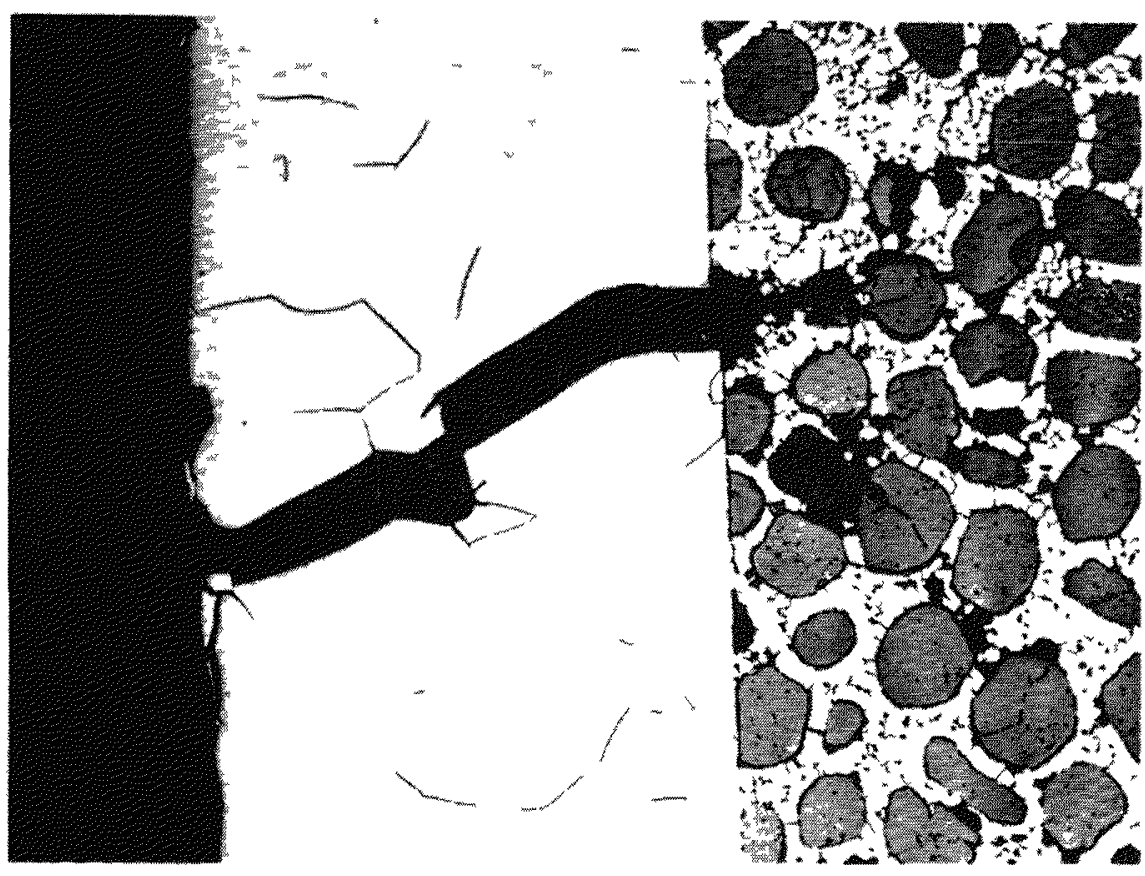

$100 x$

Murakami's Etch

04561

b. Typical Cracking in $\mathrm{Clad}$

FIGURE 18. PELLET E8 AFTER 100 THERMAL CYCLES

The $\mathrm{UO}_{2}$ in this pellet was from a lot

that had not been decoatod. 


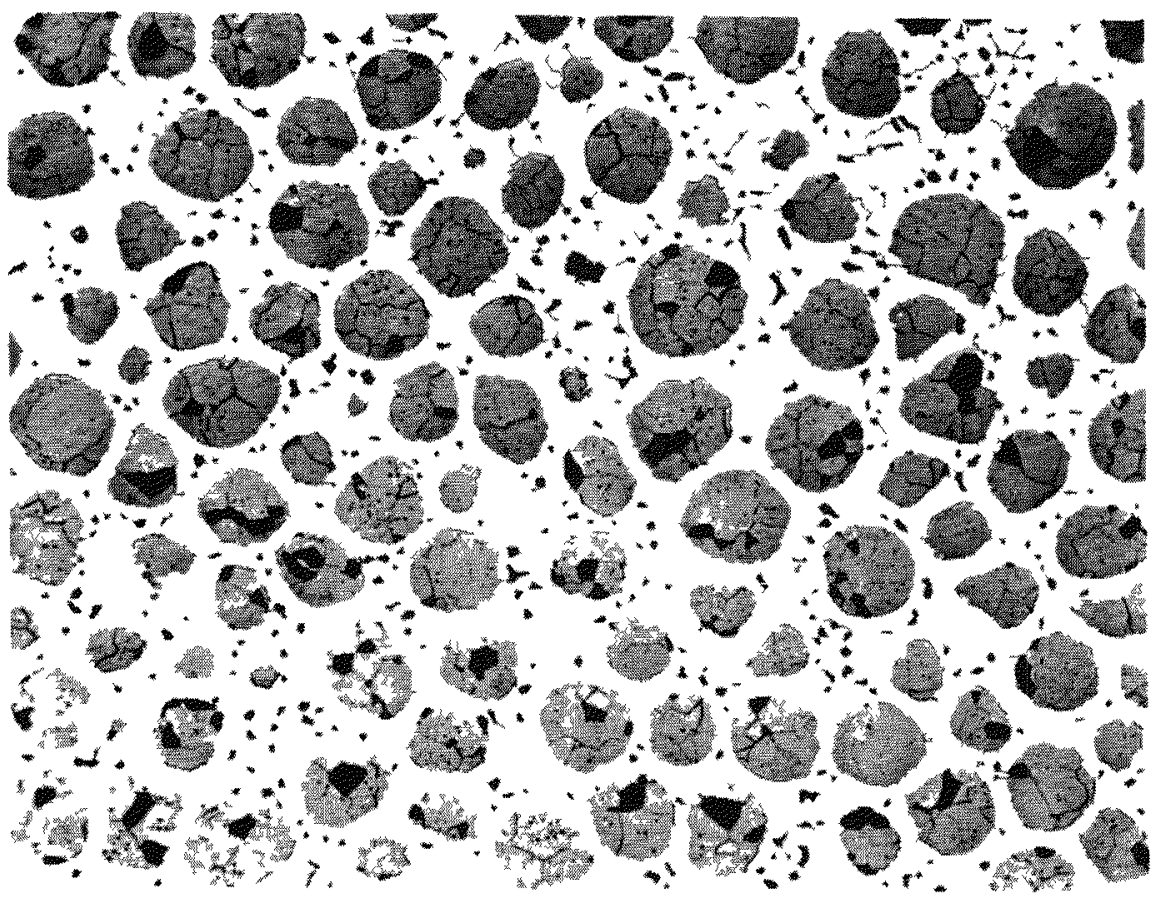

$100 \times$

Murakami's Etch

OA539

a. Typical Core Structure

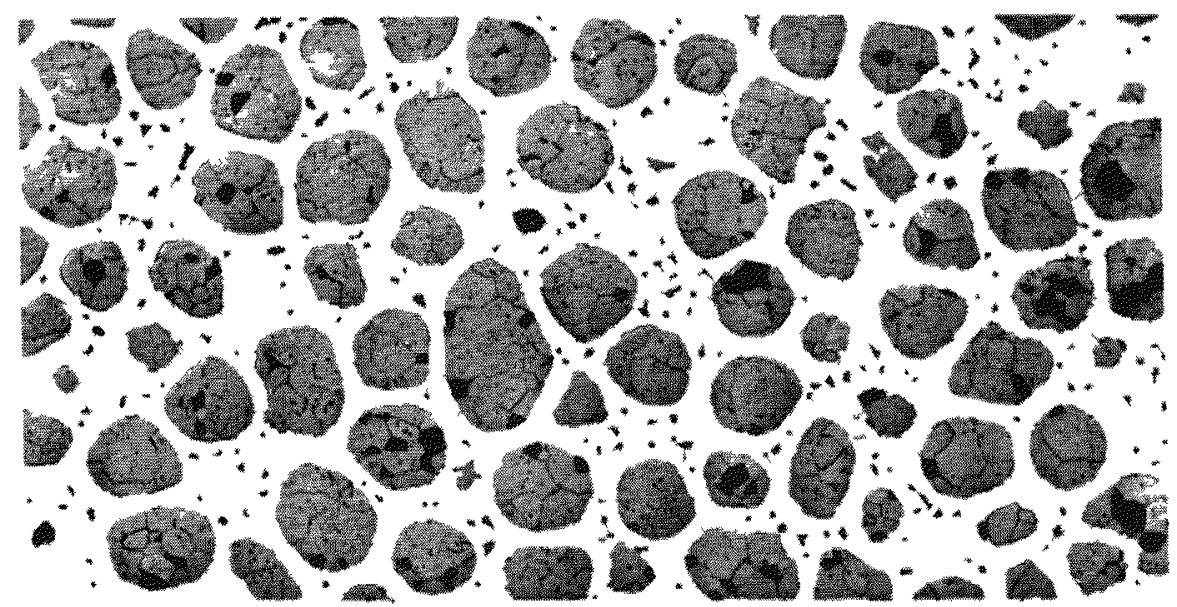

$100 \mathrm{X}$

Murakami's Ftch

$O A>38$

b. Clu to Core Interface

PIGURE 49. MTCROSTRUCIURE OF PLITET EI

This pelzet was not thermal cycled. 
The remaining specimen showed fracturing of the outer clad but showed far less growth on length and diameter although the weight loss for all four pellets was nearly identical.

\section{Supporting Studies}

In addition to the fabrication of the clad fuel pellet, Battelle was responsible for the fabrication of the tantalum-10 w/o tungsten containment vessel and the encapsulation of the clad fuel pellet within the containment vessel. This required the development of brazing techniques for attachment of the tantalum-10 w/o tungsten thermocouple wells to the clad fuel pellet and to the containment vessel itself. Development of electron beam welding procedures for the girth weld of the containment vessel also were developed.

Brazing Studies

The initial hraging studies uere conducted with tantalum-10 $\% / 0$ tungsten and tungsten specimens. The tantalum alloy specimen was prepared from a 0.75-in.-diameter rod in which four spaced holes were drilled to hold four pins of the tantalum alloy. This specimen simulated the end of the containment vessel through which the thermocouple wells pass. A tungsten specimen simulating the clad fuel pellet was made from bar stock.

Wetting studies with the tantalum alloy and the tungsten were made with the following candidate materials in vacuum: 


$\begin{array}{lc}\text { Alloy } & \text { Brazing Temperature, } F \\ \mathrm{Cb}-6 \mathrm{~V} & 4350 \\ \mathrm{Cb}-40 \mathrm{~V} & 3500 \\ \mathrm{Cb}-5 \mathrm{OV} & 3500 \\ \mathrm{Cb}-65 \mathrm{~V} & 3600 \\ \mathrm{Cb} & 4500-4560 \\ \mathrm{Ta}-3 \mathrm{Si} & 4600\end{array}$

All of the columbium-vanadium alloys wet both the tantalum-10 tungsten and tungsten-base metals. There was considerable porosity in the tantalum-10 tungsten joints but little reaction between the base metal and the brazing alloy. The wetting properties of these alloys do not appear to be exceptional; although the joint was filled, there was not much filleting around the pins which represented tubing. The columbium had excellent wetting properties, the joint was filled, there was good filleting, and little or no porosity was evident. Some reaction between the base metal and the columbium braze metal occurred. Metallographic examination of the joints made with the tantalum-3 silicon alloy indicated that silicon penetrates the grain boundaries of the base metal to an undesirable degree. Because of the possibility of producing a brittle phase, the tantalum-3 silicon alloy was discarded.

Additional brazing studies were conducted to further investigate the apparent reaction of the columbium braze with the base metal. Highpurity arc-cast columbium was used and excellent joints were made. Metallographic examination indicated that an excessive amount of a second phase was present. Joints were made using columbium from several sources with similar results. It was determined that a higher vacuum during brazing was required to eliminate this second phase. The pumping system is capable of less than 
$10^{-5}$ torr at room temperature. A typical pressure at the brazing temperature of $4525 \mathrm{~F}$ was $2 \times 10^{-4}$ torr. A time of $5 \mathrm{~min}$ at brazing temperature was found to be adequate for good joints without excessive alloying with the base metal.

Because of the encouraging results with the columbium braze, no further work was done in this area until actual assembly of the containment vessel assemblies. The final brazing work on this program substantiated the results of the preliminary study.

\section{Electron-Beam-Welding Studies}

The girth joint shown on the drawing of the containment vessel assembly (Figure 1) was made by electron-beam welding. Early in the study an older type electron-beam welder with a relatively wide beam was used. This machine, although capable of producing a satisfactory joint, produced a wide weld and about 0.060 in. shortening of the capsule. When the final containment vessel assemblies were fabricated, another welder had been purchased and this unit was capable of producing a more desirable weld. The weld beam was considerably narrower, thus producing less heating of the clad pellet during welding. The shortening of the vessel was reduced to about 0.008 in. during the welding process.

The welds were accomplished by holding the two portions of the containment vessel in a special fixture. The larger end containing the clad pellet was held in a rotating chuck, and the other end containing the fill tube and the support spring was axially loaded to maintain contact at the butt joint area. Prior to the actual welding operation, the girth joint was tack welded in three places by the electron beam to prevent any shifting 
during welding. The containment vessel was then rotated for 1 revolution under the electron beam. The welding parameters to achieve full penetration were:

$\begin{array}{ll}\text { Acceleration voltage } & 30 \mathrm{kv} \\ \text { Beam Current } & 50 \mathrm{ma} \\ \text { Rotation speed } & 6 \mathrm{rpm}\end{array}$

After the wela was about 70 percent complete, the power was manually reduced to prevent excessive penetration of the heated containment vessel.

The actual welds are discussed in the section on assembly of the containment vessel assemblies.

Fabrication of Containment Vessel Assemblies for Thermal Cycling

To evaluate the design and fabrication procedure for the containment vessel assembly and to determine its behavior during thermal cycling, three assemblies were fabricated. The original intent was to process and evaluate only one assembly which contained a clad pellet containing depleted $\mathrm{UO}_{2} \cdot$ However, the growth characteristics of this clad pellet were greater than expected and two additional assemblies containing clad pellets with enriched $\mathrm{UO}_{2}$ were fabricated and evaluated. The fabrication procedures and results of the thermal cycle tests are discussed below.

Fabrication and Thermal Cycling of the First Mock-Up Containment Vessel Assembiy

T he containment vessel assembly containing the depleted $\mathrm{UO}_{2}$ pellet was fabricated to the specifications shown in the drawing in Figure 1. The clad fuel pellat was processed in the Identical manner as the enriched pellets 
described in a preceeding section of this report. The only differences were In the fuel, the grinding of the positioning lugs on each end of the pellet, and the machining (EDM) of the recesses for the thermocouple wells.

The pellet and the thermocouple wells were brazed into the containment vessel using the procedures developed early in the program. The exact position of the pellet within the assembly was maintained by placing the pellet on a pedestal of Ta-10W material. The columblum braze rings were placed on top of the pellet and a smali amount of adhesive that completely burns off during brazing was applied tc maintain the position of the braze material. The capsule was slipped over the pellet and the thermocouple wells positioned. Four more rings of braze material were placed at the entry of the wells Into the capsule. The assembly was then brazed at 4525 F for 5 minutes.

Following brazing, the tantalum-10 tungsten support spring, the domed end closure and the brazed component were assembled and electron beam welded. The fill tube had been brazed in place prior to this operation. The braze foints and the weld were visually inspected prior to pressure checking at 10,000 psi helium pressure. This pressure check was performed in a blast-proof bunker. The specimen was imme rsed in alcohol and observed visually during the entire pressure checking operation. No leaks were detected. The leak-tight fittings were left in place and used for the back filling with helium to 3 psia. The backfill with helium was accomplished by evacuating and flushing with helium 5 times followed by careful filling exactly to 3 psia. A large dial gage was used to determine the internal pressure. A valve at the outlet of the fill tube was closed and the containment vessel and the valve separated from the system. The fill tube was flattened 
about $1 / 4 \mathrm{in}$. back from the end of the containment vessel and this was then cut in the flattened area and welded simultaneously in an electron beam welder. This containment vessel assembly was then thermal cycled 100 times to a temperature of $1770 \mathrm{~K}$. Ten minutes were taken to reach $500 \mathrm{C}$ and the remaining temperature increase was accomplished in approximately 10 minutes. After holding for 5 minutes at temperature the assembly was allowed to cool to a black heat and then apply a flow of inert gas (argon) to increase the cooling rate. A total cycle time of about $\mathrm{I} \mathrm{hr}$ was required.

This mock-up containment vessel assembly showed only I minor defect during thermal cycling. This was a pin hole in one of the braze joints. No leaks through this joint were detected. No change in outside dimensions was noted, but a slight weight gain ( 0.03 percent after 100 cycles) was noted. The tantalum-10 tungsten vessel apparently picked up some oxygen during the cycling.

The mock-up containment vessel assembly was sectioned after thermal cycling. The pellet had grown about 4 percent on the diameter and about 4.8 percent in length. This growth was sufficient to cause contact between the clad pellet and the wall of the containment vessel. It was also evident that the positioning Iugs at the thin end of the pellet had expanded into the wall of the vessel and had restricted freedom of movement of the pellet in the vesse1. This is shown in Figure 50a. A photomacrograph of the clad pellet at higher magnification is shown in Figure 50b. This shows that the cladding of the fueled pellet cracked and chipped out easily during metallographic preparation. 


\section{7}

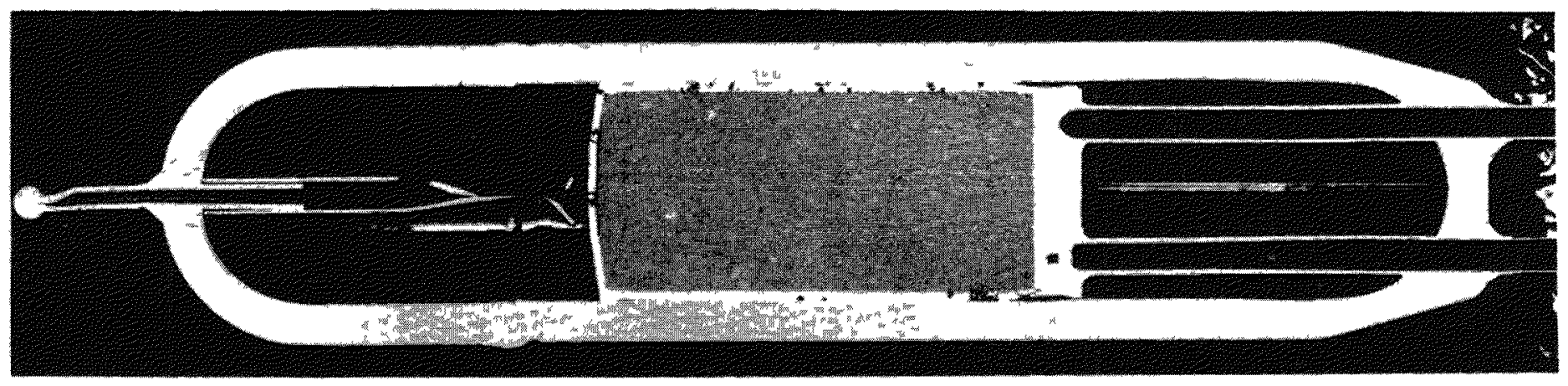

$2 \mathrm{X}$

OA710

a. Containment Vessel After Thermal Cycling

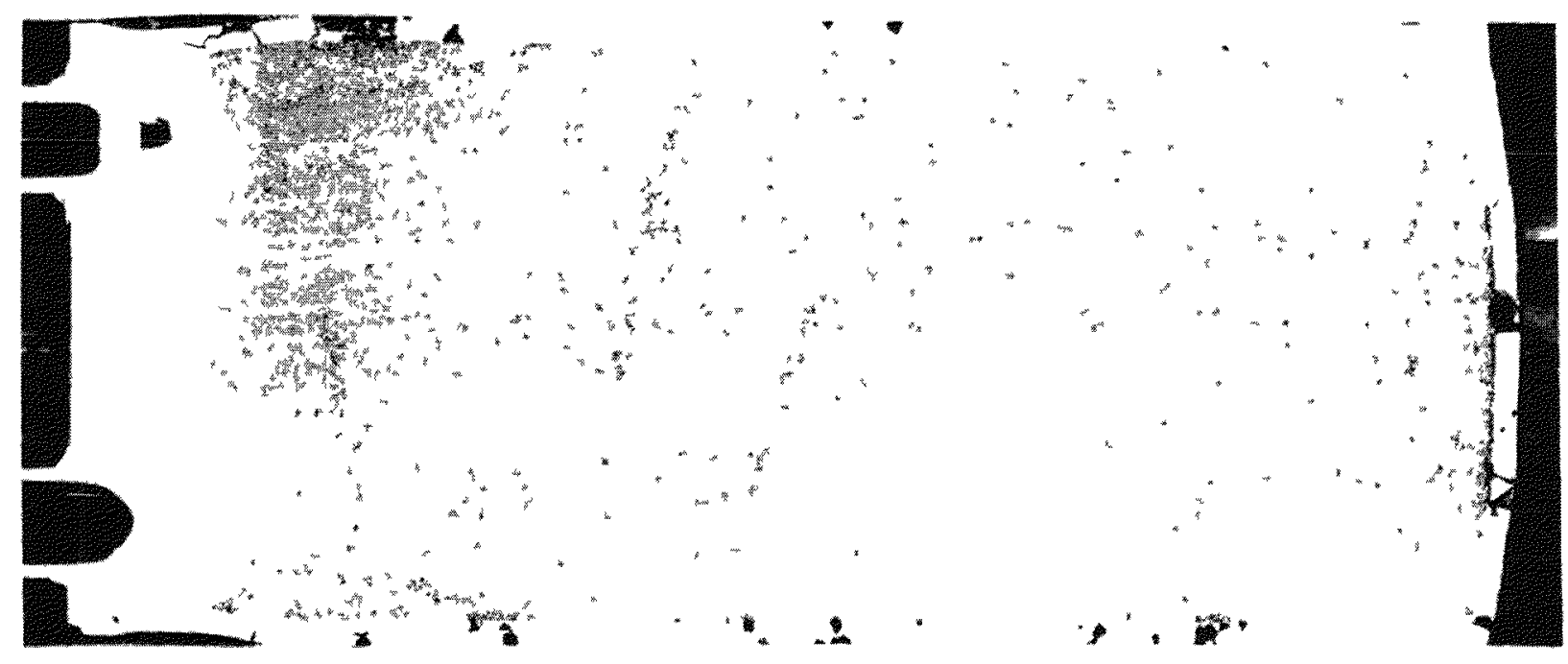

$5 X$

OA711

b. Enlarged View of Clad Fuel Pollot

FIGURE 50. MOCK-UP CONIAINMENT VESSEL ASSEMBLY AFTFR 100 THERMAL CYCLES TO $1770 \mathrm{~K}$ 
The braze joints of the thermocouple wells through the vessel were satisfactory but the braze joints between the tip of the thermocouple wells and the clad pellet were separated. The crack that existed in this location was very narrow measuring only 0.0001 to $0.0004 \mathrm{in}$. in width. This is shown in Figure 51. Figure 52a shows a portion of the core, the clad, and the clad in contact with the containment vessel wall. A brittle thin layer is apparent on the exterior of the tungsten-clad fuel pellet. This was also noted in areas not in contact with the tantalum-10 tungsten containment vessel and must have resulted from a reaction with gases within the vessel. This same reaction zone can be seen to a lesser degree in Figure 53a. Since the containment vessel show in Figure 53 a was cycled only 25 times, the width of the zone appears to be dependent upon the time at temperature. High-purity helium was used as the fill gas, and trace impurities would be gettered by the containment vessel. The only other source of products to cause this reaction would be from the fuel form after cracking of the clad had occurred. Figure $52 \mathrm{~b}$ shows the core at higher magnification. A considerable gas exists around each $\mathrm{UO}_{2}$ particle. The electron-beam weld and the closure of the fill tube appeared satisfactory after thermal cycling.

Fabrication and Thermal Cycling of Modified Containment Vessel Assemblies

The results of this first thermal-cycle test of the containment vessel assembly indicated two areas that required further investigation. These were the growth characteristics of the fuel pellet in the assembly and an improved method of centering the pellet within the vessel. The lugs on the clad pellet, particularly on the end with the thin clad, expand into the vessel wall and restrict growth in the longitudinal direction. 


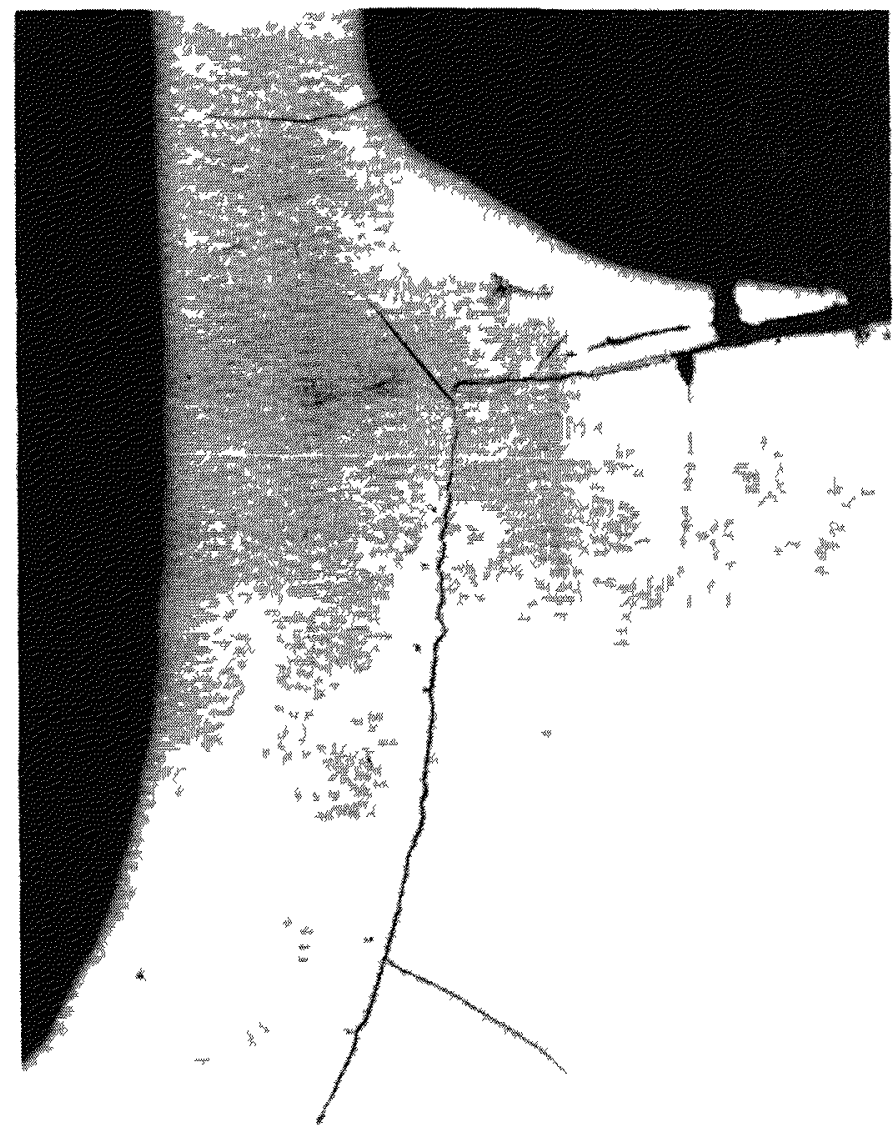

$75 X$

50 Lactic, $30 \mathrm{HNO}_{3}, 5 \mathrm{HF}$

OA723

FIGURE 51. BRAZE OF THERMOCOUPLE WELL TO CLAD PELTET AFTER 100 THERMAI CYCTES

Note the separation between the thermocouple well and the pellet. 


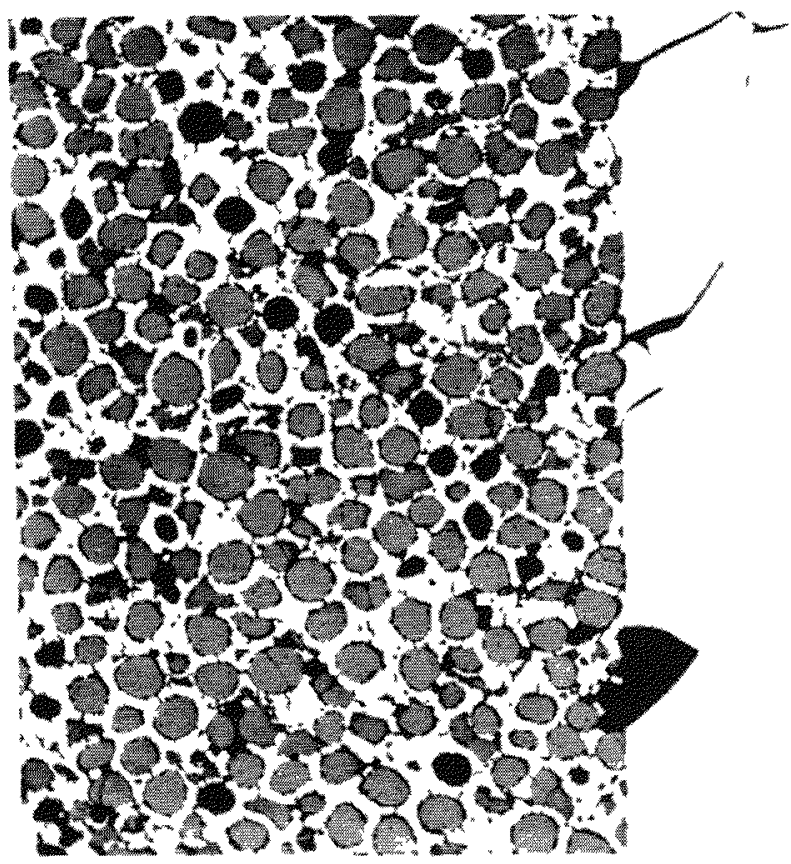

$75 x$

a. 50 Lactic, 30 HNO

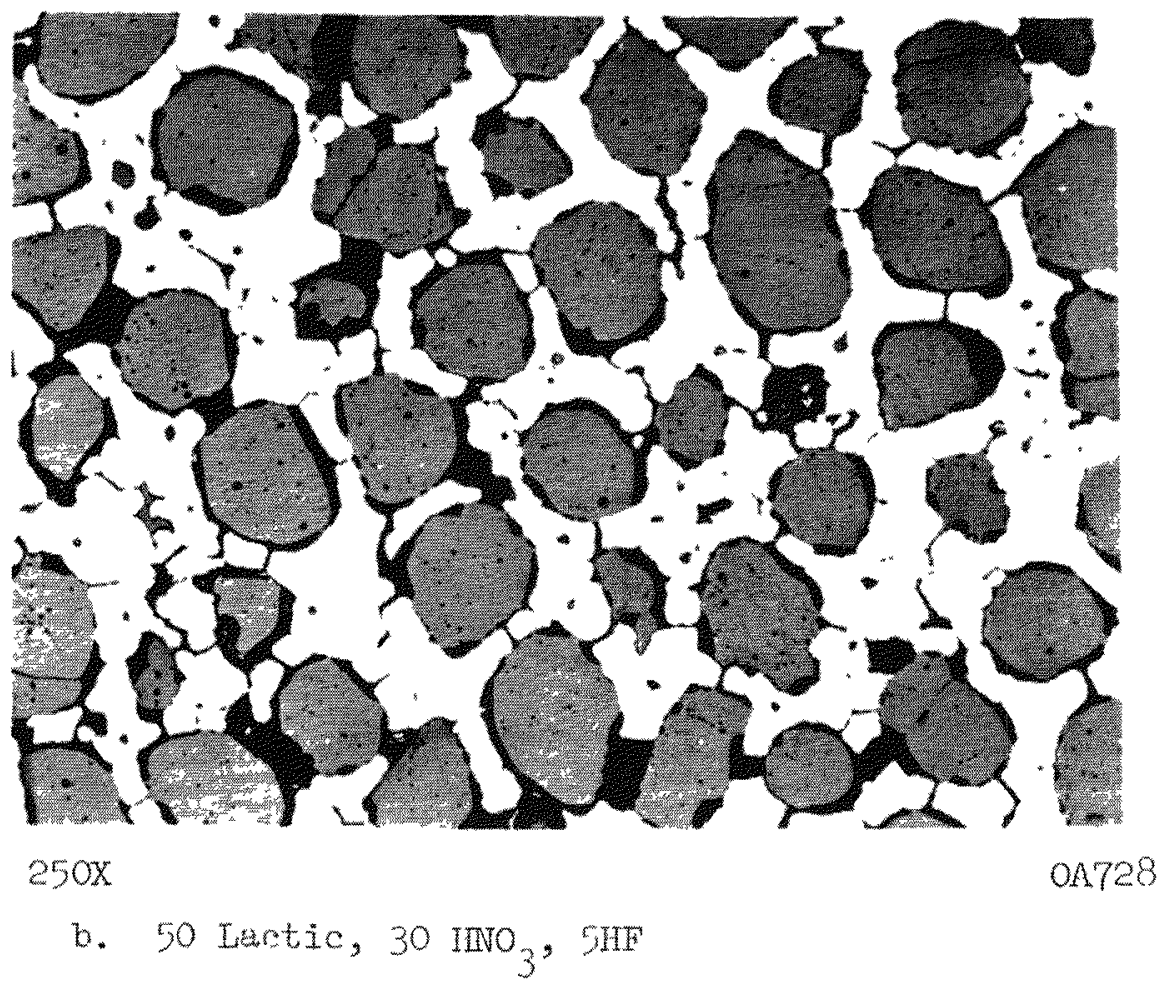

FIGURE 52. CLAD EUEL PETLET STRUCTURE AFTER THERMAL CYCLING 
91
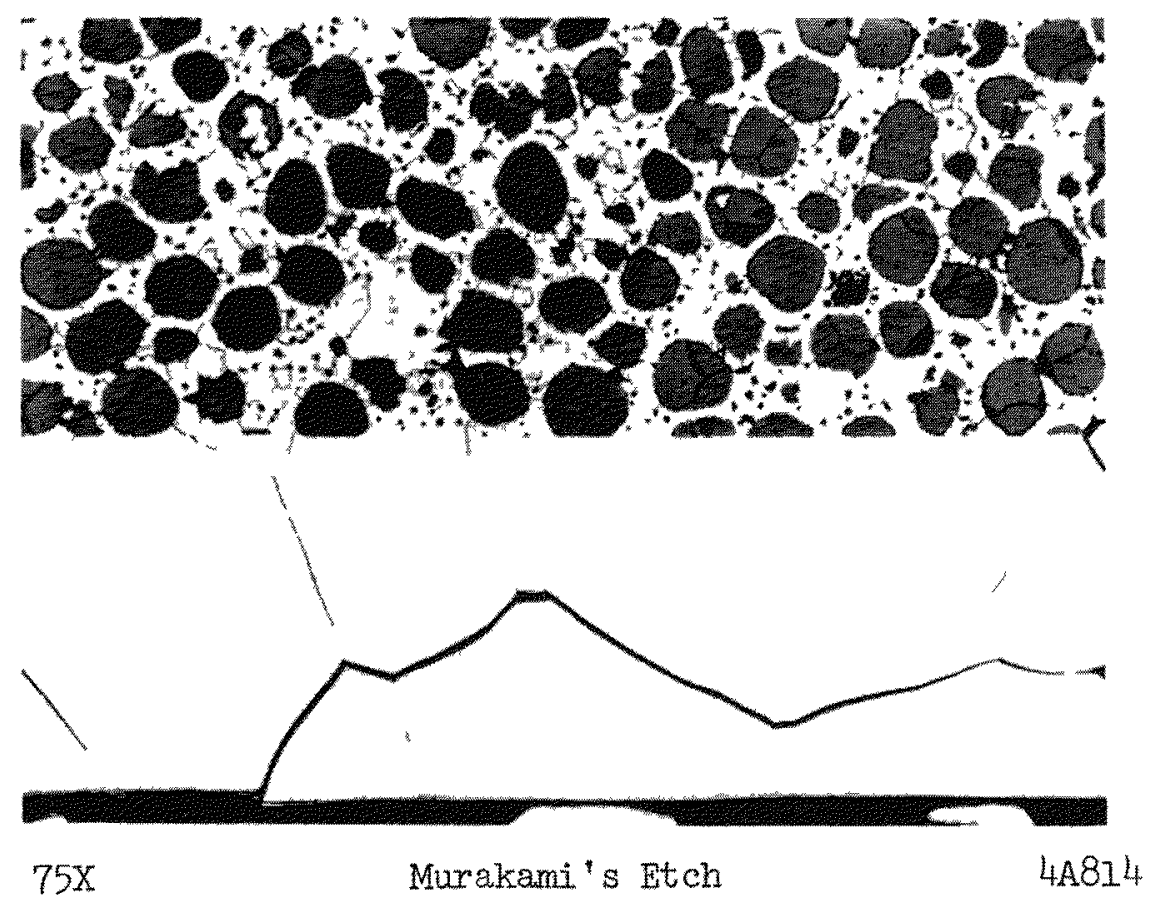

a. Clad to Corn Interface

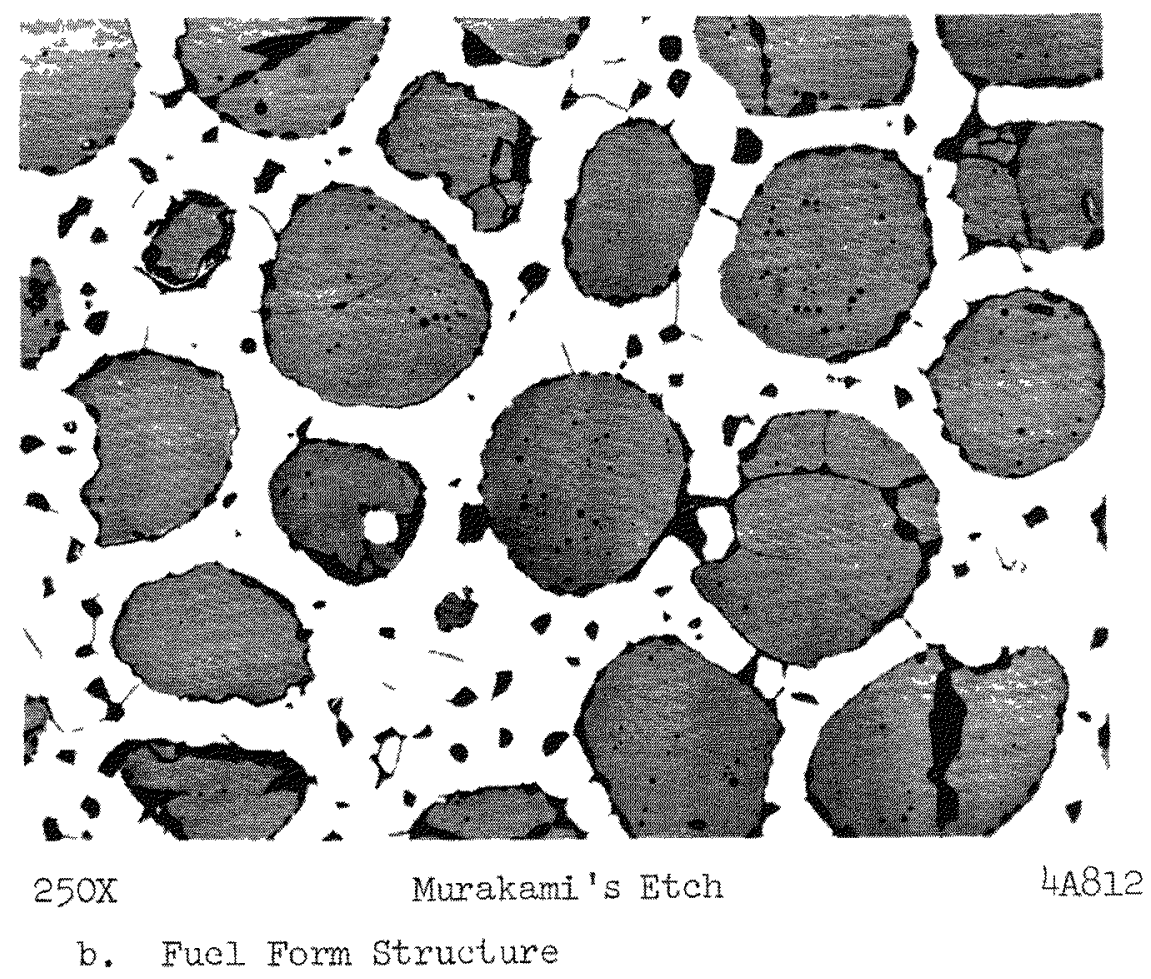

FIGURE 53. STRUCTURE OF PELLET ELO FOLLOWING 25 THERMAL, CYCLES IN A CONTAINMENT VESSEL ASSEMBLY 
To further investigate these two areas, two additional containment vessel assemblies containing enriched fuel pellets were fabricated. Two different approaches for positioning of the pellet were evaluated, and the relation of pellet temperature to the vessel temperature was determined by placing a thermocouple in one well in each vessel.

The clad pellets for these two containment vessel assemblies contained enriched $\mathrm{UO}_{2}$. Both of these pellets (Pellets $\mathrm{E} 3$ and ElO) had heatcheck marks from grinding on the thin end, and Pellet ElO also had a crack on the thin end. The pellets were abraded lightly in an attempt to remove the heat checking but following brazing of the pellets into the containment vessels, the heat checking was again evident. Pellet $\mathrm{E} 3$ had the positioning lugs removed from the thin end only, and Pellet Elo had the positioning lugs removed from both ends. During brazing, Pellet E3 was centered on the thin end by tantalum wires which were removed after brazing. Pellet ElO had two tantalum wires wrapped longitudinally about the pellet, and these wires were pigtailed at the thick end of the pellet. Both pellets were then brazed into their containment vessels by the same technique used with the previous assembly. Unavailability of the electron-beam welder required that the girth weld be made by tungsten are in an inert gas chamber. The vessels were pressure checked at $200 \mathrm{psi}$ (due to the lack of full penetration of the girth weld), backfilled with 3 psia of helium, and sealed. Prior to thermal cycling, the vessels were dye-penetrant inspected and helium leak checked.

These two vessels were thermal cycled in an identical manner to the previous containment vessel assembly with the exception that inspection was made at 10 cycles and the test was terminated after 25 cycles. A 
thermocouple was placed in a thermocouple well in each vessel and the temperature recorded to determine the relation between the interior temperature of the vessel at the pellet and the exterior temperature of the pellet used for control. The thermocouples used were tungsten -5 rhenium/tungsten-26 rhenium contained in a 0.040-in.-diameter tantalum sheath. Good agreement in temperature was obtained with no appreciable lag in the temperature of the pellet as compared to the temperature of the exterior of the pellet. Inspection of the vessels after 10 and 25 thermal cycles by dye-penetrant and helium leak-detection techniques showed no defects. After 25 thermal cycles to $1770 \mathrm{~K}$, the vessels were sectioned and examined metallographically. The pellet with positioning lugs on the thick end (Pellet E3) showed growth on the diameter of 1.2 percent and on the length of 1.7 percent. The values for the pellet with the positioning lugs removed from both ends (Pellet E10) had a 1.6 percent growth in diameter and a 1.7 percent growth in length. Metallographic examination of the sectioned vessels showed severe cracking of the tungsten clad; this appeared to be due to the sectioning operation. The other half of each pellet was removed from the vessel assembly and dye-penetrant inspected. Cracking was found to be adjacent to the sectioning plane. The remainder of the pellet, except for the heat checking on the thin end, appeared satisfactory. Photomacrographs of the vessel assembly containing Pellet ElO is shown in Figure 54. A separation between the thin end and the fuel form is very apparent. A poor bond between these two components probably existed 


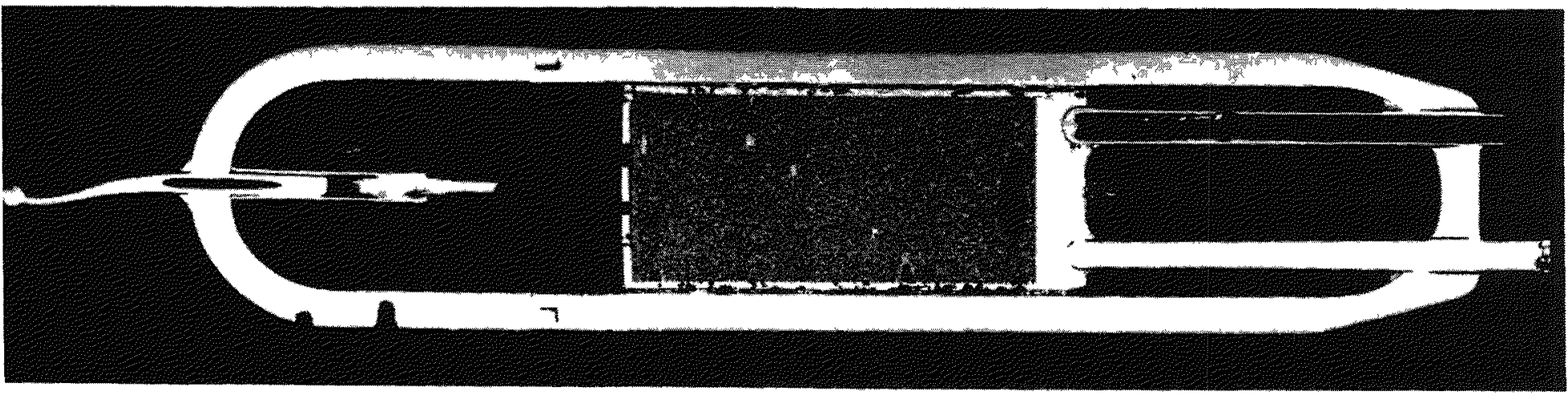

$2 \mathrm{X}$ $4 A 772$

a. Containment Vessel After Thermal Cycling

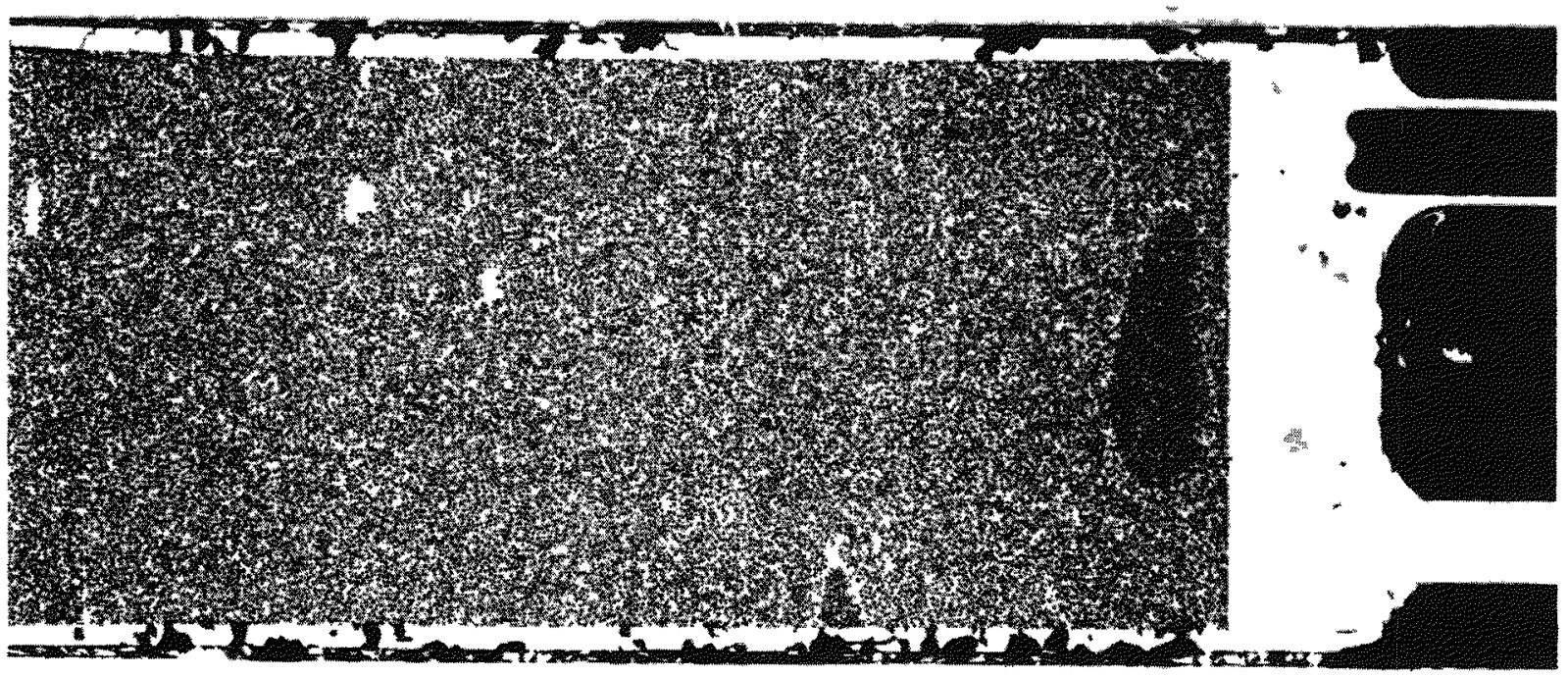

$5 X$

$4 A 773$

b. Enlarged View of Clad Fuel Pellet

FIGURE 54. CONIAINMENT VESNEL ASSEMBLY CONTAINING HINRICHED FUEL PELIET EIO AFTER 25 CYCLES TO $1770 \mathrm{~K}$ 
prior to thermal cycling since this end contained a crack, and the crack did not propagate into the fuel form. Also, some separation in the braze between the pellet and the thermocouple well was apparent. The structure of the clad fuel pellet is much superior to that of the enriched pellets cycled 100 times. Photomicrographs of this pellet (E10) are shown in Figure 53. As discussed previously, a thin brittle zone on the exterior of the tungsten clad can be seen in Figure 53a. The removal of the positioning lugs appears to be very beneficial in permitting unrestricted growth of the pellet in the containment vessel. Removal of the lugs from both ends and centering with tantalum wire is the preferred approach. This insures positive location of the pellet both during brazing and during subsequent operation.

Fabrication of Containment Vessel Assemblies for Delivery to NASA

The objectives of this porition of the program were to fabricate three containment vessel assemblies containing enriched pellets and one assembly containing a clad pellet made from depleted $\mathrm{UO}_{2}$. The objectives were met except that only two rather than three assemblies containing enriched pellets were delivered.

Initial Fabrication Procedure

The four containment vessel assemblies fabricated during this portion of the program were prepared in an identical manner to the mock-up containment vessel assembly described earlier. The thermocouple wells were brazed to the tantalum-10 tungsten vessel and the fuel pellet in the same 
operation. The stainless steel extension tubes were brazed to the thermocouple wells in a subsequent operation. In order to expedite the program schedule, this work was done prior to the evaluation (after thermal cycling) of the mock-up containment vessel assembly.

The evaluation of the mock-up assembly showed that radial growth of the fuel pellet during cycling caused the lower positioning lugs to become embedded in the containment vessel assembly. This restricted free axial growth of the pellet which would cause compressive loading of the thermocouple wells and bulging of the thin end clad as shown in Figure 54. Two approaches were considered to provide sufficient clearance in the four brazed assemblies so that contact between the vessel wall and the pellet would not occur after some growth of the pellet had taken place. One of the approaches was removal of the positioning lugs by electrical-discharge machining. This process, however, may have caused some smàll cracks in the tungsten clad. The other approach was to enlarge the vessel wall by pickling in hydrofluoric acid. The acid would attack the vessel wall but leave the pellet untouched. This approach was adopted. The vessel was protected on the exterior by a water-filled molybdenum tube sealed to the vessel assembly by a Teflon 0-ring. The vessel was placed at such an angle that the acid level would just be even with the positioning lugs at one point. The vessel was then rotated at $3 \mathrm{rpm}$ to provide even attack on the vessel wall. Sufficient material was removed so that an additional clearance of about 6 mils was provided. 
Following pickling, the vessels were vacuum treated at $1500 \mathrm{~F}$ for $1 \mathrm{hr}$ to remove any resulting residue of the pickling operation.

The vessels were then assembled with the support spring and domed end closure, electron beam welded, pressure checked at 10,000 psi helium pressure, filled with 3 psia helium pressure and sealed. This was accomplished in a similar manner to that described previously. It was then determined that the attack on the vessel wall extended at least $1 / 4$ in. above the base of the pellet. This additional clearance along this length was considered too great to be tolerated from a heat-transfer standpoint. The containment vessel assembly with the clad pellet containing depleted fuel was delivered to NASA In this condition. The modifications to the vessels containing enriched pellets are described below.

Modifications to the Assemblies Containing Enriched Pellets

The uvilificaition proposed by NASA to provide a uniform clearance along the length of the fuel pellet is shown in Figure 55. The containment vessel was cut above the pellet and the two sections separated. The positIoning lugs were removed by grinding and tantalum wire wrapped Iongitudinally along the pellet as shown. A new lower section of the tantalum-10 tungsten containment vessel was machined and the fill tube brazed into place. This procedure was accomplished for two of the vessel assemblies. The removal of the lower portion of the third assembly resulted in cracking of the clad on the fuel pellet. The fuel pellet in this vessel was brazed in one area to the vessel wall. 


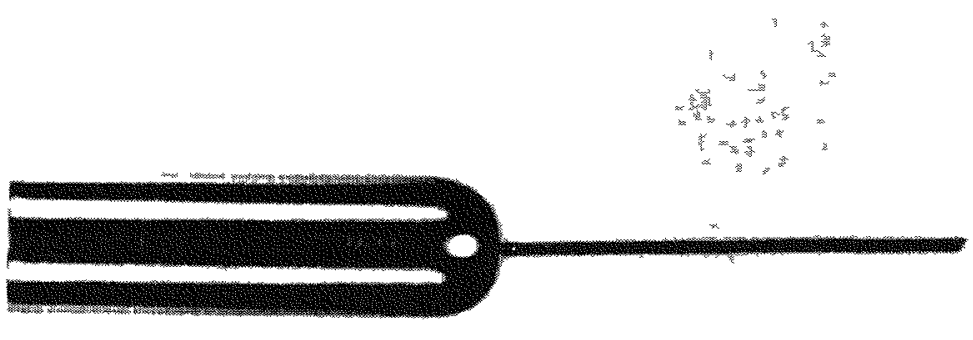

FIGURE 55. CONTAIMMENT VESSEL MODIFICATION PRIOR TO WELDING 
Electron beam welding of the vessels resulted in danage to the thermocouple wells because of excessive penetration during welding. This occurred on both vessels modified as shown in Figure 55. These two vessels were cut open and the pellets removed. Pickling in hydrofluoric acid to remove the ends of the thermocouple wells resulted in cracking of the clad in one pellet. The thermocouple wells were removed from the other pellet by EDM. The pellet cracked by pickling and the pellet cracked during removal of the Iower portion of the vessel assembly were ground to remove the cladding and reclad in accordance with the established procedure. These pellets were then ground to size without positioning lugs and the recesses for the thermocouple wells EDM'd in the thick end. The design of this recess was modified to prevent flow of the columbium-braze material on the top of the pellet. This new design is shown in Figure 56. This design also positively positions the braze ring so that there would not be any movement, during assembly for brazing.

These three pellets, two of which had been re-clad were wire wrapped with tantalum wire and assembled into new containment vessel assemblies with new themocouple wells and prepared for brazing. Excessively high temperature during brazing resulted in melting of the molybdenum boat used to contain the assemblies and resulted in loss of the three containment vessels. The pellets were removed and examined. Two of the pellets had pullout of grains on the tnin end of the pellet. Attempts were made to patch these by densifying tungsten powder onto these ends by gas-pressure bonding. This approach was not satisfactory so the tungsten clad was removed by grinding and both pellets reclad. After the clad had been bonded, the pellets were machined and inspected. 

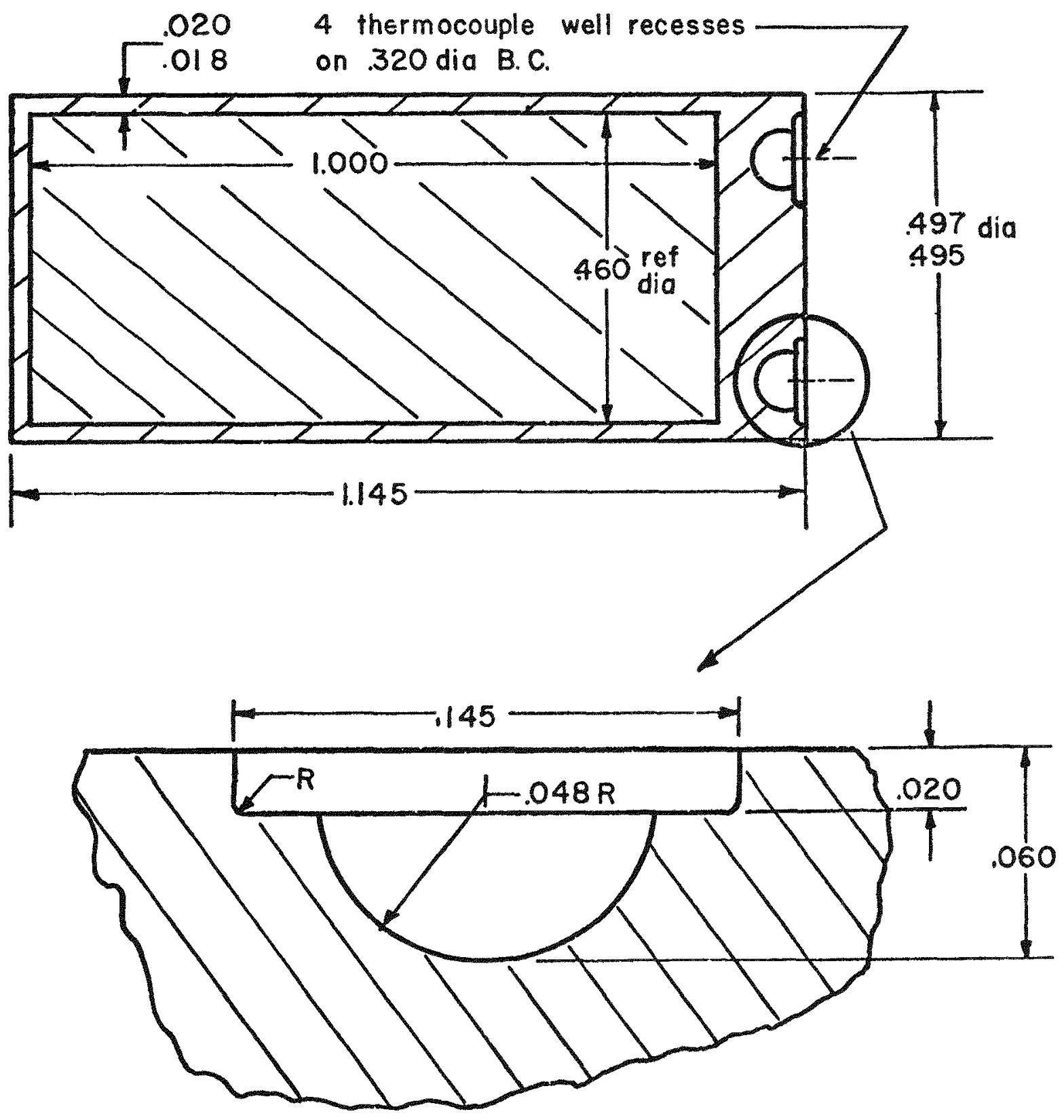

$P 747-515$

FIGURE 56. CLAD FUEL PELLET INCORPORATING MODIFIED RECESSÉS FOR THE THERMOCOUPLE WELLS 
101

The three pellets and new themnorouple wells were again assembled Into new containment vessel assemblies and brazed. The stainless steel extension tubes were also brazed into place. The domed end closures together with the support springs were assembled and electron beam welded onto the portion of the vessel containing the pellet and the themocouple wells. During pressure testing, the thermocouple wells collapsed on two of the vessels. Examination of the material used in the fabrication of the thermocouple wells indicated that the material was unalloyed tantalum and not tantalum-10 tungsten as believed.

These two vessels containing the collapsed thermocouple wells were EDM'd to remove the thermocouple from the vessel and to free the pellet. The tips of the thermocouple wells were removed from the thick end of the pellet by EDM and examined for cracking by dye-penetrant inspection and macroscopic inspection at 30x. These pellets were assembled into the containment vessel after wrapping with tantalum wire together with new thermocouple wells of tantalum-10 tungsten and the columbium braze material. One assembly was irreparably damaged during brazing and was scrapped. The other vessel was brazed satisfactorily. The stainless steel extension tubes were copper brazed into place. The vessel was then assembled with the support spring and the domed end closure and electron beam welded. In Figure 57 is shown the tantalum10 tungsten components and the fuel pellet in an exploded view. In Figure 58 is shown a containment vessel assembly after brazing, electron beam welaing, pressure checking, filling with helium to 3 psia and sealing.

Following sealing of the two vessels they were helium leak checked by placing in vacuum and monitoring the pump effluent with a heliurn leak detector. Also, smears were taken of the tungsten clad pellets after machining to verify that no $\mathrm{UO}_{2}$ was on the exterior surface of the pellet. 


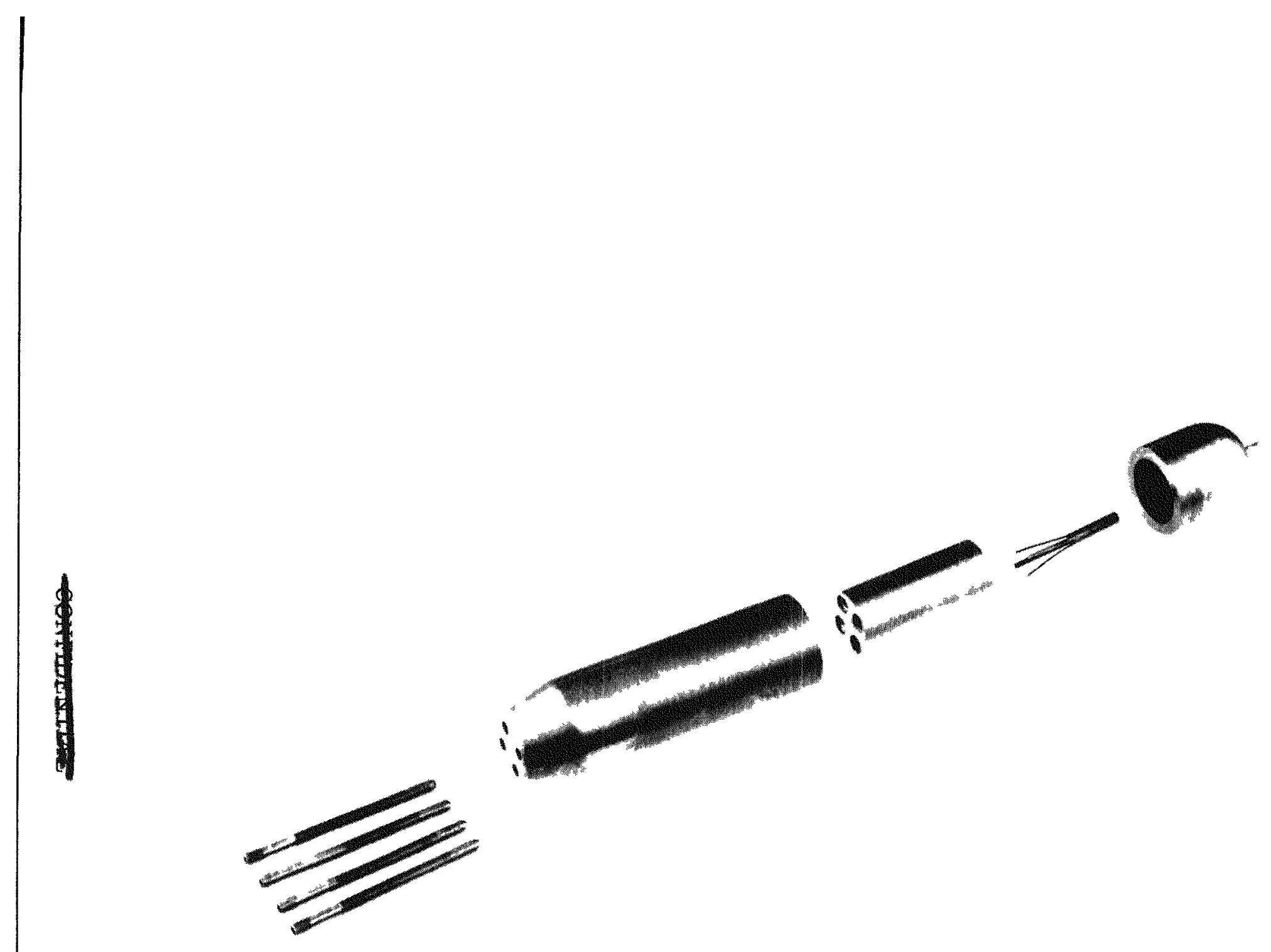

FIGURE 57. CONTAINMENT TESSEL COMPONENTS PRIOR TO ASSEMBLY

The clad fuel pellet is wrapped with tantalum dire prior to assembly. 


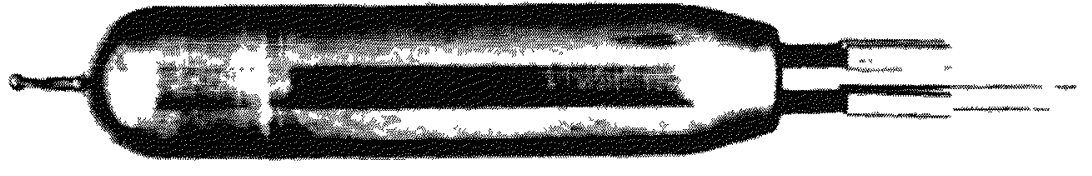

IX

37690

FIGURE 58. COMPLETED CONTAINMENT VESSEL ASSEMBLY 
The sealed assemblies were then ground on the OD at the weld zone to remove any material protruding above the vessel wall. The vessels were then radiographed to verify that all components were in their proper position on the interior of the pellet and that there was no damage to the support spring during electron beam welding. This is shown in Figure 59 for both vessels delivered to NASA. Following this operation, the vessels were cleaned in MEK and absolute alcohol and the serial number and part number electroetched onto each vessel to complete the required work.

A detajled procedure for the complete fabrication and assembly of a typical vessel is given in Appendix A. Appendix B gives the thermal histories of each of the pellets in the completed assemblies.

\section{CONCLUSIONS AND RECOMMENDATIONS}

As a result of the research effort on this program the following goals were achieved.

1. A fabrication procedure for preparation of a clad fuel pellet was achieved. This pellet consists of a fuel form fabricated from tungsten coated $\mathrm{UO}_{2}$ particles blended with fine tungsten. Hot isostatic pressing is used to consolidate the fuel form. Tungsten-cladding material is bonded to the densified fuel form by gas-pressure bonding to produce a clad fuel pellet capable of withstanding 100 thermal cycles to $2000 \mathrm{~K}$ without failure. 


\section{5}

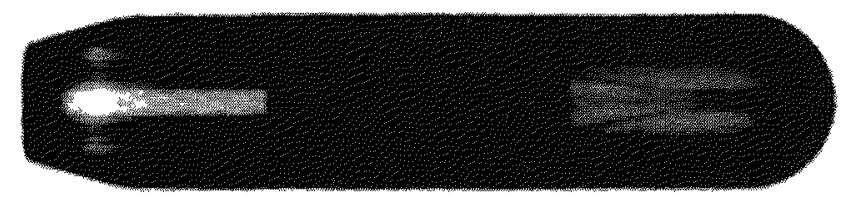

\section{$304-010$}

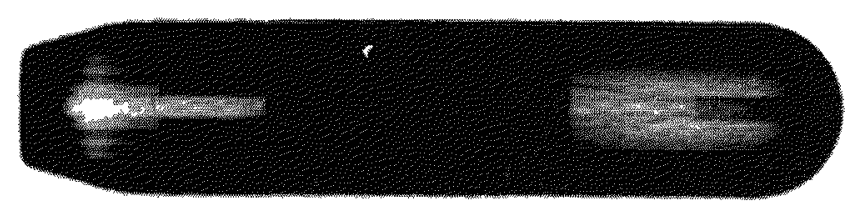

\section{4-011}

\section{IX}

FIGURE 59. RADIOGRAPH OF CONTAINMENT VESSELS 304-010 AND 304-011 AFTER WEIDING, PRESSURE CHECKING, AND SEALING 
2. A fabrication technique was developed for the containment vessel assembly. The techniques developed include high-temperature brazing and electron-beam-welding procedures for the assembly, welding, and sealing of the containment vessel assembly .

3. Two containment vessel assemblies with clad pellets made from enriched $\mathrm{UO}_{2}$ were completed for delivery to NASA for irradiation studies. In addition to these two vessels, two clad pellets and one mock-up containment vessel assembly were delivered to NASA.

The procedure for the preparation of the fuel form and the cladding and the gas-pressure-bonding parameters for these components appear to be the controlling factors in the fabrication of clad fuel pellets with desirable thermal-cycle characteristics. The progressive improvement obtained during the program as exemplified by the third thermal-cycle experiment showed the dependence of satisfactory thermal-cycle characteristics on the following procedures.

1. The cladding components of high-purity arc-cast tungsten should be prepared so that surfaces are free of imperfections. This is achieved by careful grinding of the end plugs and honing of the ID of the tubular component to remove surface damage caused by EDM. 
2. High-temperature hydrogen treatment of the fuel form and cladding components prior to bonding.

3. Bonding at high temperature $(3100-3200 \mathrm{~F})$ and high pressure (>15,000 psi) to assure highquality bonds between alI components.

4. Relaxation of the tungsten clad pellet after bonding by release of the autoclave gas pressure while maintaining temperature.

The research effort on this study indicated that additional work should be directed toward two areas.

1. A research program should be conducted to determine the factors affecting growth of the pellet during thermal cycling. The primary areas of interest are the effect of fuel loading, fuel particle size, halide content of the coated fuel particles, and the effect of a stabilizing agent in the $\mathrm{UO}_{2}$ fuel particles. A comprehensive study covering these aspects should identify the primary factors controlling the growth of the fuel pellet during thermal cycling or irradiation.

2. A change in design should be incorporated in future containment vessel assemblies to eliminate the use of the high-temperature brazing cycle presently required for the joining of the 
108

thermocouple wells to the clad pellet and to the containment vessel. This high-temperature cycle causes excessive grain growth in the tungsten cladding and measurable growth of the fuel pellet. These factors have a deleterious effect on the subsequent performance of the pellet during thermal cycling or irradiation. 


\section{CIAD FUEL PELLET - CONTATRMENT VESSEI FABRICATION PROCEDURE AND SPECTFICATION}

A step-by-step fabrication procedure for the clad fuel pellet and the containment vessel assembly is given below. Following the fabrication procedure, the pertinent dimensions and weights for the assemblies produced on this program are given.

\section{Fabrication Procedure}

1. Obtain $\mathrm{UO}_{2}$ particles to meet contract specifications

(a) Density - 92-95 percent of theoretical

(b) Particle size - 60-100 $\mu$ diameter

(c) Purity - Impurities shall not exceed 2 parts per hundred and halides shall be less than $30 \mathrm{ppm}$

(d) Stoichiometry - Shall not vary more than I part per hunäred ổ oxygen

The specifications for the enriched pellets prepared on this program are given in Table 3 of this report.

2. Vapor coat the $\mathrm{UO}_{2}$ with tungsten to obtain a coating weight equal to the $\mathrm{UO}_{2}$ weight. AnaIyses of the coated particles used in the preparation of the clad pellets in the containment vessels delivered to NASA are given in Table 4 of this report.

3. Blend coated particles with tungsten fines $(0.88$ micron powder) to obtain a fuel loading of $50 \mathrm{v} / \mathrm{o}$ $\mathrm{UO}_{2}$ - A Parawax binder (0.2 percent) is applied to each particle by dissolving the binder in a carbon 
tetrachloride $\left(\mathrm{CCl}_{4}\right)$ carrier. After the carrier has evaporated, the particles are screened to break up any clusters. The tungsten fines are then added to the particles and the mix blended while heat is applied. As the Parawax coating on each particle softens, a uniform coating of tungsten fines is picked up on each particle.

4. Cold die press the above blend to obtain a pellet 0.570 in. diameter $\times 2.050$ in. long. The density of the pellet should be approximately 70 percent.

5. Vacuum outgas pellets at $1500 \mathrm{C}$ for at least $1 / 2$ $\mathrm{hr}$ to remove binder.

6. Hot isostatic press fuel form in a molybdenum container to obtain a density of at least 92 percent. HIP parameters of $2900 \mathrm{~F}$ and $10,000 \mathrm{psi}$ for $\dot{3} \mathrm{hr}$ are minimum requirements to obtain this density. Following $\mathrm{HIP}$, the container is removed by leaching in dilute nitric acid, and then the fuel form is dipped in a $\mathrm{NaOH}$ solution to remove the pickling residue.

7. Grind fuel form to .462 in. diameter $\times 1.000$ in. long.

8. Hydrogen heat treat fuel form at $1750-1800 \mathrm{C}$ for $1-1 / 2 \mathrm{hr}$ using slow heat-up and cool-down $(500 \mathrm{c} / \mathrm{hr})$. Weigh fuel form.

9. Electrical-discharge machine arc-cast tungsten rod, $0.562-0.625 \mathrm{in}$. diameter $\times 1.200 \mathrm{in}$. Iong to obtain a 0.445 -in.-diameter hole. 
10. Hone ID of above tube to 0.464-in. diameter and grind $O D$ to $0.530-i n$. diameter. Grind end plugs, 0.462-in. diameter $x .050-i n$. thick and $0.462-i n$. diameter by $0.150-i n$. thick.

21. Dye-penetrant inspect and visually inspect the tungsten clad components at $30 \mathrm{x}$.

12. Hydrogen heat treat clad components at a minimum temperature of $1850 \mathrm{~F}$ for $\mathrm{I} \mathrm{hr}$.

13. Assemble clad components and fuel form in a molybdenum container, weld, evacuate, and seal. Gas-pressure bond at $3100+\$$ and at least 15,000 psi for $3 \mathrm{hr}$. Bleed off autoclave gas at a rate of $\$ 100 \mathrm{psi} / \mathrm{min}$ to approximately $300 \mathrm{psi}$ while maintaining temperature.

14. Remove can by selective leaching and grind OD and ends to obtain dimensions shown in Figure 56 of this report.

15. EDM thermocouple recesses as shown in Figure 56.

16. Inspect fuel pellet by dye-penetrant inspection and visually at $30 \mathrm{x}$. Weigh clad fuel pellet.

17. Smear and check for $\mathrm{UO}_{2}$ on pellet exterior.

18. Wrap two lengths of 0.009-in.-diameter tantalun wire on pellet and pigtail in the center of the fuel pellet on the thick end.

19. Machine tantalum-10 percent tungsten vessel components and thermocouple wells. Inspect parts. 
20. Braze tantalum-10 percent tungsten fill tube into domed end closure using columbium wire at $4525 \mathrm{~F}$ for $5 \mathrm{~min}$ in vacuum of $10^{-5}$ torr.

21. Columbium braze thermocouple wells to vessel and pellet at 4525 F for 5 min after a slow heat-up cycle of at least $1 \mathrm{hr}$.

22. Copper braze stainless steel extension tubes to thermocouple wells at approximately $2100 \mathrm{~F}$ for 5 min.

23. Check fit of tantalum-10 percent tungsten support spring. Provide about .010-in. clearance.

24. Assemble brazed portion of vessel, support spring, and domed end closure. Electron beam weld vessel components.

25. Pressure check vessel at 10,000 psi and visually check for leaks at this pressure.

26. Evacuate and backfill to 15 psig five times with helfum. Evacuate and backfill to 3 psia and seal fill tube.

27. Helium leak check vessel by placing in evacuated chamber and checking vacuum pump effluent.

28. Electroetch serial number and part number on exterior of vessel. 
Vessel Specjfications

A. Vessel - Serial No. 304-010

Part No. CF 351044-A

Pellet Specifications

Dimensions measuring from thick end plug

$\begin{array}{lll}\text { TOP } & - & 0.4974-\text { in. diameter } \\ \text { MIDDLE } & - & 0.4976 \text { in. diameter } \\ \text { BOTTOM } & = & 0.4977-\text { in. diameter } \\ \text { LENGTH } & - & 1.1470 \text { in. }\end{array}$

Weight Total - $58.0995 \mathrm{~g}$

Fue1 Form - $39.8792 \mathrm{~g}$

$\mathrm{UO}_{2} \quad-\quad 14.4363 \mathrm{~g}$

Vessel Specifications

Inside Diameter - 0.5180-in. diameter

Outside Diameter measuring from thermocouple end

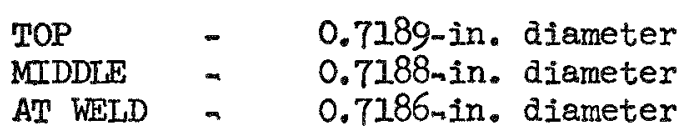

B. VesseI - Serial No. 304-011

Part No. CF 351044-A

Pellet Specifications

Dimensions measuring from thick end plug

\begin{tabular}{|c|c|c|}
\hline TOP & & 0.4968-in. diameter \\
\hline MIDDLE & 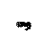 & 0.4968-in. diameter \\
\hline BOTMOM & - & 0.4970-in. diameter \\
\hline LENGTH & - & 1.1467.in. \\
\hline
\end{tabular}

- Weight Total - $57.9315 \mathrm{~g}$

Fuel Form - $39.3197 \mathrm{~g}$

$\mathrm{UO}_{2} \quad-\quad 14.2337 \mathrm{~g}$

Vessel Specifications

Inside Diameter - 0.5175-in. diameter 


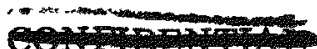

114

Outside diameter measure from thermocouple end

$\begin{array}{lll}\text { TOP } & - & 0.7188 \text { in. diameter } \\ \text { MIDDLE } & - & 0.7186 \text { in. diameter } \\ \text { AT WEID } & - & 0.7182 \text { in. diameter }\end{array}$


Appendix B

\section{THERMAL HISTORY OF FUEI PELIETSS}

During the fabrication of the final containment vessel assemblies for delivery to NASA, the fuel pellets were subjected to various thermal processing treatments. The treatinents for each vessel are listed below.

Thermal History of the Pellet in VesseI No. 304-010

1. Cold pressed fuel form vacuum treated at $1500 \mathrm{C}$ for $\mathrm{I} / 2 \mathrm{hr}$ to remove binder.

2. Gas-pressure bonded at $2900 \mathrm{~F}$ and $10,000 \mathrm{psi}$ for $3 \mathrm{hr}$.

3. After grinding to size, fuel form was hydrogen treated at 1750-1800 C for $1-1 / 2 \mathrm{hr}$.

4. Fuel form gas-pressure bonded at $3100+\mathrm{F}$ and $30,000 \mathrm{psi}$ for $1-1 / 2 \mathrm{hr}$; temperature maintained for about $5 \mathrm{hr}$ during reduction of pressure to 300 psi.

5. Pellet brazed at $4500 \mathrm{~F}$ - about 5 min at temperature.

6. Stainless steel tubes copper brazed to vessel containing pellet at 2100-2200 F.

7. Pellet and vessel vacuum treated at $1500 \mathrm{~F}$ for $\mathrm{I} \mathrm{hr}$ to remove residue from pickling to enlarge vessel ID.

8. Pellet brazed into new containment vessel; temperature in excess of $4500 \mathrm{~F}$.

9. Pellet gas-pressure bonded at $3000+\mathrm{F}$ and 30,000 psi for $1-1 / 2 \mathrm{hr}$. Temperature held for about $5 \mathrm{hr}$ during reduction of pressure. The powder that was bonded onto bottom of pellet was contaminated with $\mathrm{UO}_{2}$.

10. Pellet heat treated at $2500 \mathrm{~F}$ for $\mathrm{I} \mathrm{hr}$ in vacuum to presinter tungsten powder.

11. Fuel form was hydrogen treated at $1750-1800 \mathrm{C}$ for $1-1 / 2 \mathrm{hr}$ after grinding. 
12. Pellet was gas-pressure bonded at $3100^{+} \mathrm{F}$ and $30,000 \mathrm{psi}$ for $1-1 / 2 \mathrm{hr}$. Temperature held for about $5 \mathrm{hr}$ during pressure reduction.

13. Pellet brazed into vessel at $4500 \mathrm{~F}$; time about $5 \mathrm{~min}$.

14. Stainless steel tubes copper brazed to vessel at 2100-2200 F.

15. Pellet brazed into vessel at $4500 \mathrm{~F}$; time about 5 min.

16. Stainless steel tubes copper brazed to vessel. Three cycles to 2100-2200 F required.

Thermal History of the Pellet in

Vesse1 No. 304-011

1. Cold pressed fuel form vacuum treated at $1500 \mathrm{C}$ for $1 / 2 \mathrm{hr}$ to remove binder.

2. Gas-pressure bonded at $2900 \mathrm{~F}$ and $20,000 \mathrm{psi}$ for $3 \mathrm{hr}$.

3. After grinding to size, fuel form was hydrogen treated at 1750-1800 C for $1-1 / 2 \mathrm{hr}$.

4. Fuel form gas-pressure bonded at $3100^{+} \mathrm{F}$ and $30,000 \mathrm{psi}$ for $1-1 / 2 \mathrm{hr}$; temperature maintained for about $5 \mathrm{hr}$ during reduction of pressure to 300 psi.

5. Peliet brazed at $4500 \mathrm{~F}$ - about $5 \mathrm{~min}$ at temperature.

6. Stainless steel tubes copper brazed to vessel containing pellet at $2100-2200 \mathrm{~F}$.

7. Pellet and vessel vacuum treated at $1500 \mathrm{~F}$ for $1 \mathrm{hr}$ to remove residue from pickling to enlarge vessel ID.

8. Pellet cracked on removal of thermocouple wells by pickling. Fuel form hydrogen treated at $1750-1800 \mathrm{C}$ for $1-1 / 2 \mathrm{hr}$ after grinding.

9. Pellet gas-pressure bonded at $3100^{+} \mathrm{F}$ for $1-1 / 2 \mathrm{hr}$ at $30,000 \mathrm{psi}$. Temperature held for about $5 \mathrm{hr}$ during pressure reduction. 
10. Pellet brazed into containment vessel at a temperature in excess of $4500 \mathrm{~F}$.

11. Pellet brazed into new containment vessel at $4500 \mathrm{~F}$; time about 5 min.

12. Stainless steel tubes copper brazed to vessel at 2100-2200 F. 